Nat. Prod. Rep., 2005, 22, 15-61

\title{
Marine natural products
}

5 John W. Blunt, ${ }^{* a}$ Brent R. Copp, ${ }^{b}$ Murray H. G. Munro, ${ }^{a}$ Peter T. Northcote ${ }^{c}$ and Michèle R. Prinsep $^{d}$

${ }^{a}$ Department of Chemistry, University of Canterbury, Christchurch, New Zealand. E-mail: john.blunt@canterbury.ac.nz

${ }^{b}$ Department of Chemistry, University of Auckland, Auckland, New Zealand

${ }^{c}$ School of Chemical and Physical Sciences, Victoria University of Wellington, Wellington, New Zealand

${ }^{d}$ Department of Chemistry, University of Waikato, Hamilton, New Zealand

\section{Received (in Cambridge, UK) $10^{\text {th }}$ November 2004}

First published as an Advance Article on the web $19^{\text {th }}$ January 2005

This review covers the literature published in 2003 for marine natural products, with 619 citations (413 for the period January to December 2003) referring to compounds isolated from marine microorganisms and phytoplankton, green algae, brown algae, red algae, sponges, coelenterates, bryozoans, molluscs, tunicates and echinoderms. The emphasis is on new compounds (656 for 2003), together with their relevant biological activities, source organisms and country of origin. Biosynthetic studies or syntheses that lead to the revision of structures or stereochemistries have been included (78), including any first total syntheses of a marine natural product. 
Covering: 2003. Previous review: Nat. Prod. Rep., 2004, $21,1$.

$1 \quad$ Introduction

$2 \quad$ Reviews

$30 \quad 3 \quad$ Marine microorganisms and phytoplankton

$4 \quad$ Green algae

$5 \quad$ Brown algae

$6 \quad$ Red algae

$7 \quad$ Sponges

$358 \quad$ Coelenterates

9 Bryozoans

$10 \quad$ Molluses

$11 \quad$ Tunicates (ascidians)

12 Echinoderms

$40 \quad 13 \quad$ Miscellaneous

14 Conclusions

15 Acknowledgements

16 References

451 Introduction

This review is of the literature for 2003 and describes 656 new compounds from 243 articles. These numbers are comparable to those of the past few years. We show structures only for new compounds, or for previously reported compounds where there has been a structural revision or a

50 newly established stereochemistry. Previously reported compounds for which first syntheses or new bioactivities are described, are referenced, but separate structures are generally not shown. 
55 A number of reviews have dealt with classes of compounds: "Sterols in microorganisms", "Bioactive macrolides and polyketides from marine dinoflagellates", "Chemistry and biology of new marine alkaloids from the indole and annelated indole series", "Brominated diterpenes of marine origin", "Sulfur-containing natural products from marine invertebrates", "The cerebrosides", "Nonribosomal peptides from marine sponges", 7 "Bioactive polyhydroxysterols and 60 their sapogenins from marine organisms", "Sphingolipids from marine organisms", "A review of research on the cyanotoxin cylindrospermopsin", ${ }^{10}$ and "The manzamine alkaloids". 11

Reviews that focus on bioactivity and development as drug candidates include: "Natural products as sources of new drugs over the period 1981-2002", "Marine natural products as prototype agrochemical agents", 13 "Detection of pharmacologically active natural products using

65 ecology", "Marine pharmacology in 2000: antitumour and cytotoxic compounds", 15 "Bioactive natural products from marine invertebrates and associated fungi", 16 "Marine pyridoacridine alkaloids and synthetic analogues as antitumour agents", 17 "Drugs from the deep: marine natural products as drug candidates", ${ }^{18}$ "Marine-derived anticancer agents in clinical trials", 19 "Marine natural products as lead anti-HIV agents", 20 "Natural products with anti-HIV activity from marine

70 organisms", "Algae, a possible source for new drugs in the treatment of HIV and other viral diseases", 22 and "Antimycobacterial natural products". ${ }^{23}$

Chemical synthesis is the theme of a number of reviews covering specific types of compounds through to more generally applicable methodology: "Total synthesis of $(+)$ macrosphelides A, C, E, F and G based on enzymatic function", 24 "The total syntheses of 75 phorboxazoles-new classes in natural product synthesis", 25 "The development of a practical total synthesis of discodermolide", 26 "Synthesis of the pyrrole-imidazole alkaloids", 27 "Chemistry of bisspiroacetal systems: natural products, synthesis and stereochemistry", 28 "Approaches towards the 
synthesis of cephalostatins, ritterazines and saponins from Ornithogalum saundersiae", "New and old challenges in total synthesis. From concept to practise",30 and "Microtubule-stabilizing marine metabolite laulimalide and its derivatives: synthetic approaches and antitumour activity". ${ }^{31}$

Other more general reviews include: "Molecular biodiversity. Case study: Porifera (sponges)", 32 "Microalgal metabolites", 33 "Enhancing marine natural product structural diversity and bioactivity through semisynthesis and biocatalysis", ${ }^{34}$ and "Marine natural products". ${ }^{35}$ References to other reviews are more appropriately placed in the following sections. The Marinlit

85 database ${ }^{36}$ continues to be updated and has again been used as the basis for the preparation of this present review.

\section{Marine micoorganisms and phytoplankton}

90 Probably the most important paper on marine microorganisms in 2003 was the first report on chemistry from the new obligate marine actinomycete taxon Salinospora. ${ }^{37}$ In excess of 2,500 strains from this taxon have now been isolated and the potent proteasome inhibitor salinosporamide A 1 was isolated from a culture of a Salinospora sp. originating from a heat-treated marine sediment sample from the Bahamas. The structure of salinosporamide A, including the absolute stereochemistry, was deduced through spectral and X-ray analyses. Salinosporamide A displayed potent and selective in vitro cytotoxicity against cell lines in the NCI panel. Salinosporamide A also exhibited highly potent inhibition of the proteasomal chymotrypsin-like proteolytic activity of purified 20S proteasome. The unique functionalisation of the core-fused $\gamma$-lactam- $\beta$-lactone bicyclic ring structure of salinosporamide A 1 appears to contribute to its potency. The thiazolyl peptide antibiotics, nocathiacins I-III 2-4, have been isolated from the culture broth of Nocardia sp. (source not given). ${ }^{38}$ The nocathiacins exhibit potent in vitro activity against a wide range of bacteria, including several multiple-drug resistant pathogens and also exhibit excellent in vivo efficacy in a systemic Staphylococcus aureus infection mouse model. ${ }^{39}$ However, nocathiacin I 2 was found to 
be identical to an antibiotic isolated from Amycolatopsis $\mathrm{sp} .^{40}$ but spectral data and stereochemical

105 details had not been originally reported for this compound. Two cyclic thiopeptides $\mathbf{5}$ and $\mathbf{6}$, obtained from a culture of Bacillus cereus isolated from the marine sponge Halichondria japonica ${ }^{41}$ exhibited potent antibacterial activities against Staphylococci and Enterococci sp., and were active against multiple-drug resistant strains. ${ }^{42}(6 Z)$-Geometry for these compounds was implied by ROESY correlations. ${ }^{1} \mathrm{H}^{-15} \mathrm{~N}$ HMBC analysis was used in determining the structure of

110 bacillamide 7, a peptidic metabolite of an algicidal marine Bacillus sp. isolated during the termination of a bloom of Cochlodinium polykrikoides in Masan Bay, Korea. ${ }^{43}$ Bacillamide was shown to be active against a wide range of dinoflagellates and raphidophytes. ${ }^{44}$ Culture of an exocellular extract of a Pseudomonas sp. associated with Ircinia muscarum from the Bay of Naples, Italy gave the cyclotetrapeptide $\mathbf{8}^{45}$ The amino acid stereochemistry was established by standard 115 methods (for example, chiral HPLC analysis of the acid hydrolysate, Marfey's method etc). Four Streptomyces sp. of diverse origin yielded a range of metabolites. Firstly, culture of a Streptomyces sp. from a sediment sample from Oahu, Hawaii, yielded the antibacterial and antifungal metabolite bonactin 9. ${ }^{46}$ Parimycin 10, a new 1,4-anthraquinone, was isolated from a Streptomycete sediment sample from Laguna de Terminos, Gulf of Mexico. Parimycin had moderate activity against $B$. subtilis, Streptomyces viridochromogenes, $S$. aureus and E. coli, in addition to activity against a number of human tumour cell lines. ${ }^{47}$ A Streptomyces sp. cultured from an unidentified Mexican marine invertebrate yielded the cytotoxic indoles 11-13 which had moderate activity against a panel of 14 tumour cell lines. ${ }^{48}$ Finally, the anthracycline komodoquinone A 14 and the aglycone komodoquinone B $\mathbf{1 5}$ were isolated from a culture of a Streptomyces sp. isolated from marine

125 sediment off Komodo Island, Indonesia. Komodoquinone A displayed dose-dependent neuritogenic activity against the neuroblastoma cell line Neuro $2 \mathrm{~A} .{ }^{49}$ A culture broth of an ATCC strain of the marine gliding bacterium Saprospira grandis yielded four neoverrucosane diterpenoids, 16-19. The relative and absolute stereochemistries of $\mathbf{1 6}$ were determined by standard methods ${ }^{50}$ (for example, X-ray analysis, NOESY and ROESY NMR experiments, the modified Mosher method, chiral 
130 HPLC, comparison of circular dichroism (CD) or other optical data against standards or model compounds etc). The marine myxobacterium Haliangium ochraceum, ${ }^{51}$ originally H. luteum, yielded several new isomers of the polyene antifungal antibiotic haliangicin. ${ }^{52,53}$ These are cishaliangicin 20 and haliangicins B-D 21-23, geometrical isomers of the polyene and epoxide moieties. The stereochemistry of the epoxide in the known haliangicin $\mathbf{2 4}^{53}$ has been determined as

135 trans. All of the haliangicins were active against the phytopathogenic fungus Phytophthora capsici. $^{54}$ Two siderophores, pseudoalterobactins A 25 and B 26, were isolated from a culture of the bacterium Pseudoalteromonas sp. isolated from the marine sponge Cinachyrella australiensis collected in Palau. Both compounds displayed strong binding affinity for the ferric ion in the chrome azurol S (CAS) assay. ${ }^{55}$ The bactericidal compound 27 , obtained from a culture of a new marine species Pseudoalteromonas phenolica sp. nov., isolated from seawater collected off Ogasawara Island Japan, ${ }^{56}$ had potent activity against methicillin-resistant $S$. aureus (MRSA) and was also strongly active against Enterococcus serolicida, E. faecium and E. faecalis. ${ }^{57}$ This compound is available commercially, but this is the first reported isolation as a natural product. Cultures of two marine bacterial strains isolated from cultures of Pecten maximus larvae in Galicia, 145 Spain, led to the first reported isolation, as natural products, of a series of DD-diketopiperazines 2831 and established them as potent inhibitors of the pathogenic marine bacterium Vibrio anguillarum. The structures were confirmed by synthesis. ${ }^{58}$ A cytotoxic polycyclic xanthone 32 has been isolated from the culture broth of the actinomycete Actinomadura sp. ${ }^{59}$ The phenoxazin-3-one antibiotics, chandrananimycins A-C 33-35, were also isolated from a culture of Actinomadura sp.

150 derived from sediment from Jiaozhou Bay, China. Chandrananimycins A-C were active against human tumour cell lines while $\mathbf{3 5}$ exhibited potent activity against the fungus Mucor meihei and the bacteria $B$. subtilis and E. coli, and antialgal activity against the microalgae, Chlorella vulgaris, C. sorokiniana and Scenedesmus suspicatus. ${ }^{60}$ The fungus Aspergillus tamarii was isolated from driftwood collected in Okinawa and cultured to yield a pentacyclic oxindole alkaloid, speradine A 155 36. The structure and relative stereochemistry of $\mathbf{3 6}$ were confirmed by X-ray analysis. Speradine A 
exhibited inhibitory activity against histone deacetylase and antibacterial activity against Micrococcus luteus. ${ }^{61}$ A culture of the fungus Aspergillus ostianus, isolated from an unidentified marine sponge from Pohnpei, was the source of three chlorinated antibiotics, the asperlactone derivatives $\mathbf{3 7}$ and $\mathbf{3 8}$ and the aspyrone derivative 39. Compound $\mathbf{3 7}$ was the most potent, inhibiting 160 the growth of the marine bacterium Ruegeria atlantica and that of E. coli and S. aureus to a lesser extent. ${ }^{62}$ Five novel depsipeptides, aspergillicins A-E 40-44, were obtained from a culture of Aspergillus carneus collected from estuarine sediment in Tasmania, Australia. The amino acid sequences were assigned by $\mathrm{MS}^{\mathrm{n}}$ ion-trap ESI mass spectrometry and stereochemistry was assigned by standard methodology. The aspergillicins exhibited modest cytotoxicity against Haemonchus

165 contortus. ${ }^{63}$ A chiral dipyrrolobenzoquinone derivative, terreusinone 45 , has been obtained from a cultured strain of the marine algicolous fungus Aspergillus terreus isolated from the surface of the marine red alga Halymenia acuminata collected from Bijin Island, South Korea. The absolute stereochemistry was determined by a combination of Horeau's method and quantum chemistry calculations. Terreusinone has intense UV-A absorbtivity. ${ }^{64}$ A culture of Penicillium brocae from

170 the tissue of the Fijian sponge Zyzzya sp. was the source of three novel cytotoxic polyketides, brocaenols A-C 46-48. These contain the unusual enolised oxepine lactone ring system. Structure determination included an INADEQUATE experiment on brocaenol A. The absolute stereochemistry of $\mathbf{4 6}$ was established by a standard method and extended to 47 and 48 by comparison of $\mathrm{CD}$ and optical rotation data. ${ }^{65}$ Brocaenols $\mathrm{A}-\mathrm{C}$ displayed moderate activity against

175 the HCT-116 cell line. Structures for brocaenols B and C were reversed in the original paper, but a correction has since been published. ${ }^{66}$ The steroids isocyclocitrinol A 49 and 22acetylisocyclocitrinol A $\mathbf{5 0}$ were extracted from a salt water culture of Penicillium citrinum isolated from Axinella sp. collected in Papua New Guinea. ${ }^{67}$ The absolute stereochemistry of $\mathbf{5 0}$ was established by standard methods, extended to 49 , leading to the structural revision of cyclocitrinol, 180 previously isolated from a terrestrial P. citrinum, ${ }^{68}$ to $\mathbf{5 1}$. Compounds $\mathbf{4 9}$ and $\mathbf{5 0}$ displayed weak antibacterial activity against Staphylococcus epidermidis and Enterococcus durans. The halovirs A- 
E 52-56, lipophilic linear peptides, are potent in vitro inhibitors of Herpes simplex viruses 1 and 2 and were isolated from a Scytalidium sp. sourced from the Caribbean seagrass Halodule wrightii. ${ }^{69}$ Two cyclic heptapeptides, scytalidamides A $\mathbf{5 7}$ and B 58, have been isolated from the culture broth of another Scytalidium sp. derived from the surface of the green alga Halimeda sp. collected off the Bahamas. The absolute configurations were confirmed by standard methods including CD measurements. Both scytalidamides displayed moderate cytotoxicity to the HCT-116 cell line in vitro. $^{70}$ Trichodermamides A 59 and B 60, modified dipeptides, were isolated from cultures of Trichoderma virens isolated from the ascidian Didemnum molle and from the surface of a green alga of the genus Halimeda, both collected in Papua New Guinea. The ascidian-derived culture contained trichodermamide A with traces of trichodermamide B while a greater quantity of trichodermamide B was isolated from the algal-derived strain. The structure of $\mathbf{5 9}$ was assigned by X-ray diffraction while the absolute stereochemistry was determined using the modified Mosher method. Trichodermamide B displayed significant in vitro cytotoxicity against HCT-116 and moderate antimicrobial activity against amphoterocin-resistant $C$. albicans, MRSA and vancomycin-resistant E. faecium. ${ }^{71}$ Trichodermamide A is closely related to penicillazine, reported from a marine-derived Penicillium sp. ${ }^{72}$ The reported structures differ only in the translocation of ester and amide bonds, but spectral data comparison suggests that these compounds may be identical. Two macrolides, modiolides A 61 and B 62, and a linear pentaketide modiolin 63 have been isolated from the culture of Paraphaeosphaeria sp. separated from the marine horse mussel Modiolus auriculatus, collected in Okinawa. The absolute stereochemistry of $\mathbf{6 1}$ was determined by the exciton chirality method ${ }^{73}$ using a $p$-methoxycinnamoyl ester, while the absolute stereochemistry of $\mathbf{6 3}$ was defined by the modified Mosher method. Modiolides A and B exhibited modest antibacterial activity against Micrococcus luteus and Neurospora crassa. ${ }^{74}$ A culture of the marine fungus Wardomyces anomalus, isolated from the green alga Enteromorpha sp. collected in the Baltic Sea, yielded two xanthone derivatives, anomalin A 64 and B $65 .^{75}$ The anomalins were only weakly antimicrobial, but anomalin A possessed significant tyrosine kinase $\mathrm{p} 56^{\text {lck }}$ enzyme 
inhibitor activity and antioxidative properties. Remisporine A 66, a novel cyclopentachromenone, isolated from a culture of the marine fungus Remispora maritima from an unspecified wood source, is unstable under normal conditions and autocatalytically dimerises stereospecifically, via a DielsAlder reaction, to remosporine B. ${ }^{76}$ A new anthraquinone, evariquinone 67, and the new prenylxanthone isoemericellin $\mathbf{6 8}$ were isolated from a culture of the fungus Emericella variecolor derived from the marine sponge Haliclona valliculata collected at Elba, Italy. The known Cglycosidic depside stromemycin $\mathbf{6 9}^{77}$ was also isolated, and the previously undescribed double bond configurations established. Evariquinone $\mathbf{6 7}$ showed antiproliferative activity towards KB and NCIH460 cells. ${ }^{78}$ A culture of a marine strain of the fungus Epicoccum purpurascens, isolated from inner tissue of the jellyfish Aurelia aurita collected from the North Sea, Germany, yielded the tetramic acid derivative epicoccamide 70. Attempts to resolve the stereochemistry at C-4 and C-8 by comparision of $\mathrm{CD}$ spectra with those of similar compounds were ambiguous. ${ }^{79}$ Two highly oxygenated polyketides, phomoxin 71 and phomoxide 72, are metabolites from a Phoma sp. isolated from a microbial mat collected from a Bahaman hypersaline pond, along with eupenoxide 73, a previously synthesised, but unpublished fungal metabolite. ${ }^{80}$ An actinomycete, Pseudonocardia sp., isolated from littoral sediment from Mauritius, Indian Ocean, was the source of a new phenazine derivative, phenazostatin D 74 which is the meso-form of the known antibiotic 225 phenazostatin B. ${ }^{81,82}$ Investigations of a collection of Lyngbya majuscula from Puerto Rico resulted in the isolation of three new metabolites, a quinoline alkaloid, 75, malyngamide $\mathrm{T} \mathbf{7 6}$ and a tryptophan derivative $\mathbf{7 7} .{ }^{83}$ Geometries for the vinyl chloride functionalities of $\mathbf{7 5}$ and $\mathbf{7 6}$ were established as $(E)$ by ${ }^{1} \mathrm{H}-{ }^{13} \mathrm{C}$ coupling constant measurement from HSQMBC NMR experiments. ${ }^{84}$ Six cyclic depsipeptides, guineamides A-F 78-83, were isolated from a collection of Lyngbya majuscula collected from Papua New Guinea. Absolute stereochemistries for most of the amino acids were determined by standard methods. Guineamides B and C were moderately cytotoxic to a mouse neuroblastoma cell line. ${ }^{85}$ L. majuscula from Papua New Guinea was the source of the novel cyclic dodecapeptide wewakazole $\mathbf{8 4}$ which contains an unprecedented number of five-membered 
heterocyclic rings (six). Due to extensive signal overlap the structural assignment required multiple

235 NMR and MS/MS experiments. The absolute stereochemistry was determined by standard methods. ${ }^{86}$ L. majuscula from the southern Kenyan Coast was the source of the cyclic depsipeptide homodolastatin $16 \mathbf{8 5}$. The absolute stereochemistries of most of the amino acids in homodolastatin 16 were determined by standard methods. Homodolastatin 1685 displayed moderate activity against oesophageal and cervical cancer cell lines. ${ }^{87}$ The cyclic peptide lyngbyastatin $3 \mathbf{8 6}$, isolated 240 from L. majuscula collected from Guam, contains two unusual amino acid units, including 4-amino2,2-dimethyl-3-oxopentanoic acid (Ibu). The configuration of the Ibu unit was established by acid hydrolysis and comparison with synthetic standards, while the absolute stereochemistries of the remaining residues were determined by standard methods. Lyngbyastatin 3, along with the previously isolated lyngbyastatin 1 and dolastatin $12,{ }^{88}$ are in fact diastereotopic mixtures of both

245 Ibu epimers. Lyngbyastatin $3 \mathbf{8 6}$ exhibited activity against KB and LoVo cell lines in vitro, but was poorly tolerated in vivo with little antitumour activity. ${ }^{89}$ Three new malyngamides, U-W 87-89, have been isolated from L. majuscula collected in Papua New Guinea. Partial relative stereochemistries only were determined. ${ }^{90}$ A collection of Lyngbya sp. from Palau yielded ulongapeptin 90, a cytotoxic cyclic depsipeptide, ${ }^{91}$ while a Lyngbya sp. from Guam yielded two new compounds, 15-norlyngbyapeptin A 91 and lyngbyabellin D $92 .{ }^{92}$ The absolute stereochemistries in each case were determined through degradative studies and/or comparison with commercially available and synthetic standards. Ulongapeptin was moderately cytotoxic against KB cells in vitro ${ }^{91}$ and lyngbyabellin D displayed activity against the $\mathrm{KB}$ cell line. ${ }^{92}$ Bioassay-guided fractionation of an extract from a Lyngbya sp. collected in Palau led to the isolation of palau'amide

255 93. Effective use was made of a band-selective $\mathrm{HMBC}$ experiment to unambiguously assign ${ }^{13} \mathrm{C}$ NMR signals that were separated by only $0.1 \mathrm{ppm} .{ }^{93}$ Except for $\mathrm{C}-37$, relative and absolute configurations were determined by standard methods. By modelling, and from NOE data, C-37 was assigned as having the $(S)$ configuration. Palau'amide 93 exhibited potent cytotoxicity against KB cells. ${ }^{94}$ Semiplenamides A-G 94-100, anandamide-like fatty acid amides, were isolated from a 
260 collection of Lyngbya semiplena collected in Papua New Guinea. The absolute stereochemistries of the amino alcohols in semiplenamides C-E 96-98 were elucidated as all L by chemical derivatisation and chiral GCMS methods. All of the semiplenamides displayed toxicity in the brine shrimp assay, while semiplenamides A, B and G exhibited weak affinity for the rat cannabinoid CB1 receptor. Semiplenamide A was also a moderate inhibitor of the anandamide membrane 265 transporter (AMT). ${ }^{95}$ Samples of the marine cyanobacterium Symploca sp. collected in Palau were the source of the depsipeptides tasipeptins A 101 and B 102, ${ }^{96}$ and a cytotoxic peptide, tasiamide B 103. ${ }^{97}$ The relative and absolute configurations of the tasipeptins and tasiamide B were determined by standard methods except for the configuration of C-28 in tasiamide B. This was tentatively suggested as $(S)$ from NMR data analysis. ${ }^{97}$ Both tasipeptins exhibited moderate cytotoxicity 270 towards KB cells in vitro. Also collected in Palau was an assemblage of a Symploca sp. cyanobacterium and an unidentified red alga. From this was isolated the iodinated diterpenes, tasihalides A 104 and B 105. These compounds possess a novel cage structure with both an oxabicyclic ring system and a cis-decalin system. These are the only examples of iodinated diterpenes in nature. Since terpenoids are almost never reported from marine cyanobacteria, but

275 halogenated terpenes are ubiquitous in red algae, the authors speculate that the more likely source of the tasihalides is the alga and not the cyanobacterium. ${ }^{98}$ Two polyunsaturated monocyclic triterpenes $\mathbf{1 0 6}$ and $\mathbf{1 0 7}$ have been isolated from a culture of the common marine diatom Rhizosolenia setigera. The structure of a related monocyclic sesterterpene $\mathbf{1 0 8}$ was also proposed on the basis of mass spectral comparisons with compounds 106 and 107. ${ }^{99}$ Amphidinolide X 109 ${ }^{100}$ 280 and amphidinolide Y $\mathbf{1 1 0}^{101}$ are cytotoxic 16- and 17-membered macrodiolides isolated from cultures of the marine dinoflagellate Amphidinium sp., originally separated from the inside cells of the marine acoel flatworm Amphiscolops sp. collected from Okinawa. Amphidinolide Y exists as a 9:1 equilibrium mixture of the 6-keto- $\mathbf{1 1 0}$ and 6(9)-hemiacetal $\mathbf{1 1 1}$ forms. Both amphidinolides $\mathrm{X}$ and Y were moderately cytotoxic against murine lymphoma L1210 and human epidermoid carcinoma $\mathrm{KB}$ cells in vitro. Feeding experiments with ${ }^{13} \mathrm{C}$-labelled acetates suggested that 
amphidinolide $\mathrm{Y}$ might be a precursor of amphidinolide $\mathrm{X} .{ }^{101}$ A culture of the dinoflagellate Symbiodinium sp., a symbiont of the soft coral Clavularia viridis collected from Okinawa, yielded two diastereoisomeric norcarotenoids 112 and 113. Both compounds exhibited moderate growthinhibitory activity in vitro against a range of human cancer cell lines. ${ }^{102}$ A culture of the free-living marine dinoflagellate Symbiodinium sp. isolated from a tide pool, Coconut Island, Hawaii, ${ }^{103}$ yielded the polyhydroxy compound zooxanthellamide A $114 .{ }^{104}$ Cultures of a strain of the dinoflagellate Prorocentrum lima ${ }^{105}$ afforded okadaic acid methyl ester 115, norokadanone 116 and an okadaic acid diol ester 117. ${ }^{106}$ Three hydroxybenzoate saxitoxin analogues, GC1-GC3 118-120, have been isolated from the cultured dinoflagellate Gymnodinium catenatum originally isolated from a planktonic bloom in Tasmania. GC1 and GC2 are the epimeric 11-hydroxysulfate derivatives of GC3, the 4-hydroxybenzoate ester derivative of decarbamoylsaxitoxin. Preliminary investigations indicate that the compounds bind to rat brain sodium channels, in keeping with known PSP toxins. ${ }^{107}$ Biosynthetic investigations using ${ }^{13} \mathrm{C}$-labelled precursors of the meroterpenoid neomarinone, originally isolated from culture of an unidentified marine

300 actinomycete from sediment from Batiquitos Lagoon, California, ${ }^{108}$ led to the structural revision of neomarinone to $121 .{ }^{109}$ A correction to the text of the article describing the structure and absolute stereochemistry of phormidolide from the marine cyanobacterium Phormidium sp. ${ }^{110}$ has been published, amending two descriptors $[(17 R, 26 R)$ to $(17 S, 26 S)] .{ }^{111}$ The absolute configuration of the fungal metabolite phomopsidin 122, derived from a cultured strain of Phomopsis sp., ${ }^{112}$ has been determined by the exciton chirality method. Phomopsidin exhibited potent anti-microtubule activity in a microtubule assembly assay utilising purified porcine brain microtubule proteins. ${ }^{113} \mathrm{~A}$ total synthesis of petrobactin, a siderophore isolated from the marine bacterium Marinobacter hydrocarbonoclasticus has been completed. Comparison of the ${ }^{1} \mathrm{H}$ NMR spectrum of the synthetic product with literature data for the natural product ${ }^{114}$ resulted in a structural revision of petrobactin 310 from 2,3-dihydroxybenzoyl- to 3,4-dihydroxybenzoyl-moieties. This 3,4-dihydroxybenzoyl analogue 123 was also synthesised, giving ${ }^{1} \mathrm{H}$ and ${ }^{13} \mathrm{C}$ NMR spectra that were consistent with those 
of the natural product. ${ }^{115}$ The first total synthesis of yanucamide A 124, which was isolated from an assemblage of L. majuscula and a Schizothrix species, ${ }^{116}$ has been achieved via amide and ester coupling methods. The synthesis established the configuration at C-3, originally unassigned due to

315 ambiguity, and revised the configuration at C-22. ${ }^{117}$ In synthetic studies towards congeners of phomactin A, total syntheses of structures isomeric to that proposed for the phomactin known as Sch 49028, also isolated from the marine fungus Phoma sp., ${ }^{118}$ are described. None of the isomers showed spectral data consistent with those of the natural product so it is proposed that Sch 49028 does not exist and that the NMR spectral data should have been assigned as phomactin A. ${ }^{119}$ Other

320 first total syntheses reported include that of $( \pm)$-spiroxin $C$, originally isolated from culture of an unidentified fungal strain from a soft coral from Vancouver Island, Canada. ${ }^{120}$ This involved a Suzuki-Miyaura cross-coupling reaction. ${ }^{121}$ Apratoxin A, a cyclodepsipeptide from Lyngbya sp. collected in both Guam ${ }^{122}$ and Palau, ${ }^{123}$ has been synthesised. ${ }^{124}$ The relative and absolute stereochemistries of amphidinoketide I 125, originally isolated from the dinoflagellate Amphidinium 325 sp. collected in the Virgin Islands, ${ }^{125}$ have been determined by total synthesis of all four diastereoisomers. Molecular modelling was used to infer that the natural product is not the thermodynamically preferred diastereoisomer. ${ }^{126}$ Two syntheses of the 19 -membered macrolide $(+)$ amphidinolide $\mathrm{T} 1^{127,128}$ have been achieved, ${ }^{129,130}$ along with the synthesis ${ }^{130}$ of amphidinolides $\mathrm{T} 3{ }^{131}$ and $\mathrm{T} 5 .{ }^{128}$ Synthesis of the structurally complex gymnocin-A, a polyether toxin with 14 330 contiguous rings, from the red tide dinoflagellate Karenia mikimotoi, ${ }^{132}$ has been accomplished through the use of $B$-alkyl Suzuki-Miyaura coupling-based methodology. ${ }^{133}$ Following the first total synthesis of gambierol, a marine polycyclic ether toxin originally isolated from the marine dinoflagellate Gambierdiscus toxicus, ${ }^{134}$ preliminary structure-activity relationship studies suggest that functionalities in the $\mathrm{H}$ ring and unsaturated sidechain are essential for potent murine 335 toxicity. ${ }^{135}$ A competitive inhibition assay using the isotopically labelled brevetoxin dihydro BTX-B $\left(\left[^{3} \mathrm{H}\right] \mathrm{PbTx}-3\right)$, demonstrated that gambierol ${ }^{134,136}$ and gambieric acid-A ${ }^{137,138}$ from the dinoflagellate Gambierdiscus toxicus inhibit the binding of brevetoxins to site 5 of the voltage-gated sodium 
channel of excitable membranes, ${ }^{139}$ while effects of brevetoxins produced by the dinoflagellate Karenia brevis (formerly Ptychodiscus breve and Gymnodinium breve) ${ }^{140}$ on the murine myeloma 340 cell line SP2/O, a possible model for in vitro studies for immune cells, suggest that the brevetoxins have an aberrant effect on cell division. ${ }^{141}$

\section{Green algae}

345 As in 2002, very few new compounds have been reported from green algae. The cyclic depsipeptide kahalalide F 126, originally isolated from both the mollusc Elysia rufescens and from the dietary source, the green alga Bryopsis sp., ${ }^{142}$ was introduced into Phase I trials by Pharma Mar SA as a lead compound against prostate cancer. The structure of kahalalide F has been corrected based on a series of degradation reactions. The planar structure only was originally defined and the stereochemistry subsequently assigned. ${ }^{143}$ The degradation results indicate that the correct structure is a stereoisomer 126, in which the original assignments for Val-3 and Val-4 have been reversed. This stereochemistry is crucial for the observed bioactivity. ${ }^{144}$ Twelve new terpene esters, $\mathbf{1 2 7 - 1 3 8}$ have been isolated from the green alga Caulerpa prolifera collected from Saronicos Gulf, Greece. The $C$. prolifera extract exhibited moderate to significant activity against three unidentified strains 355 of marine bacteria, in addition to strong growth inhibitory effects on the fouling microalga Phaeodactylum tricornutum. ${ }^{145}$ The first total synthesis of $( \pm)$-dihydrorhipocephalin, a bioactive sesquiterpene isolated from Caribbean marine green algae of the genera Penicillus and Udotea, ${ }^{146}$ has been reported. ${ }^{147}$

\section{Brown algae}

A wider range of compounds has been reported from brown algae in 2003 than in 2002, when terpenes and steroids were the predominantly reported compound classes. Six tetraprenyltoluquinols 
139-144, two triprenyltoluquinols 145 and 146 and two tetraprenyltoluquinones 147 and 148 were

365 isolated from the brown alga Cystoseira crinita collected from the south coast of Sardinia. All compounds were tested for antioxidative properties in the $\alpha, \alpha$-diphenyl- $\beta$-picrylhydrazyl radical (DPPH) and thiobarbituric acid reactive substances (TBARS) assay systems. Compounds 139-146 exhibited potent radical-scavenging effects while 147 and 148 were significantly less active, but still comparable to that of butylated hydroxytoluene (BHT). The radical scavenging activity of compounds 142, 144 and 148 was further assessed using the Trolox equivalent antioxidant capacity (TEAC) and photochemiluminescence (PCL) assays that confirmed the potent radical scavenging ability. Compounds 139 and 140 were moderately cytotoxic against several carcinoma cell lines. ${ }^{148}$ Four hydroazulene diterpenes, dictyone acetate 149, dictyol F monoacetate 150, isodictytriol monoacetate 151 and cystoseirol monoacetate 152, were isolated from the brown alga Cystoseira 375 myrica collected in the Gulf of Suez. All four compounds exhibited moderate cytotoxicity against the murine cancer cell line KA3IT, but reduced cytotoxicity against normal NIH3T3 cells. ${ }^{149}$ Dictyone acetate along with a pachydictyol A derivative 153 (incorrect structures shown in original reference) were also isolated from the brown alga Dictyota dichotoma collected from the Red Sea. ${ }^{150}$ D. dichotoma from the Arabian Sea was the source of two seco-dolastanes dichotone 154 380 and dichotodione $\mathbf{1 5 5},{ }^{151}$ two dolastane diterpenoids, dichototetraol 156 and dichopentaol $\mathbf{1 5 7},{ }^{152}$ and the related dichotenones A 158 and B 159, two enone dolastane diterpenoids. ${ }^{153}$ The configurations of $\mathbf{1 5 4}$ and $\mathbf{1 5 5}$ were determined by comparison of spectral data against those of known compounds. The new diterpene dictyocrenulol 160 was isolated from the brown alga Dictyota crenulata collected from Easter Island. ${ }^{154}$ Eisenia bicyclis collected at Johgashima Island, 385 Japan, was the source of nine novel oxylipin compounds 161-169. ${ }^{155}$ Five of these, eiseniachlorides A-C 161-163 and eiseniaiodides A 164 and B 165, are ecklonialactone derivatives and two more, 166 and 167, are cymathere type oxylipins. Stereochemistries of compounds 161-165 and 169 were elucidated by NMR analyses, but the relative stereochemistry at C-9 in $\mathbf{1 6 8}$ could not be determined unambiguously. Olefin geometry in $\mathbf{1 6 6}$ was ambiguous, but considered to be $(Z)$ on biosynthetic 
390 grounds, and at least one olefin in compound 167 was $(Z)$. A 22-membered cyclic lactone, lobophorolide 170, was isolated from the common brown alga Lobophora variegata, collected at several reef locations in the Bahamas and from the Red Sea. The structure was elucidated by spectral data analysis and comparison against data published for tolytoxin ${ }^{156}$ and swinholide A. ${ }^{157,158}$ It is proposed that lobophorolide and tolytoxin share the same relative configuration at all stereogenic centres in the macrolide portion of the molecule, while a $(6 R)$ configuration is suggested for both compounds rather than the $(6 S)$ configuration proposed previously for tolytoxin. ${ }^{156}$ The absolute configuration of lobophorolide is proposed to be the same as that of tolytoxin based on optical rotation. Lobophorolide $\mathbf{1 7 0}$ displayed potent and highly specific activity against the marine filamentous fungi Dendryphiella salina and Lindra thalassiae in addition to

400 potent activity against $C$. albicans and antineoplastic activity against the HCT-116 cell line. ${ }^{159}$ The brown alga Sargassum asperfolium, collected in the Suez Gulf, was the source of the steroidal metabolite saringosterone $\mathbf{1 7 1},{ }^{160}$ while a novel steroid $\mathbf{1 7 2}$ has been isolated from the brown alga $S$. carpophyllum from the South China Sea. ${ }^{161}$ Ecklonia stolonifera collected from S. Korea yielded a new phlorotannin, eckstolonol $\mathbf{1 7 3}$, which possessed potent DPPH radical scavenging activity. ${ }^{162}$

405 Dolabellane 1, originally isolated from the opistobranch mollusc Dolabella californica, ${ }^{163}$ has been characterised as the major secondary metabolite and active chemical defense agent against herbivores (sea urchins and fish) in the brown alga Dictyota pfaffi. ${ }^{164}( \pm)$-Hedaol B, a bisnorditerpene isolated from the Japanese brown alga Sargassum sp., ${ }^{165}$ has been synthesised with geranyl acetone as a starting material and alkylation of silyl cyanide as the key step in the 410 synthesis. ${ }^{166}$

\section{Red algae}

The genus Laurencia continues to be a prolific source of new metabolites. A brominated bisabolene 415 derivative, aldingenin A 174, was isolated from Laurencia aldingensis collected from Brazil. 
Biogenetic considerations were of value in the structural assignment. ${ }^{167}$ From L. microcladia from Elba Island, a calenzanane sesquiterpene, debromoisocalenzanol 175 and an indene-type sesquiterpene $\mathbf{1 7 6}$ were isolated, ${ }^{168}$ while four new sesquiterpenes, $\mathbf{1 7 7 - 1 8 0}$ including the snyderol derivatives 179 and 180, have been isolated from L. obtusa collected from Bademli, Turkey.

420 Compound 179 was active against D6 and W2 clones of the malaria parasite Plasmodium falciparum. ${ }^{169}$ Laurencia perforata, collected from the Great Barrier Reef, Australia, was the source of the sesquiterpenes 4-hydroxy-1,8-epi-isotenerone 181 and two 3-epi-perforenone A derivatives, 182 and 183. ${ }^{170}$ A collection of L. obtusa from Greece yielded four new brominated diterpenes, ${ }^{171}$ prevezols C-E 184-186, and neorogioldiol B 187, together with the known prevezol B 188, whose structure has been revised from that reported originally. ${ }^{172}$ Prevezol B and neorogioldiol displayed significant cytotoxicity against the human tumour cell lines MCF7, PC3, HeLa, A431 and K562 while prevezol C only exhibited significant cytotoxicity against HeLa and A431 cell lines. Prevezol D was moderately active against all cell lines. ${ }^{171}$ Two labdane type brominated diterpenes $\mathbf{1 8 9}$ and 190 have been isolated from L. obtusa from Greece. These structures contain unprecedented eightand seven-membered ether rings respectively. ${ }^{173}$ Six new bromophenols, 191-196 were isolated from Rhodomela confervoides collected from the coast of Qingdao, China. ${ }^{174}$ Compounds 193 and 195 may be artifacts of the extraction and isolation processes. ${ }^{174}$ Compounds 194 and 195 were also reported in another paper by the same authors, along with the isolation of the known 3-bromo-4,5dihydroxybenzoic acid methyl ester (but new as a natural product) from the same source $(R$. confervoides). ${ }^{175}$ This benzoyl ester has previously been synthesised ${ }^{176}$ but the spectral data were not reported. $R$. confervoides from Qingdao was also the source of bromophenols, 197 and 198 . The phenol 198, which might also be derived from 197 during isolation, ${ }^{177}$ exhibited moderate activity against five strains of bacteria. ${ }^{178}$ Five monoterpenes $\mathbf{1 9 9 - 2 0 3}$ of the ochtodane class have been isolated from the red alga Portieria hornemanni (source not given). ${ }^{179}$ The marine polyether triterpenoid dehydrothyrsiferol, originally isolated from the red alga Laurencia pinnatifida, ${ }^{180}$ was shown to induce apoptosis in estrogen-dependent and independent breast cancer cells. ${ }^{181}$ Elatol, a 
halogenated sesquiterpene alcohol from the red alga L. elata $^{182}$ inhibited six species of human pathogenic bacteria, with significant antibacterial activities against Staphylococcus epidermis, Klebsiella pneumonia and Salmonella sp. ${ }^{183}$ Iso-obtusol from the red alga Laurencia obtusa ${ }^{184,185}$ exhibited antibacterial activity against four bacterial species with significant activity against $K$. pneumonia and Salmonella sp. Further tests indicated that both compounds were bacteriostatic rather than bacteriocidal against the bacteria tested. ${ }^{183}$ Glutathione transferase specific activity in Katharina tunicata (black chiton) was shown to be affected by the brominated phenol lanosol, ${ }^{186}$ which is prevalent among filamentous red algae of the Rhodomelaceae, and frequently consumed by $K$. tunicata. ${ }^{187}$ The first asymmetric total syntheses of (+)-3-(E)- and (+)-3-(Z)-pinnatifidenyne, originally isolated from Laurencia pinnatifida, ${ }^{188,189}$ have been reported and utilise an "olefin geometry-dependent" internal alkylation to give excellent stereoselectivity. ${ }^{190}$ The seven-membered ring ether $(+)$-neoisoprelaurefucin $\mathbf{2 0 4}$, originally isolated from $L$. nipponica, ${ }^{191}$ has also been synthesised, allowing the assignment of the absolute stereochemistry of the natural product. ${ }^{192} \mathrm{~A}$ nickel-catalysed coupling reaction of an alkynyl enone and an alkenylzirconium were the key steps in the synthesis of isodomoic acid G 205, originally isolated from the red alga Chondria armata from Kyushu Island. ${ }^{193}$ The sidechain stereochemistry was established as $\left(5^{\prime} R\right)$ by comparison of CD spectra of the natural and synthetic products. ${ }^{194}$

\section{$\begin{array}{lll}460 & 7 & \text { Sponges }\end{array}$}

Sponges continue to be an important source of novel secondary metabolites and a notable growing trend is the characterisation of compounds from bacteria and fungi that have been isolated from sponges. Such compounds have been included in Section 3 of this review. There has also been increased interest in fatty-acid derivatives, many of which have biological activities. An unusual galactofuranosylceramide, ectyoceramide 206, was isolated from the Bahaman sponge Ectyoplasia ferox, ${ }^{195}$ while a Jaspis species collected in Vanuatu was found to contain the cytotoxic sphingosine 
derivatives jaspines A 207 and B 208. ${ }^{196}$ The Korean sponge Erylus nobilus was the source of the taurine derivative 209. ${ }^{197}$ Another Korean sponge, a Stelletta species, has yielded two cytotoxic compounds, glycerol ether $\mathbf{2 1 0}^{198}$ and cyclitol derivative norsarcotride A 211. ${ }^{199}$ Plakevulin A 212, found to inhibit DNA polymerases $\alpha$ and $\gamma$, was isolated from the Okinawan sponge Plakortis sp. ${ }^{200}$ Latrunculia corticata, collected in the Gulf of Aqaba, Israel, was found to contain decalactone glycosides latrunculinoside A 213 and B 214, which have anti-feedant activity against goldfish. ${ }^{201}$ An inhibitor of membrane type 1 matrix metalloproteinase (MT1-MMP), callysponginol sulfate A 475 215, was isolated from Callyspongia truncata collected in Japan. ${ }^{202}$ An undescribed Korean species of Stelletta was found to contain cytotoxic acetylenic acids: stellettic acid A 216, $(Z)$ - and (E)stellettic acid B 217 and 218, and stellettic acid C 219 that exhibited marginal to moderate toxicity to five human tumour cell lines. ${ }^{203}$ Interestingly, the same sponge also yielded the glycerol derivatives of 217, the mildly cytotoxic 220 and 221 (inactive), along with other

480 lysophosphatidylcholines and monoglycerides 222-225. ${ }^{204}$ From a seemingly identical Stelletta species, collected at a different Korean location, a similar series of acetylenic acids was isolated including 216, a dimeric anhydride 226 and a desmethoxy analogue 227; all were mildly cytotoxic to human leukemia cells. ${ }^{205}$ The Indonesian sponge Callyspongia pseudoreticulata yielded the diyne 228, which was found to be toxic in the brine shrimp assay. ${ }^{206}$ A Diplastrella species, 485 collected in the Philippines, yielded a series of polyacetylenic diols, the diplynes A-E 229-233 and corresponding sulfates $\mathbf{2 3 4 - 2 3 6 .}{ }^{207}$ Three new chlorinated polyacetylenes $\mathbf{2 3 7 - 2 3 9}$ were isolated from the Californian sponge Haliclona lunisimilis ${ }^{208}$ along with known compounds originally isolated from the Haliclona's nudibranch predator, Diaulula sandiegensis. ${ }^{209}$ The moderately cytotoxic polyacetylenic amide, callyspongamide A 240, was obtained from Callyspongia fistularis 490 collected in the Red Sea. ${ }^{210}$ Three new amides, 241-243, along with the previously reported clathrynamide A $\mathbf{2 4 4},{ }^{211}$ were isolated from an Okinawan Psammoclemma species. ${ }^{212}$ The stereochemistry of $\mathbf{2 4 4}$ was determined (Mosher method). All four compounds were found to be antifungal. The absolute stereochemistry of the amino alcohol xestoaminol $\mathrm{C}$, originally isolated 
from a Fijian Xestospongia species, ${ }^{213}$ has been established as $(2 S, 3 R)$ by the synthesis of the $N, O$ diacetyl derivative from $(S)$-alanine. ${ }^{214}$ A racemic synthesis of 2-methoxy-13-methyltetradecanoic acid, isolated from a Puerto Rican specimen of Amphimedon complanata, ${ }^{215}$ has been reported. ${ }^{216}$ (R)-Strongylodiol B, originally isolated from a Strongylophora species, ${ }^{217}$ was synthesised enantioselectively using a $\mathrm{Zn}$ (II) acetylide addition to an aldehyde. ${ }^{218}$ Callyberynes $\mathrm{A}$ and $\mathrm{B}$, also known as callypentaynes, obtained from Japanese specimens of Callyspongia truncata ${ }^{219}$ and Callyspongia sp., ${ }^{220}$ were synthesised using sequential Cadiot-Chodkiewicz cross-coupling reactions. ${ }^{221}$ Erylus trisphaerus, collected in Dominica, was found to contain the mildly cytotoxic polyketide lactone, trisphaerolide A $245 .{ }^{222}$ A Madagascar specimen of Plakortis aff. simplex yielded three cyclic peroxides, the plakortolides H 246 and I 247 and andavadoic acid 248, all of which were cytotoxic against a range of human tumour cell lines. ${ }^{223}$ The antimicrobial tetramic acid, melophlin C 249, from an Indonesian specimen of Melophlus sarassinorum, was isolated as an inseparable mixture of four stereoisomers arising from the stereogenic centres at C-5 and C-10 (as evidenced by NMR and modified Marfey's method). A further twelve, less active tetramic acids, melophlins D-O 250-261, were also isolated from the same sponge. ${ }^{224}$ Both plakortides M 262 and N 263, isolated from a collection of Plakortis halichondrioides from Puerto Rico,

510 exhibited potent cytotoxicity to an array of human tumour cell lines. ${ }^{225}$ A Japanese specimen of Monotria japonica yielded the monotriajaponides A-D 264-267 which can lyse starfish oocytes without disruption of nuclear structure. ${ }^{226}$ Interestingly, the absolute stereochemistries of 265-267, as determined by reduction and a modified Mosher method, were opposite to those determined for the plakortides $\mathbf{2 6 2}$ and $\mathbf{2 6 3}$. The asymmetric synthesis of (+)-rottnestol, originally isolated from a 515 Haliclona species, ${ }^{227}$ using a Stille coupling firmly established the absolute stereochemistry as $(12 R)$. Similarly, syntheses of (+)-raspailol A and (+)-raspailol B, originally obtained from a Raspailia species, ${ }^{228}$ have established a $(12 R)$ configuration for these two metabolites also. ${ }^{229}$ An unusual bis-dimedone thioether with strong UV A and B absorption, benzylthiocrellidone 268, was isolated from a Great Barrier Reef collection of Crella spinulata; the structure was reported in 
$2002,{ }^{230}$ but was omitted from the 2002 review. ${ }^{231}$ Okadaic acid, originally isolated from

Halichondria okadai, ${ }^{232}$ and subsequently found to be a dinoflagelate and shellfish toxin, ${ }^{233,234}$ has been investigated for potential as a defense molecule for the Adriatic sponge Suberites domuncula. Use of an ELISA assay established that okadaic acid was localised in the epithelium of the lacunae and water channels of the sponge, as well as in bacteria located in the sponge tissue. It was postulated that okadaic acid acts as a stimulant of the sponge immune system to the presence of bacteria, but in higher concentrations causes apoptosis. ${ }^{235}$ Two analogues of okadaic acid, 27-Oacetylokadaic acid 269 and 27-O-acetyldinophysistoxin 1 270, were isolated from a British Columbian sponge Merrianum oxeato and found to be potent G2 checkpoint inhibitors and highly cytotoxic. ${ }^{236}$ A Papua New Guinean sponge, Cymbastela sp., was found to contain the cytotoxic 530 peptide milnamide D 271 along with the related peptides hemiasterlin ${ }^{237}$ and milnamide A. ${ }^{238}$ All three compounds were inhibitors of tubulin polymerisation. ${ }^{239}$ Three unusual new cyclic peptides, the kapakahines E-G 272-274, have been isolated from a Micronesian collection of Cribrochalina olemda and reported as cytotoxic to P388 murine leukemia cells. ${ }^{240}$ The previously described sulfoxide, waiakeamide 275, and a new sulfone analogue $\mathbf{2 7 6}$ were isolated from a Haliclona sp.

535 collected in Palau. The sulfone $\mathbf{2 7 6}$ was found to inhibit the settlement of larvae of the blue mussel (Mytilus edulis galloprovincialis). ${ }^{241}$ The myriastramides A-C 277-279 were isolated from the same Philippine collection of Myriastra clavosa that had previously yielded the clavoside macrolides. ${ }^{242,243}$ Leucamide A, originally isolated from the Australian sponge Leucetta microraphis, ${ }^{244}$ has been synthesised. ${ }^{245}$ Due to differences in biological activity, the cis, cis- $\mathbf{2 8 0}$

540 and reputed trans,trans- $\mathbf{2 8 1}$ isomers of ceratospongamide, originally isolated from the Indonesian symbiotic pairing of the red alga Ceratodictyon spongiosum and the sponge Sigmadocia symbiotica, ${ }^{246}$ continue to attract considerable attention from synthetic chemists. Although both rotamers had been synthesised previously, ${ }^{247}$ slight differences in the NMR spectra of the synthetic trans,trans isomer $\mathbf{2 8 1}$ and the isolated natural product were noted. Suspecting a possible epimerisation the trans, trans-[D-allo-Ile] isomer, 282 was synthesised, by two separate routes, to 
produce a compound that is identical in all respects to the natural isomerisation product. ${ }^{248}$ Phakellistatins $1^{249}$ and $10,{ }^{250}$ have been synthesised. ${ }^{251}$ Phakellistatin 1 was found to exist as the all-cis rotamer at the proline residues, while phakellistatin 10 was determined to be all-trans. Interestingly, both synthetic products were more than 100-fold less cytotoxic than the natural 550 product. $^{251}$ A large $(500 \mathrm{Kg})$ collection of a Phakellia species from Chuuk, Micronesia, yielded the growth inhibitory phakellistatin $12 \mathbf{2 8 3},{ }^{252}$ while a Chinese collection of Phakellia fusca yielded the very cytotoxic phakellistatin $13 \mathbf{2 8 4} .^{253}$ The macrolide spirastrellolide A was isolated as its methyl ester 285 from the Caribbean sponge Spirastrella coccinea. Unlike many other sponge-derived antimitotic macrolides, 285 does not effect tubulin polymerisation. ${ }^{254}$ An asymmetric synthesis of (-)-peloruside A, the antipode of the natural product $\mathbf{2 8 6}$ originally isolated from the New Zealand sponge Mycale hentscheli, ${ }^{255}$ has been achieved via a Mitsunobu-type lactonisation. ${ }^{256}$ The synthetic antipode proved to be biologically inactive in cytotoxicity assays, but established the absolute stereochemistry of the natural (+)-enantiomer $\mathbf{2 8 6}$ as drawn. The relative and absolute stereochemistries of the C23-C35 portion of reidispongiolide A $\mathbf{2 8 7}$, isolated from the New

560 Calidonean sponge Reidispongia coerulea, ${ }^{257}$ have been established by synthesis of an ozonolysis fragment of the natural product. ${ }^{258}$ The total synthesis of (+)-13-deoxytedanolide, originally isolated from the Japanese sponge Mycale adherens, ${ }^{259}$ has been accomplished. ${ }^{260}$ The natural enantiomer of lasonolide A, isolated from a Caribbean Forcepia species, ${ }^{261}$ has also been synthesised and found to be bioactive. ${ }^{262}$ The hexabromobiphenylether from Dysidea herbacea ${ }^{263}$

565 has been synthesised and found to be a potent aldose reductase (ALR2) inhibitor. ${ }^{264}$ The Micronesian sponge Cribrochalina olemda was found to contain a new $N$-methyl-D-aspartate (NMDA) receptor ligand, cribronic acid 288, which has potent convulsant activity in mice. ${ }^{265}$ The known antioxidant amino acid L-5-hydroxytryptophan was found to be a major constituent of the NW Atlantic intertidal sponge Hymeniacidon heliophila and was observed to suppress apoptosis in 570 human lymphocytes at concentrations similar to those found in the sponge tissue. Since UV light induces apoptosis, it is proposed that the high concentrations of L-5-hydroxytryptophan act to 
protect this sponge species from sunlight UV damage. ${ }^{266}$ The pyridinium alkaloid simplakidine A 289 was isolated from the Caribbean sponge Plakortis simplex. ${ }^{267}$ The rather remarkable trispyridinium alkaloid viscosamine $\mathbf{2 9 0}$ has been isolated from the Arctic sponge Haliclona viscose.

575 The trimeric nature of this alkaloid was deduced from a series of ions in the mass spectrum. ${ }^{268}$ Halitulin 291, isolated from a South African collection of Haliclona tulearensis, ${ }^{269}$ has been synthesised, establishing C-15 as $(S) .{ }^{270}$ Clathryimine, originally isolated from Clathria basilana, ${ }^{271}$ has been synthesised using palladium-catalyzed cross-coupling reactions. ${ }^{272}$ Hachijodines F and G, isolated originally from Xestospongia and Amphimedon species, ${ }^{273}$ have been synthesised. The $N$ 580 oxide moieties were introduced using modified Mukiyama conditions. ${ }^{274}$ Pyrinodemin A 292, isolated from a Okinawan collection of an Amphimedon species, ${ }^{275}$ continues to attract considerable attention from synthetic organic chemists. ${ }^{231}$ The position of the cis double bond has been contentious, with the originally published structure 292 being modified to $293^{276}$ and $294^{277}$ respectively. The structure $\mathbf{2 9 4}$ has now been synthesised asymmetrically by two independent 585 groups establishing the absolute stereochemistry of the bicyclic core. ${ }^{278,279}$ One group was also able to compare the spectral data to the original spectra of the natural product and confirm the structure as 294. ${ }^{278}$ Petrosin and petrosin A, originally isolated from Petrosia seriata, ${ }^{280,281}$ were found to inhibit HIV-1 replication and HIV-1 reverse transcriptase. ${ }^{282}$ The total synthesis of the (+)-antipode of nakadomarin A 295, originally isolated from an Amphimedon species, ${ }^{283}$ has established the 590 absolute stereochemistry of the (-)-natural enantiomer as $(R R R R) .{ }^{284}$ Three new manzamine alkaloids 296-298, the related harman-1-one 299, and des- $N$-methylxestomanzamine A 300 were isolated from an Indonesian sponge. ${ }^{285}$ Three $\beta$-carbolines, 3-bromofascaplysin 301, 14 bromoreticulatine $\mathbf{3 0 2}$ and 14-bromoreticulatate 303, have been reported as metabolites of Fascaplysinopsis reticulata from Indonesia and Fiji. 3-Bromofascaplysin was also reported as a 595 metabolite of the tunicate Didemnum sp. ${ }^{286}$ Three iodine-containing indole alkaloids, plakohypaphorines A-C 304-306, were also obtained from the same Caribbean Plakortis simplex collection that yielded simplakidine (vide supra). This is the first report of naturally occurring 
iodoindole alkaloids. ${ }^{287}$ Damirones $A$ and $\mathrm{B}^{288}$ have been prepared from the corresponding makaluvamines by alkaline hydrolysis, suggesting that the damirones may be artifacts of isolation and not naturally-occurring compounds. ${ }^{289}$ The Indonesian sponge Biemna fortis yielded the pyridoacridine alkaloid labuanine $\mathbf{3 0 7}$, which along with two related synthetic pyridoacridine alkaloids and the previously isolated biemnadin, ${ }^{290}$ were found to be inducers of neuronal differentiation. ${ }^{291}$ Several new antimicrobial aaptamine type alkaloids 308-312 were isolated from an Indonesian Xestospongia species, ${ }^{292}$ while from a Japanese Neopetrosia sp. a further tetrahydroisoquinoline alkaloid, renieramycin J 313, was reported. ${ }^{293}$ The dark blue, cytostatic and antimicrobial metabolite, cribrostatin $6 \mathbf{3 1 4}$, was isolated from a species of Cribrochalina from the Maldives. ${ }^{294}$ The dictyodendrins A-E 315-319, isolated from the Japanese sponge Dictyodendrilla verongiformis were found to inhibit telomerase activity. ${ }^{295}$ Phloeodictine A1, originally isolated from a New Caledonian sponge of the genus Phloeodictyon, ${ }^{296}$ has been synthesised. ${ }^{297} \mathrm{~N}, \mathrm{~N}$ -

610 Dimethyl naamine D 320 and leucettamine C 321 are reported as new, mildly antimicrobial metabolites of two Fijian Leucetta species. ${ }^{298}$ The same research group has also isolated three further imidazole-containing alkaloids, calcaridine A $\mathbf{3 2 2}$ spirocalcaridine A $\mathbf{3 2 3}$ and spirocalcaridine C 324, from one of the two Leucetta collections. ${ }^{299}$ Isonaamidines A and C, originally isolated from an Indo-Pacific Leucetta species, ${ }^{300}$ have been synthesised. ${ }^{301}$ Sventrin, 615 isolated from Agelas sventes, ${ }^{302}$ has been synthesised by a Red-Al reduction of an alkyne. ${ }^{303}$ An MT1-MMP inhibitor, ageladine A 325, was isolated from a Japanese Agelas nakamuri collection. ${ }^{304}$ Oroidin-type alkaloids with novel skeletons, the latonduines A $\mathbf{3 2 6}$ and B 327, were obtained from an Indonesian Stylissa carteri collection. ${ }^{305}$ A Stylissa aff. massa, obtained from Japanese waters, was found to contain a geranylgeranyltranferase type I inhibitor, massadine $620328 .^{306}$ Crambescidin 826 329, isolated from a Monanchora sp. collected in Palau, was found to be a potent inhibitor of HIV-1 envelope-mediated fusion, along with the known compounds crambescidin $800^{307}$ and fromiamycalin, ${ }^{308}$ while dehydrocrambine A 330, also isolated from this sponge, was found to be a weak inhibitor only. ${ }^{309}$ A related antibacterial guanidine alkaloid, Sch 
575948 331, was isolated from a Ptilocaulis spiculifer (Crambe crambe) specimen. ${ }^{310}$ Two

antimitotic guanidine/bromotyrosine alkaloids, ceratamines A $\mathbf{3 3 2}$ and B 333, were isolated from a Papua New Guinean Pseudoceratina sp. ${ }^{311}$ An Indian collection of Psammaplysilla purpurea was found to contain the antibacterial bromotyrosine-derived alkaloids purpuramine K 334 and L 335. ${ }^{312}$ Aerothionin, originally isolated from Verongia aerophoba, ${ }^{313}$ has been found to be active against drug-resistant strains of Mycobacterium tuberculosis and several other Mycobacterium

630 sp. ${ }^{314}$ A Chinese collection of the sponge Phakellia fusca yielded a remarkable series of fluorinated uracil derivatives 336-340. The presence of fluorine was confirmed by X-ray diffraction and ${ }^{19} \mathrm{~F}$ NMR studies. This is the first report of fluorine-containing marine natural products. ${ }^{315}$ Spongederived merosequiterpenoids continue to be a fruitful area of research for both natural product and synthetic chemists. Isoarenarol 341, isolated from a Papua New Guinean collection of Dysidea 635 arenaria, was found to be a potent protein kinase inhibitor. ${ }^{316}$ Spongiaquinone, isolated from Stelospongia conulata, ${ }^{317}$ has been prepared in an asymmetric synthesis. The absolute stereochemistry was assigned based on comparison of the optical rotation of the synthetic methyl ether with that of the natural compound. ${ }^{318}$ A Micronesian Aka species has yielded three new sesquiterpenoid quinols, akaol A 342, 343, and the tentatively assigned siphonodictyol I $344 .^{319}$

640 Also isolated was siphonodictyal C 345, originally isolated from Siphonodictyon coralliphagum ${ }^{320}$ and previously described as a free phenol. However the sample isolated from the $A k a$ sp. had identical NMR spectra and clearly shows the presence of $\mathrm{SO}_{3} \mathrm{Na}$ by ESIMS. ${ }^{319}$ The sulfate group is lost in EIMS, the technique used for characterisation in the original isolation procedure. ${ }^{320}$ Siphonodictyal C was a modest inhibitor of complexation in the CDK4/cyclin D1 assay. ${ }^{320}$ The 645 moderately cytotoxic neodactyloquinone 346 and the dactylolactones A-D 347-350 were obtained from an Okinawan collection of Dactylospongia elegans. ${ }^{321}$ A Great Barrier Reef species of Spongia yielded the sesquiterpenoid aminoquinone cyclosmenospongine 351, which was found to be moderately cytotoxic to murine Ehrlich carcinoma cells. ${ }^{322}$ Methanolic extracts of an Indonesian sponge of the genus Hyrtios yielded three new puupehenone derivatives 352-354, but which are 
650 proposed to be artifacts of isolation from puupehenone. ${ }^{323}$ The biosynthesis of the sesquiterpenoid dichloroimines, stylotellanes A and B, ${ }^{324}$ was investigated. Incorporation of labelled farnesyl isocyanide and farnesyl isothiocyanate demonstrated the role of these compounds as intermediates in the formation of the stylotellanes. ${ }^{325}$ 10-Formamido-4-cadinene 355, isolated from the Japanese sponge Acanthella cavernosa, was found to inhibit the settling of the cyprid (barnacle) larvae 655 Balanus ainphitrite. ${ }^{326}$ The Indonesian sponge Axinyssa aculeata and its nudibranch predator Phyllidia varicosa were both found to contain the moderately antifungal 9-thiocyanatopupukeanane sesquiterpenoids 356 and $357 .{ }^{327}$ 2-Thiocyanatoneopupukeanane 358, originally isolated from the sponge Phycopsis terpnis, ${ }^{328}$ was subsequently revised to the endo stereochemistry on the basis of long-range ${ }^{1} \mathrm{H}-{ }^{1} \mathrm{H}$ coupling and NOE correlations. ${ }^{329}$ Both enantiomers have been synthesised from $660(R)$-carvone via the corresponding alcohols ${ }^{330}$ and the stereochemistry of $\mathbf{3 5 8}$ has now been fully established via an X-ray structure of the nitrobenzoate derivative of the corresponding alcohol. ${ }^{331} \mathrm{~A}$ Japanese Axynissa species yielded the mildly cytotoxic diterpene, axinyssene $359 .{ }^{332}$ An enantioselective synthesis of (-)-nakamurol, originally isolated from the Okinawan sponge Ageles nakamuri, ${ }^{333}$ established the relative and absolute stereochemistries of the naturally-occurring $\mathbf{3 6 0}$ 665 enantiomer. ${ }^{334}$ Synthesis of the proposed structure of aplyroseol-14 361, originally isolated from the New Zealand sponge Aplysilla rosea, ${ }^{335}$ did not yield spectra similar to those of the natural product. The revised structure, $\mathbf{3 6 2}$, was synthesised and found to be spectrally identical with aplyroseol-14. ${ }^{336}$ Six cycloamphilectenes isolated from an Axinella species collected in Vanuatu were found to be potent inhibitors of nitric oxide production by murine macrophages. ${ }^{337}$ Only one 670 ( $N$-formyl-7-amino-11-cyclocamphilectene) of the six compounds in this study has had a structure determination published. ${ }^{338}$ The C-25 sesterterpenoids and related nor-compounds are characteristic of sponges, especially those of Dictyoceratid origin. A cytotoxic norsesterterpenoid, mycaleperoxide 363, was isolated from a Mycale species collected in Thailand. The relative and absolute stereochemistries were established by standard methodology, including chemical 675 interconversions. ${ }^{339}$ Two moderately cytotoxic norsesterterpenoids, sarcotins N 364 and O 365, 
along with a sesterterpenoid 366, four pyrrolosesterterpenoids 367-370 and ent-kurospongin 371 were isolated from two Korean Sarcotragus species. ${ }^{340}$ The previously reported sarcotin I $\mathbf{3 7 2}^{341}$ was found to have the $(21 R)$ configuration. ${ }^{340}$ Three norsesterterpenoids $\mathbf{3 7 3}-\mathbf{3 7 5}$ and two sesterterpenoids $\mathbf{3 7 6}$ and 377, isolated from an Okinawan Ircinia species, were found to be moderately cytotoxic. ${ }^{342}$ Darwinella australensis collected from NW Australia contained sesterterpenoid sulfates $\mathbf{3 7 8}-\mathbf{3 8 0}$ that inhibited the cell division of sea urchin eggs, but were not cytotoxic to human leukemia cells. ${ }^{343}$ An Ircinia species collected at $-70 \mathrm{~m}$ by dredging in the Gulf of Mexico contained a tricyclic sesterterpenoid, Sch 599473 381, ${ }^{344}$ while the Antarctic sponge, Suberites caminatus yielded the rearranged sesterterpenoid aldehyde caminatal $382 .{ }^{345} \mathrm{An}$ asymmetric synthesis of (-)-cacospongionolide F, isolated from Fasciospongia cavernosa, ${ }^{346}$ confirmed the original stereochemical assignments. ${ }^{347}$ The bicyclic lactone astakolactin $\mathbf{3 8 3}$ and the pentacyclic diacetate 16-acetoxy-dihydrodeoxoscalarin $\mathbf{3 8 4}$ were obtained from specimens of Cacospongia scalaris collected in Greece. ${ }^{348}$ A Spongia species collected in Japan yielded three cytotoxic pentacyclic sesterterpenoids $\mathbf{3 8 5}-\mathbf{3 8 7}$. $^{349}$ Seven new polyhydroxy sterols $\mathbf{3 8 8}-\mathbf{3 9 4}$ were isolated from a Japanese Acanthodendrilla species along with three known agosterols. These were found to be proteasome inhibitors. ${ }^{350}$ Clathriol B 395, isolated from the New Zealand sponge Clathria lissosclera, was found to inhibit the production of superoxide from human neutrophils. ${ }^{351}$ A sterol sulfate, Sch 572423 396, along with the previously described halistanol sulfate, ${ }^{352}$ isolated from a Topsentia species collected in the Bahamas, were found to bind to $\mathrm{P} 2 \mathrm{Y}_{12}$ receptors. ${ }^{353}$ Another deep-water Bahaman sponge, belonging to the family Astroscleridae, yielded the trisulfated sterol Sch $575867397,{ }^{354}$ while a series of steroidal oligoglycosides, the mycalosides BI 398-405, have been isolated from the Cuban sponge Mycale laxissima. The mycalosides are inhibitors of the fertilisation of sea urchin eggs. ${ }^{355}$ Four significantly cytotoxic steroidal alkaloids, plakinamines I-K 406-408 and dihydroplakinamine K 409, were isolated from a Philippine sponge

700 Corticium niger. ${ }^{356}$ The halogenated and rearranged norsteroid, nakiterpiosin 410, isolated from the Okinawan Terpios hoshinota, was found to be cytotoxic to murine P388 leukemia cells. ${ }^{357}$ 
Hippospongic acid A, originally isolated from a Japanese Hippospongia species, ${ }^{358}$ inhibits all classes of vertebrate DNA polymerases and human topoisomerases I and II, but is inactive towards DNA polymerases from plants, insects and prokaryotes. ${ }^{359}$ Two mildly cytotoxic polyoxygenated triterpenes, yardenones A 411 and B 412 were isolated from a Yemenese collection of Axinella cf. bidderi. ${ }^{360}$

\section{$8 \quad$ Coelenterates}

710 The number of new metabolites reported annually from coelenterates has remained relatively constant over the 2002-2003 period. A new sphingosine derivative $\mathbf{4 1 3}$ was reported from a soft coral Nephthea sp. collected at the Andaman and Nicobar Islands, Indian Ocean, ${ }^{361}$ while investigations of Sinularia grandilobata and Sinularia sp. specimens from the same location afforded 414-416 as antimicrobial metabolites. ${ }^{362}$ The absolute stereochemistry of the $N$-palmitate

715417 , isolated from a Bay of Bengal collection of Nephthea sp., was deduced by analysis of ${ }^{1} \mathrm{H}-{ }^{1} \mathrm{H}$ coupling constants of the acetonide derivative and comparison of optical properties with known compounds. ${ }^{363}$ Acylspermidines 418-420, isolated from an Okinawan collection of Sinularia sp. soft coral, ${ }^{364}$ were all potently cytotoxic towards A431 cells. In a separate study $\mathbf{4 1 9}$ and $\mathbf{4 2 0}$ were found to be potent inhibitors of plant vacuolar $\mathrm{H}^{+}$-pyrophosphatase. ${ }^{365}$ The phenol 421 was isolated 720 from a Taiwanese collection of Isis hippuris, ${ }^{366}$ while investigation of a Japanese collection of the stony coral Tubastraea sp. afforded bisindole alkaloids 422-424. ${ }^{367}$ From Israel, eight new oxylipin derivatives were reported from Gulf of Aqaba collections of Dendronephthya sp. (425-428), Tubipora musica (429 and 430) and Dendrophyllia sp. (431 and 432) coelenterates. ${ }^{368}$ Stereochemical configurations were secured by standard methods. All eight metabolites exhibited biological activity towards bacteria, brine shrimp, sea urchin egg development and crown gall potato tumours. Fifteen new members of the clavulone family of prostanoids $433-447$ were reported from an Okinawan collection of Clavularia viridis. ${ }^{369}$ The absolute configurations of 433- 
443,445 and 446 were secured by analysis of CD data while those of 444 and 447 were proposed based upon biogenetic considerations. Prostanoids 448-450, possible biosynthetic precursors to the clavulones, were also isolated from an Okinawan collection of $C$. viridis. ${ }^{370}$ By utilising protease and detergent fractionation methodology, clavulones and arachidonic acid have been located in host C. viridis membranes, as opposed to the closely associated symbiont Symbiodinium sp. ${ }^{371}$ Sesquiterpenes ainigmaptilones A 451 and B 452 were isolated from a Weddell Sea, Antarctica, collection of Ainigmaptilon antarcticus. ${ }^{372}$ Ainigmaptilone A demonstrated activity in a number of 735 ecologically-relevant assays, including antibiotic and feeding deterrence properties. Furanosesquiterpene 453, reported from the Antarctic gorgonian Dasystenella acanthina, bears a trans-ring junction as determined by NOESY NMR experiments and comparison with related cisfused isomers. ${ }^{373}$ Asymmetric synthesis of both enantiomers of acetoxytubipofuran 454, originally isolated from a Japanese collection of Tubipora musica, ${ }^{374}$ defined the absolute stereochemistry as 740 shown, ${ }^{375}$ while the structure of echinofuran ${ }^{376}$ has been confirmed by racemic synthesis. ${ }^{377}$ Confertol 455 and nephalbidol 456 were isolated from the soft corals Sinularia conferta and Nephthea albida respectively, ${ }^{378}$ while cladioxazole 457 was isolated from an Andaman Island, Indian Ocean, collection of Cladiella $\mathrm{sp} .^{379}$ A full account of the synthesis of the dolabellane diterpene claenone, previously reported from Clavularia sp., ${ }^{380}$ the first synthesis of palominol, 745 from Eunicea laciniata, ${ }^{381}$ and a new route to dolabellatrienone, also from E. laciniata, ${ }^{381,382}$ have also been reported. ${ }^{383}$ Stereoselective synthesis of $(+)-4,5$-deoxyneodolabelline, a metabolite of an Australian collection of Cespitularia sp., ${ }^{384}$ has been reported. ${ }^{385}$ The structure of kallosin A 458, a rearranged pseudopterane diterpenoid isolated from a Caribbean collection of Pseudopterogorgia kallos, was secured by spectroscopic and X-ray analyses. ${ }^{386}$ Elisabethin A, isolated from $P$.

750 elisabethae, ${ }^{387}$ has been synthesised utilising intramolecular [4+2] cyclisation under biomimetic conditions. ${ }^{388}$ The first synthesis of the related diterpene elisapterosin B and a new route to colombiasin A, also isolated from P. elisabethae, ${ }^{389,390}$ have been achieved based on [5+2] and [4+2] intramolecular cyclisations of a common diene intermediate. ${ }^{391}$ New members of the 
elisapterosin family, D 459 and E 460, were reported from a Caribbean collection of the same organism. ${ }^{392} P$. elisabethae is also a well recognised source of anti-inflammatory diterpenes, new examples of which include elisabethadione 461, elisabethol 462, pseudopterosins M-O 463-465 and seco-pseudopterosins E-G 466-468. ${ }^{393}$ Of the eight diterpenes, 461, 464 and 466 were the most potent in the mouse ear edema assay. The chemical steps involved in the biosynthesis of the pseudopterosins in P. elisabethae have been studied using ${ }^{3} \mathrm{H}$-labelled precursors, ${ }^{394}$ with a subsequent study showing that diterpene production is occurring within the dinoflagellate symbiont Symbiodinium sp. ${ }^{395}$ Preparation of all four C-1 and C-7 stereoisomers of pseudopteroxazole 469, a mildly antimycobacterial diterpene isolated from P. elisabethae, ${ }^{396}$ required a revision of assigned stereochemistry to that shown, ${ }^{397}$ while a new bioactive congener, homopseudopteroxazole $\mathbf{4 7 0}$, has been reported from the same organism collected near San Andrés Island, Colombia. ${ }^{398}$ The 765 structures of the $P$. elisabethae metabolites, elisabatins $\mathrm{B}^{399}$ and $\mathrm{C},{ }^{400}$ have been confirmed by Xray studies. ${ }^{401}$ Investigation of a Great Barrier Reef collection of Sarcophyton cherbonnieri yielded furano-cembranoids 471-473, while the same study ${ }^{402}$ also reported new seco-cembranoids 474 and 475 from a Fijian collection of Nephthea sp. in addition to the known cembrane decaryiol. ${ }^{403}$ Modest cytotoxicity towards a panel of tumour cell lines was exhibited by $\mathbf{4 7 1}, \mathbf{4 7 3}$ and decaryiol while the latter was shown to arrest the cell cycle at G2/M. Structures of sarcocrassolide B $\mathbf{4 7 6}^{404}$ and sarcophyocrassolide A 477, ${ }^{405}$ cytotoxic cembrane diterpenes isolated from a Chinese collection of Sarcophyton crassocaule, were secured by X-ray studies, ${ }^{406}$ as was that of 11-epi-sinulariolide acetate 478, ${ }^{407}$ previously reported from gorgonians collected from the Gulf of Elat. 11-epiSinulariolide acetate was found to exhibit moderate cytotoxicity towards a range of tumour cell 775 lines. In addition to a number of known metabolites, new nor-cembrane diterpenes leptocladolides A 479, B 480 and C 481 were isolated from a Taiwanese collection of Sinularia leptoclados, while 479 and related compounds 1-epi-leptocladolide A 482 and (7E)-leptocladolide A 483 were isolated from an ethanolic extract of S. parva. ${ }^{408}$ Both $\mathbf{4 7 9}$ and $\mathbf{4 8 3}$ exhibited modest cytotoxicity towards two tumour cell lines, but $\mathbf{4 8 2}$ was less active. Two known diterpenes, sinuleptolide $\mathbf{4 8 4} 4^{409}$ and 
780 norcembrenolide $485,{ }^{410}$ inhibit LPS-induced TNF- $\alpha$ production by murine macrophage-like cells in a dose-dependent manner. ${ }^{411}$ Note that while the characterisation data for the two diterpenes reported in the reference agree with original and recent reports, ${ }^{408}$ the structures are represented with incorrect relative stereochemistry at C-11. Cembranes $\mathbf{4 8 6}-\mathbf{4 8 9}$ were isolated from an eastern Caribbean collection of Eunicea tourniforti. ${ }^{409}$ The structure and relative stereochemistry of the 785 highly oxygenated diterpene providencin 490, purified from Caribbean collections of Pseudopterogorgia kallos, was secured by X-ray analysis. ${ }^{410}$ Mild cytotoxicity towards human tumour cell lines was observed for 490. In addition to the known metabolites stolonidiol 491 and stolonidiol monoacetate 492, two new dolabellane diterpenes, clavinflols A 493 and B 494, were isolated from a Taiwanese collection of Clavularia inflata. ${ }^{411}$ While 491, 492 and 494 exhibited selective cytotoxicity towards the KB cell line, 493 was selective towards the Hepa cell line. In contrast, the acetoxy derivatives 495 and 496 were essentially inactive in the same assays. Pachyclavulariolides M-R 497-502 were isolated from a Taiwanese collection of Pachyclavularia violacea ${ }^{412} \mathrm{P} 388$ cell line growth inhibition was observed for 497. (Z)-Sarcodictyin A $\mathbf{5 0 3}$ is a potently cytotoxic diterpenoid isolated from a Japanese collection of Bellonella albiflora. ${ }^{413}$ The 795 absolute stereochemistry of $\mathbf{5 0 3}$ was related to sarcodictyin A $\mathbf{5 0 4}$ by transesterification and comparison of CD spectra. Spectroscopic discrepancies observed for the enantioselectively synthesised structure originally proposed for alcyonin $\mathbf{5 0 5}$, isolated from the Okinawan soft coral Sinularia flexibilis, ${ }^{414}$ has led to the proposal that the correct structure of the natural product is the allylic peroxide 506. ${ }^{415}$ The structures of briarellins E $\mathbf{5 0 7}$ and F 508, isolated from a Puerto Rican 800 collection of Briareum asbestinum, ${ }^{416}$ were confirmed by enantioselective total synthesis, which also established the absolute configuration of the diterpenes. ${ }^{417}$ In addition to a number of known compounds, new briarellins J-P 509-515, two unnamed congeners 516 and 517 and polyanthellin A 518 were reported from a Puerto Rican collection of Briareum polyanthes. ${ }^{418}$ Spectroscopic evidence was also presented for revision of the structure of briarellin A from $\mathbf{5 1 9}^{419}$ to peroxide 520, and reformulation of the structures of $\mathbf{5 2 1}$ and 522, isolated from an Australian collection of 
Briareum sp. in $1989,{ }^{420}$ to the enantiomers of $\mathbf{5 1 8}$ and $\mathbf{5 2 3}$ respectively. Antimalarial testing against Plasmodium falciparum indicated 511, 516 and 517 to be the most active. Two investigations of the chemistry of Junceella juncea, one using specimens collected from the Tuticorin coast of the Indian Ocean, yielded juncins I-M 524-528, ${ }^{421}$ while a Taiwanese collection 810 of the same organism afforded juncin N 529. ${ }^{422}$ Additional studies of $J$. juncea from Taiwan afforded juncenolides B-D 530-532 ${ }^{423}$ and juncenolide E 533, ${ }^{424}$ of which $\mathbf{5 3 1}$ exhibited mild cytotoxicity towards Hepa and KB cell lines. ${ }^{423}$ A different diterpene structure 534, isolated from an Indian Ocean collection of $J$. juncea, was also given the trivial name juncenolide $\mathrm{B} .{ }^{425}$ A Taiwanese collection of Junceella fragilis yielded 9-O-deacetylumbraculolide A 535. ${ }^{426}$ The structurally

815 related epoxides briaexcavatolides S-V 536-539 were isolated from Taiwanese specimens of Briareum excavatum, ${ }^{427}$ while a Taiwanese collection of $J$. fragilis was the source of junceellolide H 540. ${ }^{428}$ Briarlides A-H 541-548, obtained from Amami Oshima, Kagoshima Prefecture collections of Briareum sp., were evaluated for cytotoxicity towards Vero and MDCK cell lines where modest activity was observed for 541, 544-546, weak activity for 542,543 and 547 while

$820 \mathbf{5 4 8}$ was inactive. ${ }^{429}$ In addition to a number of known metabolites, seven new briaranes, erythrolides R-U 549-552, an erythrane, erythrolide V 553, and two aquariane-skeletoned diterpenes, aquariolides B 554 and C 555, were reported from a Caribbean collection of Erythropodium caribaeorum. ${ }^{430}$ Aquariolide A 556, previously isolated from aquarium-grown specimens of E. caribaeorum, ${ }^{431}$ was also identified from the organism collected in the wild. The relative stereochemistries of 549-555 were determined either by conversion to known related derivatives, or by interpretation of ROESY NMR data, while for erythrolide S 550, Mosher methodology established the absolute configuration of the 3-hydroxybutanoyl side chain as (3'S). The biosynthetic relationships between a number of erythrolide diterpenes, involving possible enzymatic-mediated di- $\pi$-methane and vinyl-propane rearrangements was discussed. The study also 830 reported that the known metabolites erythrolides $\mathrm{P}^{432}$ and $\mathrm{J}^{433}$ exhibited modest cytotoxicity towards the MCF7 tumour cell line. An Okinawan collection of Xenia sp. yielded the known metabolite 
xeniolide $\mathrm{A}^{434}$ as well as new xenicane diterpenes dihydroxeniolide A $\mathbf{5 5 7}$ and isoxeniatriacetate 558. ${ }^{435}$ The absolute configuration of $\mathbf{5 5 7}$ was established (Mosher method), while the absolute configuration of $\mathbf{5 5 8}$ was determined by synthesis from the stereochemically-defined xeniolide A. ${ }^{436}$

835 13-Epi-9-deacetoxyxenicin $\mathbf{5 5 9}$ was isolated as a cytotoxic component of Asterospicularia laurae collected on the Great Barrier Reef, Australia. ${ }^{437}$ Good activity was observed for $\mathbf{5 5 9}$ against P388D1 cells, while the known metabolite 13-epi-9-deacetylxenicin $\mathbf{5 6 0}^{438}$ was less active. DCM or ether solutions of 559 readily underwent autoxidation to afford the hydroperoxide $\mathbf{5 6 1}$, while $\mathbf{5 6 0}$ was found to be resistant to further reaction. The stereochemistries of sesterterpenes cladocorans A 840562 and B 563, isolated from Mediterranean collections of Cladocora cespitosa, ${ }^{439}$ have been revised by total synthesis, ${ }^{440}$ while preparation and testing of related stereoisomers indicated the series exhibits cytotoxicity towards a panel of human tumour cell lines. ${ }^{441}$ Pregnane acetal $\mathbf{5 6 4}$ was isolated from an ethanol extract of Subergorgia suberosa, collected off the Mandapam coast, Indian Ocean, ${ }^{442}$ while a Taiwanese collection of Isis hippuris afforded the polyoxygenated steroids hippuristerones E-I 565-569. ${ }^{443}$ New gorgosterol and ergosterol derivatives 570-574 were isolated from a Great Barrier Reef collection of Capnella lacertiliensis. ${ }^{444}$ All compounds exhibited weak antifungal activity while $\mathbf{5 7 3}$ and $\mathbf{5 7 4}$ also weakly inhibited tyrosine kinase p56 ${ }^{\text {lck }}$. The spiroketal steroid 575 was isolated from a Tuticorin coast, Indian Ocean collection of Gorgonella umbraculum, ${ }^{445}$ while the mildly cytotoxic gibberoketosterol $\mathbf{5 7 6}$ was isolated from a Taiwanese 850 collection of Sinularia gibberosa. ${ }^{446}$ A South China Sea collection of Nephthea chabroli afforded the weakly cytotoxic sterols $\mathbf{5 7 7}$ and $\mathbf{5 7 8},{ }^{447}$ and the arabinopyranosylsterol $\mathbf{5 7 9}$ was isolated from Cladiella krempfi, also collected in Chinese waters. ${ }^{448}$ APETx1, a 4,552 Da 42-amino acid peptide cross-linked by three disulfide bonds, was isolated from the sea anemone Anthopleura elegantissima. ${ }^{449}$ The toxin inhibits HERG voltage-dependent $\mathrm{K}^{+}$channels via gating modification 855 rather than channel pore occlusion. Pore formation by equinatoxin II, a protein toxin isolated from the Mediterranean sea anemone Actinia equina, ${ }^{450}$ has been examined using combinations of ${ }^{31} \mathrm{P}$ NMR, ${ }^{31}$ P MAS NMR, electron microscopy, ${ }^{451}$ FTIR $^{452}$ and toxin mutagenesis. ${ }^{453}$ The ability of 
surface plasmon resonance to study membrane binding processes of pore forming toxins has been reviewed. $^{454}$

860

\section{Bryozoans}

Once again, few new compounds have been reported from bryozoans. The structural determination of the alkaloids pterocellins A $\mathbf{5 8 0}$ and B 581, isolated from the marine bryozoan Pterocella vesiculosa collected in New Zealand, relied in part on an X-ray diffraction study of pterocellin A 580. Both pterocellins A and B exhibit potent antimicrobial and antitumour activity in vitro, but only displayed modest activity in an in vivo hollow fibre assay. ${ }^{455}$ The $\beta$-carboline alkaloid 8hydroxyharman $\mathbf{5 8 2}$ was isolated from a sample of the New Zealand marine bryozoan Cribricellina cribraria. ${ }^{456}$ A number of brominated alkaloids and a diterpene from the North Sea bryozoan Flustra foliacea ${ }^{457,458,459,460,461}$ were tested against bacteria derived from marine and terrestrial environments. These compounds exhibited significant activities against one or more marine bacterial strains originally isolated from $F$. foliacea, but only weak activities against the terrestrial bacteria. Dihydroflustramine $\mathrm{C}^{462}$ and flustramine $\mathrm{D}^{461}$ exhibited $N$-acyl-homoserine lactone (AHL)-antagonistic activity as determined by using the biosensors Pseudomonas putida (pKRC12), P. putida (pAS-C8) and E. coli (pSB403). ${ }^{458}$ A synthesis of the cytotoxic isoquinoline alkaloid perfragilin A, originally isolated from the bryozoan Membranipora fragilis, ${ }^{463}$ has been reported. $^{464}$

10

\section{Molluses}

There was a slight increase in new chemistry identified from molluscs in 2003 over that reported for the time frame of the previous review. Irregular polypropionates placidenes C-F 583-586 and hydroperoxide $\mathbf{5 8 7}$ were isolated from a Mediterranean collection of Placida dendritica. ${ }^{465}$ It is 
likely that $\mathbf{5 8 7}$ is derived from the known metabolite placidene A $\mathbf{5 8 8},{ }^{466}$ but whether the

885 hydroperoxide is an artifact of isolation, or a true natural product is unclear. The first synthesis (racemic) of the unsaturated polypropionate photodeoxytridachione, isolated from Placobranchus ocellatus $^{467}$ and other molluscs, ${ }^{468}$ has been reported. ${ }^{469}$ Five new azaspiracid analogues 589-593, identified using tandem mass spectrometric techniques, were isolated from Mytilus edulis collected off the west coast of Ireland. ${ }^{470}$ The stereochemistries of the new azaspiracid analogues are 890 arbitrarily shown as matching that of azaspiracid-1 594, ${ }^{471}$ the structure and stereochemistry of which has been called in to question by stereoselective synthetic studies. ${ }^{472,473}$ The isolation of $N$ methyl-D-glutamic acid $\mathbf{5 9 5}$ from the Japanese mollusc Scapharca broughtonii is the first report of this amino acid derivative as a natural product. ${ }^{474}$ Monterey Bay, California, collections of Calliostoma canaliculatum afforded the disulfide-linked dimer of 6-bromo-2-mercaptotryptamine

$895 \mathbf{5 9 6}$ as a channel-gating antagonist of voltage-gated potassium channels. ${ }^{475}$ 6-Bromoindirubin $\mathbf{5 9 7}$, isolated from the Mediterranean mollusc Hexaplex trunculus, and the synthetic oxime $\mathbf{5 9 8}$ were found to be potent inhibitors of glycogen synthase kinase-3 (GSK-3). ${ }^{476}$ The molecular geometry of GSK-3 $\beta$ inhibition by $\mathbf{5 9 8}$ was determined by a co-crystallisation X-ray study. Radio- and stable isotope incorporation studies have identified nicotinic acid and acetate as biosynthetic precursors of 900 haminol-2, ${ }^{477}$ a de novo biosynthesised metabolite of the Mediterranean mollusc Haminoea orbignyana. ${ }^{478}$ The ability of the fungal alkaloid gliotoxin to act as a bioaccumulated toxin of shellfish has been examined using Mytilus edulis. ${ }^{479}$ Lamellarin D, a polycyclic alkaloid first isolated from molluscs of the genus Lamellaria,${ }^{480}$ has been found to be a potent inhibitor of the DNA-processing enzyme topoisomerase I. ${ }^{481}$ Japanese and US collections of Aplysia kurodai and $A$. 905 californica were sources of the gut and vasculature contraction inhibitory pentapeptide Pro-ArgGln-Phe-Val-amide (PRQFVa). ${ }^{482}$ Precursoral peptide cDNA was successfully cloned while PRQFVa-positive neuron distribution in CNS and peripheral tissue was mapped using in situ hybridisation and immunocytochemistry. Five excitatory peptides, r11a-e 599-603 were isolated from the venom of the fish-hunting cone snail Conus radiatus collected in the Philippines. ${ }^{483}$ 
910 Further molecular analysis of cDNA clones defined the isolated peptides as belonging to a new class, the I-superfamily, of conotoxins, which contain a scaffold with four disulfide bonds (linkages not defined). The solution conformation of $\alpha$ A-conotoxin EIVA $\mathbf{6 0 4}$, originally isolated from the Atlantic cone shell C. ermineus, ${ }^{484}$ was determined by NMR experiments and restrained molecular dynamics calculations. ${ }^{485}$ A South China Sea collection of Conus betulinus yielded $\kappa$-conotoxin 915 BtX 605, a 31 residue four disulfide bond-containing $\mathrm{K}^{+}$channel up-modulator. ${ }^{486}$ As noted in Section 4, the revised structure ${ }^{487}$ of kahalalide F 126, a potently cytotoxic ${ }^{488}$ depsipeptide isolated from the mollusc Elysia rufescens and the algal dietary source Bryopsis sp., ${ }^{142}$ has been confirmed by careful analysis of degradation products and chiral derivatisation. ${ }^{144}$ The mechanism of biological action of dolastatin 11, a cytotoxic depsipeptide isolated from the sea hare Dolabella auricularia, ${ }^{489}$ involves stabilisation of F-actin, which has been studied using X-ray fibre diffraction of oriented filament sols. ${ }^{490}$ Also isolated from a Japanese collection of the sea hare D. auricularia, dolabellanin B2, a 33 amino acid residue peptide, exhibits a broad spectrum of antimicrobial activity. ${ }^{491}$ The solution structure of attractin, a 58-residue water-borne protein pheromone isolated from Aplysia californica has been determined by NMR methods. ${ }^{492}$ Austrodoral $\mathbf{6 0 6}$ and

925 austrodoric acid $\mathbf{6 0 7}$ are new nor-sesquiterpenes isolated from the Antarctic nudibranch Austrodoris kerguelenensis, but with $\mathbf{6 0 7}$ most likely being an artifact of isolation. ${ }^{493}$ As noted in Section 7, the thiocyanatopupukeanane sesquiterpenes $\mathbf{3 5 6}$ and $\mathbf{3 5 7}$ were isolated as an epimeric mixture from the nudibranch Phyllidia varicosa and the nudibranch's dietary sponge Axinyssa aculeata. ${ }^{327}$ While both compounds were isolated from the digestive gland of the nudibranch, epimer $\mathbf{3 5 7}$ was found to 930 accumulate in the mantle, suggestive of a role in chemical defense. Both compounds exhibited mild toxicity towards brine shrimp and antimicrobial activity with $\mathbf{3 5 7}$ being more potent. De novo biosynthesis, via mevalonic acid, of fatty acid ester derivatives of drimane $\mathbf{6 0 8}$ and sesquiterpene $\mathbf{6 0 9}^{494}$ in the nudibranch Doriopsilla areolata has been determined by feeding studies utilising [1$\left.{ }^{13} \mathrm{C}\right]$ glucose, $\left[1,2-{ }^{13} \mathrm{C}_{2}\right]$ glucose and $\left[1,2-{ }^{13} \mathrm{C}_{2}\right]$ acetate ${ }^{495}$ Investigation of the diterpenoid acylglycerol 935 fraction of an extract of the mantle of the Antarctic nudibranch Austrodoris kerguelenensis afforded 
the acylglycerols 610 and $\mathbf{6 1 1} .^{496}$ Also isolated were two known 1,2-diacylglyceryl esters, previously reported from the same organism, ${ }^{497,498}$ the structures of which were corrected to $\mathbf{6 1 2}$ and 613 based upon interpretation of HMBC NMR correlations. The de novo biosynthesis of the structurally related diterpenoid glyceride verrucosin $\mathrm{A}^{499,500}$ by the Mediterranean nudibranch Doris

940 verrucosa has been investigated using both ${ }^{13} \mathrm{C}$ - and ${ }^{14} \mathrm{C}$-labelled precursors. ${ }^{501}$ Four new labdane diterpenes 614-617 were isolated from the pulmonate Trimusculus peruvianus, collected near the Antofagasta Coast of Chile. ${ }^{502}$ Absolute stereochemistry was secured by standard methods. Compounds 616 and 617 exhibited mild cytotoxicity towards human tumour cell lines in vitro. The structure of aplysiallene 618, deduced for a metabolite isolated from a Japanese collection of the sea

945 hare Aplysia kurodai, ${ }^{503}$ has been retracted ${ }^{504}$ and corrected to the known bromoallene algal metabolite 619. ${ }^{505}$ The first diastereoselective synthesis of (-)-spongian-16-oxo-17-al, originally isolated from the nudibranch Ceratosoma brevicaudatum, ${ }^{506}$ has confirmed the absolute stereochemistry of the metabolite, while synthesis of the related compound (-)-acetyldendrillol-1 620, isolated from the nudibranch Cadlina luteomarginata, ${ }^{507}$ has led to correction of

950 stereochemistry at C-17. ${ }^{336}$ A further collection of Trimusculus peruvianus, again from the Antofagasta Coast of Chile, yielded two mildly cytotoxic polyhydroxylated steroids $\mathbf{6 2 1}$ and $\mathbf{6 2 2} .{ }^{508}$ The stereochemistries of $\mathbf{6 2 1}$ and $\mathbf{6 2 2}$ were determined by interpretation of NOESY NMR data and comparison of chemical shifts with stereochemically-defined related compounds.

\section{$95511 \quad$ Tunicates (ascidians)}

The number of new secondary metabolites reported from ascidians has remained essentially static for each of 2002 and 2003. Three new glycosphingolipid molecular species, the major component

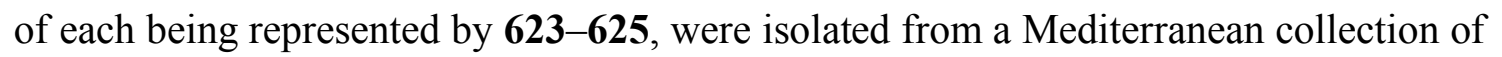

960 Microcosmus sulcatus. ${ }^{509}$ A full account of the synthesis of lobatamide C, a cytotoxic macrolide isolated from Aplidium lobatum collected off the southwestern coast of Australia, ${ }^{510}$ has been 
reported. ${ }^{511}$ In addition, preliminary V-ATPase inhibition structure-activity data was reported indicating the importance of the salicylate ring and enamide moieties for activity. The absolute configuration of iejimalide B $\mathbf{6 2 6}$, a cytotoxic 24-membered macrolide isolated from a Japanese 965 collection of Eudistoma cf. rigida, ${ }^{512}$ has been defined by analysis of ${ }^{1} \mathrm{H}-{ }^{1} \mathrm{H}$ and ${ }^{1} \mathrm{H}-{ }^{13} \mathrm{C}$ coupling constants, distance geometry calculations and analysis of oxidative degradation products. ${ }^{513}$ During the study the gross structure was also corrected to that shown (13Z). Floresolides A 627 , B 628 and C 629 are moderately cytotoxic cyclofarnesylated hydroquinones isolated from an Aplidium sp. ascidian collected at Flores Island. ${ }^{514}$ The structures and absolute configurations of all three metabolites were secured by X-ray analysis of 629. The structures of the 3-aza-[7]-paracyclophanecontaining alkaloids haouamines A 630 and B 631, isolated from Aplidium haouarianum collected off Tarifa Island, Cádiz, were also secured by X-ray analysis. ${ }^{515}$ Both haouamines exhibited two sets of NMR signals, attributed to the presence of isomers resulting from either atropisomerism or slow pyramidal inversion of the bridgehead amine. Of the two compounds, haouamine A was the 975 more potent antitumour agent. Ascidians are a well-established source of cyclic peptides, many of which exhibit cytotoxicity. Didmolamides A 632 and B 633 are cyclic hexapeptides containing all (S)-configuration amino acids isolated from Didemnum molle collected in Madagascar. ${ }^{516}$ Both compounds exhibited modest cytotoxicity towards a panel of tumour cell lines. Six new congeners of the bistratamide family of cyclic hexapeptides, E-J 634-639, were reported from a Tablas Island, 980 Philippines collection of Lissoclinum bistratum. ${ }^{517}$ All six compounds showed weak to moderate activity towards the HCT-116 tumour cell line. A full account of the synthesis of mollamide, a cytotoxic cycloheptapeptide isolated from an Australian collection of Didemnum molle, ${ }^{518}$ has been reported. ${ }^{519}$ The solution structure of the cytotoxic cycloheptapeptide trunkamide A $\mathbf{6 4 0}{ }^{520,521}$ has been determined using 2D-NMR data and simulated annealing methods. ${ }^{522}$ Fluorescent analogues of 985 ascidian-derived depsipeptides didemnin B and tamandarin A have been used to study short-term predator-prey relationships between fish and marine invertebrate larvae. ${ }^{523}$ Plicatamide, a modified octapeptide isolated from the blood of a San Diego Bay specimen of Styela plicata, ${ }^{524}$ and several 
synthetic analogues have been found to exhibit potent antimicrobial activity, to cause $\mathrm{K}^{+}$efflux in Staphylococcus aureus, were potently hemolytic for human red blood cells, and formed cationselective channels in model lipid bilayers. ${ }^{525}$ Structure-activity studies of halocidin, an antimicrobial peptide (3443 Da) isolated from hemocytes of the solitary ascidian Halocynthia aurantium, ${ }^{526}$ identified one congener with potent antimicrobial activity, but reduced hemolytic activity. ${ }^{527}$ Further biological investigation of the cytotoxic depsipeptide aplidine, isolated from Aplidium albicans ${ }^{528}$ indicates that the compound inhibits the growth and induces apoptosis in MOLT-4 cells through inhibition of vascular endothelial growth factor (VEGF) secretion which blocks the VEGFVEGFR-1 autocrine loop necessary for growth of these cells. ${ }^{529}$ In addition, aplidine prevents the in vitro aggregation of the prion peptide PrP $106-126 .{ }^{530}$ EPR studies of vanadium-binding proteins, isolated from the vanadocytes of the ascidian Ascidia sydneiensis samea, indicate that up to 24 vanadium ions bind per protein molecule in a mononuclear state and that coordination is through amine nitrogens. ${ }^{531}$ The absolute configuration of etzionin $\mathbf{6 4 1}$, an antifungal diketopiperazine hydroxamate originally isolated from an unidentified Red Sea ascidian, ${ }^{532}$ has been secured by synthesis of all four stereoisomers of derivative $\mathbf{6 4 2}$, and direct comparison of optical rotation values with the same natural derivative. ${ }^{533}$ An initial attempt at expanding the structure-activity relationship of the cytotoxic quinolizidine alkaloid clavepictine B isolated from the Bermudian ascidian Clavelina picta ${ }^{534}$ has indicated the importance of sidechain unsaturation, and that relative stereochemistry about the ring system does not seem to be important for cytotoxicity. ${ }^{535}$ Two full accounts of the stereoselective synthesis of lepadiformine, a biologically active alkaloid isolated from the ascidians Clavelina lepadiformis and C. moluccensis, ${ }^{536,537}$ have been reported. ${ }^{538,539}$ The structurally related ascidian alkaloids (+)-cylindricines C-E, isolated from an Australian collection $\left\lfloor 010\right.$ of Clavelina cylindrica, ${ }^{540}$ were prepared using ruthenium-catalysed hydrative diyne cyclisation methodology. ${ }^{541}$ The quaternised indole-enamine conicamin 643 was isolated as a histamine antagonist from a Mediterranean collection of Aplidium conicum. ${ }^{542}$ Cynthichlorine 644, previously known as a synthetic product from the chlorination of methylindolyl methylester, ${ }^{543}$ was isolated 
from a Moroccan collection of Cynthia savignyi. ${ }^{544}$ The alkaloid exhibited antifungal activity

$\lfloor 015$ towards two tomato pathogenic fungi and bacteria and was also cytotoxic in the brine shrimp lethality assay. Studies of an unidentified ascidian collected in Madagascar have afforded the mildly cytotoxic alkaloids barrenazine A 645 and B 646. ${ }^{545}$ The structures of the barrenazines were secured by use of ${ }^{1} \mathrm{H}_{-}{ }^{15} \mathrm{~N}$ HMBC NMR experiments, while the observance of optical rotatory properties for 645 suggested the $\left(R^{*}, R^{*}\right)$ configuration. Further investigation of the Mediterranean collection of Aplidium conicum yielded conicaquinones A 647 and B 648, both of which exhibited cytotoxicity towards a rat glioma cell line. ${ }^{546}$ Kottamide E 649, the first example of a natural product bearing the amino acid 4-amino-1,2-dithiolane-4-carboxylic acid (Adt), was isolated from the New Zealand ascidian Pycnoclavella kottae. ${ }^{547}$ Benzotrithioles related to the cytotoxic pentathiepin ascidian alkaloids varacin ${ }^{548}$ and lissonclinotoxin $\mathrm{A}^{549,550}$ have been prepared and optical rotatory properties and crystal structures investigated. ${ }^{551}$ Lissoclinotoxins E 650 and F 651 were isolated as mildly cytotoxic components of a Philippine didemnid ascidian. ${ }^{552}$ The relative orientation of the aromatic rings of 650 and 651 were deduced, as shown, based upon molecular modeling studies. New members of the rigidin family of pyrrolopyrimidine alkaloids, rigidins B-D 652-654, were isolated from an Okinawan collection of Cystodytes sp., ${ }^{553}$ while rigidin E 655 was isolated from a Papua

$\left\lfloor 030\right.$ New Guinea collection of a Eudistoma species. ${ }^{554}$ Rigidins B-D were mildly cytotoxic towards the L1210 murine leukemia cell line ${ }^{553}$ while rigidin $\mathbf{6 5 6}^{555}$ and rigidin E were not cytotoxic towards A431 and wild-type and p53 deficient HCT-116 human tumour cell lines. ${ }^{554}$ Two $\beta$-carboline alkaloids, eudistomins W 657 and X 658, were isolated from Chuuk Atoll, Micronesia collections of a Eudistoma species. ${ }^{556}$ The absolute stereochemistry of 657 was ascertained (Mosher method), $\lfloor 035$ and $\mathbf{6 5 8}$ was found to be more potent in antimicrobial assays. Shishijimicins A-C 659-661 are extraordinarily potent cytotoxic enediyne antibiotics isolated from a South Japan collection of Didemnum proliferum. ${ }^{557}$ Relative and absolute stereochemistries were determined by standard methods and by comparison of $\mathrm{CD}$ data with that reported for the calicheamicins, terrestrial microbe-derived enediyne antibiotics. Distomadines A 662 and B 663 are new 6-hydroxyquinoline 
1040 alkaloids from the New Zealand ascidian Pseudodistoma aureum. ${ }^{558}$ The structure of styelsamine C, an hydroxylpyridoacridine alkaloid isolated from the Indonesian ascidian Eusynstyela latericius, ${ }^{559}$ has been confirmed by synthesis. ${ }^{560}$ As noted in Section 7, 3-bromofascaplysin 301 was isolated from extracts of a Didemnum species ascidian collected at Chuuk Atoll, Micronesia, as well as from Fijian collections of Fascaplysinopsis sponges. ${ }^{286}$ The structure of sebastianine A, a pentacyclic 1045 alkaloid isolated from a Brazilian collection of Cystodytes dellechiajei, ${ }^{561}$ has been confirmed by total synthesis. ${ }^{562}$ Continued study of ascididemin, isolated from a Japanese collection of a Didemnum sp., ${ }^{563}$ indicates that derivatives are also active in antiparasitic assays, ${ }^{564}$ that the antitumour activity can be varied somewhat predictably, ${ }^{565,566}$ and that a mechanism of reductive activation to form reactive oxygen species also contributes to the cytotoxicity of the parent 1050 alkaloid. ${ }^{567}$ The structure of bengacarboline, a cytotoxic alkaloid isolated from a Fijian collection of a Didemnum sp. ${ }^{568}$ has been confirmed by total racemic synthesis. ${ }^{569}$ A convenient solid-phase synthesis of the ascidian metabolites lamellarin $\mathrm{L}^{570}$ and $\mathrm{U}^{571}$ has been reported. ${ }^{572} \mathrm{New}$ improved syntheses of (-)-diazonamide A $\mathbf{6 6 4}$ have been reported, ${ }^{573,574}$ and investigation of the mechanism of action of 664 and analogue 665 indicate that the alkaloids are potent inhibitors of microtubule $\left\lfloor 055\right.$ assembly, possibly at a unique site. ${ }^{575}$ Efficient syntheses of the naturally occurring cytotoxic ecteinascidins ET-729, -745, -759B, $-736,-637$ and $-594^{576,577,578,579,580}$ from the fermentation product cyanosafracin B have been reported. ${ }^{581}$ The parent compound, ET-743, continues to progress through clinical trials. ${ }^{582,583,584}$ Ritterazine B, a dimeric steroidal alkaloid isolated from Ritterella tokioka, ${ }^{585}$ induces apoptosis in HL-60 cells and causes cell cycle accumulation at G2/M,

$\left\lfloor 060\right.$ but has no caspase activation effect nor does it alter phosphorylation of bcl-2. ${ }^{586}$ Aplidiasterols A 666 and B 667 are new cytotoxic secosterols isolated from a Mediterranean collection of Aplidium conicum. ${ }^{587}$ The structure and absolute stereochemistry of a steroidal sperm-activating and attracting factor 668 isolated from the ascidian Ciona intestinalis ${ }^{588}$ has been unambiguously determined by total synthesis. ${ }^{589}$ 


\section{Echinoderms}

A similar number of new compounds were reported from echinoderms in 2003 compared with 2002. This field continues to be dominated by glycosylated ceramides and saponins. Taurine

$\lfloor 070$ derivative $\mathbf{6 6 9}$ was isolated from a Gomun Island, Korea, collection of the starfish Certonardoa semiregularis. ${ }^{197}$ Investigation of the Patagonian starfish Anasterias minuta afforded a range of metabolites including the new glucosylceramide anasterocerebroside A $670 .{ }^{590}$ The known ceramide $\mathbf{6 7 1}^{591,592}$ was also characterised for the first time. A Japanese collection of the starfish Luidia maculata yielded four ceramide lactosides, luidialactosides A-D 672-675. ${ }^{593}$ The position of

$\lfloor 075$ the olefin in the long chain base of $\mathbf{6 7 4}$ was deduced by FABMS analysis of a dimethyl disulfide derivative. Three ganglioside molecular species, SCG-1-3, the major species of which are represented by 676-678, were isolated from the Japanese sea cucumber Stichopus chloronotus. ${ }^{594}$ All three species displayed neuritogenic activity against PC12 cells in the presence of nerve growth factor. A structurally more complex ganglioside molecular species SJG-2 679, isolated from a

$\left\lfloor 080\right.$ Japanese collection of Stichopus japonicus, also exhibited neuritogenic activity. ${ }^{595}$ Brine shrimp lethality assay-directed fractionation of the starfish Certonardoa semiregularis, collected off Komun Island, Korea, afforded thirteen new polyhydroxysterols. These were certonardosterols AM 680-692, ${ }^{596}$ as well as the known $693 .{ }^{597}$ Side chain configurations at C-24 (for 686 and 693), C25 (for 680) and both C-24 and C-25 (for 688) were determined (Mosher method). All of the sterols, with the exception of $\mathbf{6 9 2}$, exhibited modest in vitro cytotoxicity towards a panel of human tumour cell lines. A range of hemolytic steroid disulfates, including new examples 694 and 695 , were reported from the starfish Pteraster pulvillus collected by trawling in the Sea of Okhotsk in the Far East. ${ }^{598}$ Unusual alkaloid cation and steroidal anion compounds 696-698 were isolated from the starfish Lethasterias nanimensis chelifera collected by trawling near the Kuril Islands in the Far

$\left\lfloor 090\right.$ East. ${ }^{599}$ Comparison of optical rotation values identified the cation as being the $(R)$-isomer of salsolinol. Steroid glycosides (saponins), commonly isolated from echinoderms, present challenges 
in structural elucidation and exhibit a diverse range of biological activities, both aspects of which have been reviewed. ${ }^{600,601}$ Four new saponins, certonardosides $\mathrm{K}-\mathrm{N}$ 699-702, isolated from the starfish Certonardoa semiregularis collected off Komun Island, Korea, exhibited varied biological activity towards a range of tumour cell lines and bacteria. ${ }^{602}$ Configuration at C-24 in 699, 701 and 702 was secured by methanolysis and analysis of MTPA ester derivatives. The polyhydroxylated steroid ketone $\mathbf{7 0 3}$ and monoglycosylated steroid $\mathbf{7 0 4}$ were reported from collections of the Far Eastern starfish Henricia sanguinolenta and H. leviuscula leviuscula. ${ }^{603}$ Both compounds mildly inhibited division of fertilised sea urchin eggs. A South China Sea collection of the sea cucumber Mensamaria intercedens yielded intercedensides A-C 705-707, novel triterpene glycosides that exhibited in vitro cytotoxicity towards a panel of human tumour cell lines. ${ }^{604}$ Intercedenside A also exhibited in vivo activity towards Lewis lung and mouse S180 sarcoma tumour models. A Sea of Japan collection of the sea cucumber Cucumaria conicospermium also afforded triterpene glycosides, cucumariosides $A_{2}-5$ 708, $A_{3}-2$ 709, $A_{3}-3710$ and isokoreoside $A$ 711, all of which contain the same pentasaccharide moiety, but differ in the number and position of the sulfate groups and the aglycone. ${ }^{605}$ Limited quantities of two new saponins ruberoside E $\mathbf{7 1 2}$ and F $\mathbf{7 1 3}$ were isolated from specimens of the starfish Asterias rubens collected in the Baltic Sea. ${ }^{606}$ The structures of both compounds were secured using a cryogenic NMR probe in an LC-NMR-MS configuration. Two mildly cytotoxic saponins, luidiaquinoside 714 and psilasteroside $\mathbf{7 1 5}$, were reported from

$\lfloor 110$ collections of the starfish Luidia quinaria collected at Sendai (Japan) and Psilaster cassiope collected in the northern Gulf of Mexico respectively. ${ }^{607}$ The pathological effects of sea urchin toxins has been reviewed. ${ }^{608}$

\section{Miscellaneous}

Three alkylpyrrole sulfamates $\mathbf{7 1 6 - 7 1 8}$ were isolated as fish-feeding deterrent metabolites from the annelid Cirriformia tentaculata, collected in Florida. ${ }^{609}$ Close to forty years after the structure of 
tetrodotoxin was elucidated, ${ }^{610,611,612}$ the first asymmetric syntheses of the alkaloid have been reported. ${ }^{613,614}$

\section{Conclusion}

In the early years of marine natural products research there was less emphasis on biological testing, but increasingly there has been a focus on the biological properties of these compounds. In the first 125 of the Faulkner reviews (1977), ${ }^{615}$ mention was made of the antibiotic properties of only a handful of compounds and reference made to the P388 activity of some Dolabella auricularia metabolites. In this review of the literature for 2003 , over 720 compounds are included with biological activities being reported for 354 of these. The distribution of biological activities and source phyla for these compounds in 2003 is shown graphically in Figures 1 and 2. The sponges and coelenterates

$\lfloor 130$ continue to dominate as source phyla of new compounds, with microorganisms being the other major source. The relative incidence of bioactivity detected was greatest from the green alga followed by tunicates, echinoderms and sponges, but in absolute numbers the sponges dominated. The reported biological testing has been grouped into five categories, but is dominated by various tests for anticancer and antimicrobial/antiinfective properties. Tunicates, echinoderms and sponges

$\lfloor 135$ were prime sources for the detection of potential anti-cancer properties. This combination of source and biological activity is very much in keeping with the data presented in the timely review on marine natural products and related compounds in clinical and advanced clinical trials. ${ }^{616} \mathrm{~A}$ graphical representation of the tabular data presented in that review is shown in Figure 3. Progress towards marine anticancer drugs dominates with the prime source phyla being sponges followed by $\lfloor 140$ microorganisms, tunicates and molluscs. The other categories where marine natural products are progressing are in drugs for pain and asthmatic conditions where the interest is centered on Conus toxins and analogues of sponge sterols respectively. ${ }^{616}$ 
Since the discovery of the arabinose-based nucleosides by Bergman over 50 years ago, ${ }^{617-619}$ the explosion of interest in alternative nucleoside compositions and the subsequent development of Ara-C and Ara-A as drugs with obvious linkages to later antiviral drugs such as acyclovir and AZT, there has been a tacit assumption that marine-based drugs would soon be forthcoming. That has not yet happened, but the first truly marine drugs should be licensed within the next two years. ${ }^{616}$ Yondelis, better known as ecteinascidin 743, is in Phase II and III trials in Europe and the USA against soft tissue sarcoma, while the Conus toxin known as Ziconotide or Prialt is in Phase III clinical trials for intractable pain with plans for launching as a new drug in 2005. Despite problems in 2003 with the European Agency for the Evaluation of Medicinal Products, Yondelis will probably also be launched in $2005 .^{616}$

\section{Acknowledgement}

We thank Ekkehard Unger for the collection of data for this review.

\section{References}

$\lfloor 1601$ J. K. Volkman, Appl. Microbiol. Biotechnol., 2003, 60, 495.

2 J. Kobayashi, K. Shimbo, T. Kubota and M. Tsuda, Pure Appl. Chem., 2003, 75, 337.

3 A. Aygün and U. Pindur, Curr. Med. Chem., 2003, 10, 1113.

4 J.-M. Kornprobst and H.-S. Al-Easa, Curr. Org. Chem., 2003, 7, 1181.

5 M. R. Prinsep, Stud. Nat. Prod. Chem., 2003, 28, 617.

$\lfloor 1656$ R. X. Tan and J. H. Chen, Nat. Prod. Rep., 2003, 20, 509.

7 S. Matsunaga and N. Fusetani, Curr. Org. Chem., 2003, 7, 945.

8 L. D. Han, J. G. Cui and C. S. Huang, Chin. J. Org. Chem., 2003, 23, 305.

9 P. Muralidhar, P. Radhika, N. Krishna, D. V. Rao and Ch. B. Rao, Nat. Prod. Sci., 2003, 9, 117. 
$\lfloor 17010 \quad$ D. J. Griffiths and M. L. Saker, Environ. Toxicol., 2003, 18, 78.

11 J.-F. Hu, M. T. Hamann, R. Hill and M. Kelly, Alkaloids, 2003, 60, 207.

12 D. J. Newman, G. M. Cragg and K. M. Snader, J. Nat. Prod., 2003, 66, 1022.

13 J. Peng, X. Shen, K. A. El Sayed, D. C. Dunbar, T. L. Perry, S. P. Wilkins, M. T. Hamann, S. Bobzin, J. Huesing, R. Camp, M. Prinsen, D. Krupa and M. A. Wideman, J. Agric. Food Chem., 2003, 51, 2246.

14 P. Proksch, R. Ebel, R. A. Edrada, P. Schupp, W. H. Lin, Sudarsono, V. Wray and K. Steube, Pure Appl. Chem., 2003, 75, 343.

15 A. M. S. Mayer and K. R. Gustafson, Int. J. Cancer, 2003, 105, 291.

16 P. Proksch, R. Ebel, R. A. Edrada, V. Wray and K. Steube, Sponges, 2003, 117.

$\lfloor 18017$ E. Delfourne and J. Bastide, Med. Res. Rev., 2003, 23, 234.

18 B. Haefner, Drug Discovery Today, 2003, 8, 536.

19 G. Schwartsmann, A. Brondani da Rocha, J. Mattei and R. M. Lopes, Expert Opinion on Investigational Drugs, 2003, 12, 1367.

20 D. J. Gochfeld, K. A. El Sayed, M. Yousaf, J. F. Hu, P. Bartyzel, D. C. Dunbar, S. P.

Wilkins, J. K. Zjawiony, R. F. Schinazi, S. S. Wirtz, P. M. Tharnish and M. T. Hamann, Mini Reviews in Med. Chem., 2003, 3, 401.

21 L.-A. Tziveleka, C. Vagias and V. Roussis, Curr. Topics in Medicinal Chemistry, 2003, 3, 1512.

22 M. Luescher-Mattli, Curr. Med. Chem. - Anti-Infective Agents, 2003, 2, 219.

23 B. R. Copp, Nat. Prod. Rep., 2003, 20, 535.

24 H. Akita, H. Nakamura and M. Ono, Chirality, 2003, 15, 352.

25 L. O. Haustedt, I. V. Hartung and H. M. R. Hoffmann, Angew. Chem. Int. Ed. Eng., 2003, 42, 2711.

26 I. Paterson and G. J. Florence, Eur. J. Org. Chem., 2003, 2193.

27 H. Hoffmann and T. Lindel, Synthesis, 2003, 12, 1753. 
28 M. A. Brimble and D. P. Furkert, Curr. Org. Chem., 2003, 7, 1461.

29 A. Gryszkiewicz-Wojtkielewicz, I. Jastrzebska, J. W. Morzycki and D. B. Romanowska, Curr. Org. Chem., 2003, 7, 1257.

30 S. Hanessian, R. Margarita, A. Hall, S. Johnstone, M. Tremblay and L. Parlanti, Pure Appl. Chem., 2003, 75, 209.

31 J. Mulzer and E. Öhler, Chem. Rev., 2003, 103, 3753.

32 W. E. G. Müller, F. Brümmer, R. Batel, I. M. Müller and H. C. Schröder, Naturwissenschaften, 2003, 90, 103.

33 Y. Shimizu, Curr. Opin. Microbiol., 2003, 6, 236.

120534 M. T. Hamann, Curr. Pharm. Des., 2003, 9, 879.

35 R. A. Hill, Annu. Rep. Prog. Chem., Sect. B, 2003, 99, 183.

36 MarinLit database, Department of Chemistry, University of Canterbury: http://www.chem.canterbury.ac.nz/ marinlit/marinlit.shtml

37 R. H. Feling, G. O. Buchanan, T. J. Mincer, C. A. Kauffman, P. R. Jensen and W. Fenical, 1210 Angew. Chem. Int. Ed. Eng., 2003, 42, 355.

38 J. E. Leet, W. Li, H. A. Ax, J. A. Matson, S. Huang, R. Huang, J. L. Cantone, D. Drexler, R. A. Dalterio and K. S. Lam, J. Antibiot., 2003, 56, 232.

39 W. Li, J. E. Leet, H. A. Ax, D. R. Gustavson, D. M. Brown, L. Turner, K. Brown, J. Clark, H. Yang, J. Fung-Tomc and K. S. Lam, J. Antibiot., 2003, 56, 226.

121540 T. Sasaki, T. Ohtani, H. Matsumoto, N. Unemi, M. Hamada, T. Takeuchi and M. Hori, J. Antibiot., 1998, 51, 715.

41 K. Nagai, K. Kamigiri, N. Arao, K.-I. Suzumura, Y. Kawano, M. Yamaoka, H. Zhang, M. Watanabe and K. Suzuki, J. Antibiot., 2003, 56, 123.

42 K.-I. Suzumura, T. Yokoi, M. Funatsu, K. Nagai, K. Tanaka, H. Zhang and K. Suzuki, J. Antibiot., 2003, 56, 129. 
43 Y. T. Park, J. B. Park, S. Y. Jeong, B. C. Song, W. A. Lim, C. H. Kim and W. J. Lee, J. Kor. Fish. Soc., 1998, 31, 767.

44 S.-Y. Jeong, K. Ishida, Y. Ito, S. Okada and M. Murakami, Tetrahedron Lett., 2003, 44, 8005.

122545 M. Mitova, G. Tommonaro and S. De Rosa, Z. Naturforsch. C Biosci., 2003, 58, 740.

46 R. W. Schumacher, S. C. Talmage, S. A. Miller, K. E. Sarris, B. S. Davidson and A. Goldberg, J. Nat. Prod., 2003, 66, 1291.

47 R. P. Maskey, E. Helmke, H.-H. Fiebig and H. Laatsch, J. Antibiot., 2003, 55, 1031.

48 J. M. Sánchez López, M. Martinez Insua, J. Pérez Baz, J. L. Fernández Puentes and L. M. Cañedo Hernández, J. Nat. Prod., 2003, 66, 863.

49 T. Itoh, M. Kinoshita, S. Aoki and M. Kobayashi, J. Nat. Prod., 2003, 66, 1373.

50 A. Spyere, D. C. Rowley, P. R. Jensen and W. Fenical, J. Nat. Prod., 2003, 66, 818.

51 R. Fudou, Y. Jojima, T. Iizuka and S. Yamanaka, J. Gen. Appl. Microbiol., 2002, 48, 109.

52 R. Fudou, T. Iizuka and S. Yamanaka, J. Antibiot., 2001, 54, 149.

R. Fudou, T. Iizuka, S. Sato, T. Ando, N. Shimba and S. Yamanaka, J. Antibiot., 2001, 54, 153.

54 B. A. Kundim, Y. Itou, Y. Sakagami, R. Fudou, T. Iizuka, S. Yamanaka and M. Ojika, J. Antibiot., 2003, 56, 630.

55 K. Kanoh, K. Kamino, G. Leleo, K. Adachi and Y. Shizuri, J. Antibiot., 2003, 56, 871.

L240 56 A. Isnansetyo and Y. Kamei, Int. J. Syst. Evol. Microbiol., 2003, 53, 583.

57 A. Isnansetyo and Y. Kamei, Antimicrob. Agents Chemother., 2003, 47, 480.

58 F. Fdhila, V. Vázquez, J. L. Sánchez and R. Riguera, J. Nat. Prod., 2003, 66, 1299.

59 J. C. Rodriguez, J. L. Fernández Puentes, J. Pérez Baz and L. M. Cañedo, J. Antibiot., 2003, 56, 318 . 
61 M. Tsuda, T. Mugishima, K. Komatsu, T. Sone, M. Tanaka, Y. Mikami, M. Shiro, M. Hirai, Y. Ohizumi and J. Kobayashi, Tetrahedron, 2003, 59, 3227.

62 M. Namikoshi, R. Negishi, H. Nagai, A. Dmitrenok and H. Kobayashi, J. Antibiot., 2003, 56, 755.

R. J. Capon, C. Skene, M. Stewart, J. Ford, R. A. J. O’Hair, L. Williams, E. Lacey, J. H. Gill, K. Heiland and T. Friedel, Org. Biomol. Chem., 2003, 1, 1856.

64 S. M. Lee, X. F. Li, H. Jiang, J. G. Cheng, S. Seong, H. D. Choi and B. W. Son, Tetrahedron Lett., 2003, 44, 7707.

65 T. S. Bugni, V. S. Bernan, M. Greenstein, J. E. Janso, W. M. Maiese, C. L. Mayne and C. M. Ireland, J. Org. Chem., 2003, 68, 2014.

66 T. S. Bugni, V. S. Bernan, M. Greenstein, J. E. Janso, W. M. Maiese, C. L. Mayne and C. M. Ireland, J. Org. Chem., 2003, 68, 6846.

67 T. Amagata, A. Amagata, K. Tenney, F. A. Valeriote, E. Lobkovsky, J. Clardy and P. Crews, Org. Lett., 2003, 5, 4393.

A. G. Kozlovsky, V. P. Zhelifonova, S. M. Ozerskaya, N. G. Vinokurova, V. M. Adanin and U. Grafe, Die Pharmazie, 2000, 55, 470.

69 D. C. Rowley, S. Kelly, C. A. Kauffman, P. R. Jensen and W. Fenical, Bioorg. Med. Chem., 11, 4263.

70 L. T. Tan, X. C. Cheng, P. R. Jensen and W. Fenical, J. Org. Chem., 2003, 68, 8767.

E. Garo, C. M. Starks, P. R. Jensen, W. Fenical, E. Lobkovsky and J. Clardy, J. Nat. Prod., 2003, 66, 423.

72 Y. Lin, Z. Shao, G. Jiang, S. Zhou, J. Cai, L. L. P. Vrijmoed and E. B. G. Jones, Tetrahedron, 2000, 56, 9607.

73 N. Harada, K. Nakanishi, Circular Dichroic Spectrometry-Exciton Coupling in Organic Stereochemistry, University Science Books: Milly Valley, California, 1983. 
74 M. Tsuda, T. Mugishima, K. Komatsu, T. Sone, M. Tanaka, Y. Mikami and J. Kobayashi, J. Nat. Prod., 2003, 66, 412.

75 A. Abdel-Lateff, C. Klemke, G. M. König and A. D. Wright, J. Nat. Prod., 2003, 66, 706.

76 F. Kong and G. T. Carter, Tetrahedron Lett., 2003, 44, 3119.

C. Hopmann, M. A. Knauf, K. Weithmann and J. Wink, PCT Int. Appl., WO 01/44264 A2.

78 G. Bringmann, G. Lang, S. Steffens, E. Günther and K. Schaumann, Phytochemistry, 2003, 63, 437.

79 A. D. Wright, C. Osterhage and G. M. König, Org. Biomol. Chem., 2003, 1, 507.

80 Z. Liu, P. R. Jensen and W. Fenical, Phytochemistry, 2003, 64, 571.

R. P. Maskey, I. Kock, E. Helmke and H. Laatsch, Z. Naturforsch. B Chem. Sci., 2003, 58, 692.

82 B.-S. Yun, I.-J. Ryoo, W.-G. Kim, J.-P. Kim, H. Koshino, H. Seto and I.-D. Yoo, Tetrahedron Lett., 1996, 37, 8529.

83 L. M. Nogle and W. H. Gerwick, J. Nat. Prod., 2003, 66, 217.

R. T. Williamson, B. L. Marquez, W. H. Gerwick and K. E. Kover, Magn. Reson. Chem., 2000, 38, 265.

85 L. T. Tan, N. Sitachitta and W. H. Gerwick, J. Nat. Prod., 2003, 66, 764.

86 L. M. Nogle, B. L. Marquez and W. H. Gerwick, Org. Lett., 2003, 5, 3.

87 M. T. Davies-Coleman, T. M. Dzeha, C. A. Gray, S. Hess, L. K. Pannell, D. T. Hendricks and C. E. Arendse, J. Nat. Prod., 2003, 66, 712.

88 G. G. Harrigan, W. Y. Yoshida, R. E. Moore, D. G. Nagle, P. U. Park, J. Biggs, V. J. Paul, S. L. Mooberry, T. H. Corbett and F. A. Valeriote, J. Nat. Prod., 1998, 61, 1221.

89 P. G. Williams, R. E. Moore and V. J. Paul, J. Nat. Prod., 2003, 66, 1356.

90 K. L. McPhail and W. H. Gerwick, J. Nat. Prod., 2003, 66, 132.

129591 P. G. Williams, W. Y. Yoshida, M. K. Quon, R. E. Moore and V. J. Paul, J. Nat. Prod., 2003, 66, 651. 
92 P. G. Williams, H. Luesch, W. Y. Yoshida, R. E. Moore and V. J. Paul, J. Nat. Prod., 2003, 66, 595.

93 C. Gaillet, C. Lequart, P. Debeire and J. Nuzillard, J. Magn. Reson., 1999, 139, 454.

P. G. Williams, W. Y. Yoshida, M. K. Quon, R. E. Moore and V. J. Paul, J. Nat. Prod., 2003, 66, 1545.

95 B. Han, K. L. McPhail, A. Ligresti, V. Di Marzo and W. H. Gerwick, J. Nat. Prod., 2003, 66, 1364.

96 P. G. Williams, W. Y. Yoshida, R. E. Moore and V. J. Paul, J. Nat. Prod., 2003, 66, 620.

P. G. Williams, W. Y. Yoshida, R. E. Moore and V. J. Paul, J. Nat. Prod., 2003, 66, 1006.

98 P. G. Williams, W. Y. Yoshida, R. E. Moore and V. J. Paul, Org. Lett., 2003, 5, 4167.

99 S. T. Belt, G. Massé, W. G. Allard, J.-M. Robert and S. J. Rowland, Tetrahedron Lett., 2003, 44, 9103.

100 M. Tsuda, N. Izui, K. Shimbo, M. Sato, E. Fukushi, J. Kawabata, K. Katsumata, T. Horiguchi and J. Kobayashi, J. Org. Chem., 2003, 68, 5339.

101 M. Tsuda, N. Izui, K. Shimbo, M. Sato, E. Fukushi, J. Kawabata and J. Kobayashi, J. Org. Chem., 2003, 68, 9109.

102 M. Suzuki, K. Watanabe, S. Fujiwara, T. Kurasawa, T. Wakabayashi, M. Tsuzuki, K. Iguchi and T. Yamori, Chem. Pharm. Bull., 2003, 51, 724.

1315103 A. A. Carlos, B. K. Baillie, M. Kawachi and T. Maruyama, J. Phycol., 1999, 35, 1054.

104 K. Onodera, H. Nakamura, Y. Oba and M. Ojika, Tetrahedron, 2003, 59, 1067.

105 B. Suárez-Gómez, M. L. Souto, M. Norte and J. J. Fernández, J. Nat. Prod., 2001, 64, 1363.

106 J. J. Fernández, B. Suárez-Gómez, M. L. Souto and M. Norte, J. Nat. Prod., 2003, 66, 1294.

107 A. Negri, D. Stirling, M. Quilliam, S. Blackburn, C. Bolch, I. Burton, G. Eaglesham, K. Thomas, J. Walter and R. Willis, Chem. Res. Toxicol., 2003, 16, 1029.

108 I. H. Hardt, P. R. Jensen and W. Fenical, Tetrahedron Lett., 2000, 41, 2073.

109 J. A. Kalaitzis, Y. Hamano, G. Nilsen and B. S. Moore, Org. Lett., 2003, 5, 4449. 
110 R. T. Williamson, A. Boulanger, A. Vulpanovici, M. A. Roberts and W. H. Gerwick, J. Org. Chem., 2002, 67, 7927.

l325 111 R. T. Williamson, A. Boulanger, A. Vulpanovici, M. A. Roberts and W. H. Gerwick, J. Org. Chem., 2003, 68, 2060.

112 M. Namikoshi, H. Kobayashi, T. Yoshimoto and T. Hosoya, J. Antibiot., 1997, 50, 890.

113 H. Kobayashi, S. Meguro, T. Yoshimoto and M. Namikoshi, Tetrahedron, 2003, 59, 455.

114 K. Barbeau, G. Zhang, D. H. Live and A. Butler, J. Am. Chem. Soc., 2002, 124, 378.

l330 115 R. J. Bergeron, G. Huang, R. E. Smith, N. Bharti, J. S. McManis and A. Butler, Tetrahedron, 2003, 59, 2007.

116 N. Sitachitta, R. T. Williamson and W. H. Gerwick, J. Nat. Prod., 2000, 63, 197.

117 Z. Xu, Y. Peng and T. Ye, Org. Lett., 2003, 5, 2821.

118 M. Chu, I. Truumees, I. Gunnarsson, W. R. Bishop, W. Kreutner, A. C. Horan, M. G. Patel, 1335 V. P. Gullo and M. S. Puar, J. Antibiot., 1993, 46, 554.

119 J. W. C. Cheing, W. P. D. Goldring and G. Pattenden, Chem. Commun., 2003, 2788.

120 L. A. McDonald, D. R. Abbanat, L. R. Barbieri, V. S. Bernan, C. M. Discafani, M. Greenstein, K. Janota, J. D. Korshalla, P. Lassota, M. Tischler and G. T. Carter, Tetrahedron Lett., 1999, 40, 2489.

l340 121 K. Miyashita, T. Sakai and T. Imanishi, Org. Lett., 2003, 5, 2683.

122 H. Luesch, W. Y. Yoshida, R. E. Moore, V. J. Paul and T. H. Corbett, J. Am. Chem. Soc., $2001, \mathbf{1 2 3}, 5418$.

123 H. Luesch, W. Y. Yoshida, R. E. Moore, V. J. Paul and T. H. Corbett, Bioorg. Med. Chem., 2002, 10, 1973.

1345124 J. Chen and C. J. Forsyth, J. Am. Chem. Soc., 2003, 125, 8734.

125 I. Bauer, L. Maranda, K. A. Young, Y. Shimizu and S. Huang, Tetrahedron Lett., 1995, 36, 991.

126 L. M. Walsh and J. M. Goodman, Chem. Commun., 2003, 2616. 
127 J. Kobayashi, T. Kubota, M. Tsuda and T. Endo, J. Org. Chem., 2000, 65, 1349.

l350 128 T. Kubota, T. Endo, M. Tsuda, M. Shiro and J. Kobayashi, Tetrahedron, 2001, 57, 6175.

129 A. K. Gosh and C. Liu, J. Am. Chem. Soc., 2003, 125, 2374.

130 C. Aïssa, R. Riveiros, J. Ragot and A. Fürstner, J. Am. Chem. Soc., 2003, 125, 15512.

131 J. Kobayashi, T. Kubota, T. Endo and M. Tsuda, J. Org. Chem., 2001, 66, 134.

132 M. Satake, M. Shoji, Y. Oshima, H. Naoki, T. Fujita and T. Yasumoto, Tetrahedron Lett., $\lfloor 355$ $2002,43,5829$.

133 C. Tsukano and M. Sasaki, J. Am. Chem. Soc., 2003, 125, 14294.

134 Satake, M. Murata and T. Yasumoto, J. Am. Chem. Soc., 1993, 115, 361.

135 H. Fuwa and M. Sasaki, J. Synth. Org. Chem. Japan, 2003, 61, 742.

136 A. Morohashi, M. Satake and T. Yasumoto, Tetrahedron Lett., 1999, 40, 97.

1360137 H. Nagai, M. Murata, K. Torigoe, M. Satake and T. Yasumoto, J. Org. Chem., 1992, 57, 5448.

138 A. Morohashi, M. Satake, H. Nagai, Y. Oshima and T. Yasumoto, Tetrahedron, 2000, 56, 8995.

139 M. Inoue, M. Hirama, M. Satake, K. Sugiyama and T. Yasumoto, Toxicon, 2003, 41, 469.

1365140 Y.-Y. Lin, M. Risk, S. M. Ray, D. Van Engen, J. Clardy, J. Golik, J. C. James and K.

Nakanishi, J. Am. Chem. Soc., 1981, 103, 6773.

141 T. K. Han, M. Derby, D. F. Martin, S. D. Wright and M. L. Dao, Int. J. Toxicol., 2003, 22, 73.

142 M. T. Hamann and P. J. Scheuer, J. Am. Chem. Soc., 1993, 115, 5825.

$\lfloor 370143$ G. Goetz, W. Y. Yoshida and P. J. Scheuer, Tetrahedron, 1999, 55, 7739.

144 I. Bonnard, I. Manzanares and K. L. Rinehart, J. Nat. Prod., 2003, 66, 1466.

145 V. Smyrniotopoulos, D. Abatis, L.-A. Tziveleka, C. Tsitsimpikou, V. Roussis, A. Loukis and C. Vagias, J. Nat. Prod., 2003, 66, 21.

146 V. J. Paul and W. Fenical, Mar. Ecol. Prog. Ser., 1986, 34, 157. 
l375 147 L. Commeiras, R. Valls, M. Santelli and J.-L. Parrain, Synlett., 2003, 1716.

148 K. M. Fisch, V. Böhm, A. D. Wright and G. M. König, J. Nat. Prod., 2003, 66, 968.

149 S.-E. N. Ayyad, O. B. Abdel-Halim, W. T. Shier and T. R. Hoye, Z. Naturforsch. C Biosci., 2003, 58, 33.

150 S. R. Gedara, O. B. Abdel-Halim, S. H. El-Sharkawy, O. M. Salama, T. W. Shier and A. F. Halim, Z. Naturforsch. C Biosci., 2003, 58, 17.

151 M. S. Ali and M. K. Pervez, Z. Naturforsch. B Chem. Sci., 2003, 58, 438.

152 M. S. Ali and M. K. Pervez, Nat. Prod. Res., 2003, 17, 281.

153 M. S. Ali, M. K. Pervez, M. Saleem and F. Ahmed, Nat. Prod. Res., 2003, 17, 301.

154 H. Soto, J. Rovirosa and A. San-Martín, Z. Naturforsch. B Chem. Sci., 2003, 58, 795.

155 K. Kousaka, N. Ogi, Y. Akazawa, M. Fujieda, Y. Yamamoto, Y. Takada and J. Kimura, J. Nat. Prod., 2003, 66, 1318.

156 S. Carmeli, R. E. Moore and G. M. L. Patterson, J. Nat. Prod., 1990, 53, 1533.

157 S. Carmely, M. Rotem and Y. Kashman, Magn. Reson. Chem., 1986, 24, 343.

158 I. Kitagawa, M. Kobayashi, T. Katori, M. Yamashita, J. Tanaka, M. Doi and T. Ishida, J. Am. Chem. Soc., 1990, 112, 3710.

159 J. Kubanek, P. R. Jensen, P. A. Keifer, M. C. Sullards, D. O. Collins and W. Fenical, Proc. Natl. Acad. Sci. USA, 2003, 100, 6916.

160 S.-E. N. Ayyad, S. Z. A. Sowellim, M. S. El-Hosini and A. Abo-Atia, Z. Naturforsch. C Biosci., 2003, 58, 333.

Ł395 161 H. Tang, Y. Yi, X. Yao, Q. Xu, S. Zhang and H. Lin, Zhongguo Haiyang Yaowu, 2003, 22, 28.

162 H. S. Kang, H. Y. Chung, J. H. Jung, B. W. Son and J. S. Choi, Chem. Pharm. Bull., 2003, 51, 1012.

163 C. Ireland and D. J. Faulkner, J. Org. Chem., 1977, 42, 3157. 
$\lfloor 400164$ J. P. Barbosa, V. L. Teixeira, R. Villaça, R. C. Pereira, J. L. Abrantes and I. C. P. da Paixão Frugulhetti, Biochem. Syst. Ecol., 2003, 31, 1451.

165 N. Takada, R. Watanabe, K. Suenaga, K. Yamada and D. Uemura, J. Nat. Prod., 2001, 64, 653.

166 Y. Li, B. Lu, C. Li and Y. Li, Synth. Commun., 2003, 33, 1417.

L405 167 L. R. de Carvalho, M. T. Fujii, N. F. Roque, M. J. Kato and J. H. G. Lago, Tetrahedron Lett., 2003, 44, 2637.

168 G. Guella, D. Skropeta, I. Mancini and F. Pietra, Chem. Eur. J., 2003, 9, 5770.

169 G. Topcu, Z. Aydogmus, S. Imre, A. C. Gören, J. M. Pezzuto, J. A. Clement and D. G. I. Kingston, J. Nat. Prod., 2003, 66, 1505.

$\lfloor 410170$ A. D. Wright, E. Goclik and G. M. König, J. Nat. Prod., 2003, 66, 435.

171 D. Iliopoulou, N. Mihopoulos, C. Vagias, P. Papazafiri and V. Roussis, J. Org. Chem., 2003, 68, 7667.

172 N. Mihopoulos, C, Vagias, E. Mikros, M. Scoullos and V. Roussis, Tetrahedron Lett., 2001, 42, 3749.

$\lfloor 415173$ D. Iliopoulou, N. Mihopoulos, V. Roussis and C. Vagias, J. Nat. Prod., 2003, 66, 1225.

174 X. Fan, N.-J. Xu and J.-G. Shi, J. Nat. Prod., 2003, 66, 455.

175 X. Fan, N. J. Xu and J. G. Shi, Chinese Chemical Letters, 2003, 14, 1045.

176 J. A. Shepherd, W. W. Poon, D. C. Myles and C. F. Clarke, Tetrahedron Lett., 1996, 37, 2395.

$\lfloor 420177$ X. Fan, N. J. Xu and J. G. Shi, Chinese Chemical Letters, 2003, 14, 939.

178 N. Xu, X. Fan, X. Yan, X. Li, R. Niu and C. K. Tseng, Phytochemistry, 2003, 62, 1221.

179 M. Kuniyoshi, N. Oshiro, T. Miono and T. Higa, J. Chin. Chem. Soc., 2003, 50, 167.

180 M. Norte, J. J. Fernández, M. L. Souto, J. A. Gavín and M. D. Garcia-Grávalos, Tetrahedron, 1997, 53, 3173. 
1425181 M. K. Pec, A. Aguirre, K. Moser-Thier, J. J. Fernandez, M. L. Souto, J. Dorta, F. DiazGonzalez and J. Villar, Biochem. Pharmacol., 2003, 65, 1451.

182 J. J. Sims, G. H. Y. Lin and R. M. Wing, Tetrahedron Lett., 1974, 39, 3487.

183 C. S. Vairappan, Biomol. Eng., 2003, 20, 255.

184 A. G. González, J. Darias, A. Díaz, J. D. Fourneron, J. D. Martín and C. Pérez, Tetrahedron 1430 Lett., 1976, 35, 3051.

185 A. G. González, M. J. Delgado, V. S. Martín, M. Martínez-Ripoll and J. Fayos, Tetrahedron Lett., 1979, 29, 2717.

186 M. Pedersen, P. Saenger and L. Fries, Phytochemistry, 1974, 13, 2273.

187 J. M. Kuhajek and D. Schlenk, Comp. Biochem. Physiol., 2003, 134C, 473.

188 A. G. González, J. D. Martín, V. S. Martín, M. Norte, R. Pérez and J. Ruano, Tetrahedron, 1982, 38, 1009.

189 M. Norte, A. G. González, F. Cataldo, M. L. Rodriguez and I. Brito, Tetrahedron, 1991, 47, 9411.

190 H. Kim, W. J. Choi, J. Jung, S. Kim and D. Kim, J. Am. Chem. Soc., 2003, 125, 10238.

$\lfloor 440191$ M. Suzuki, Y. Misano, Y. Matsuo and M. Masuda, Phytochemistry, 1996, 43, 121.

192 H. Lee, H. Kim, S. Baek, S. Kim and D. Kim, Tetrahedron Lett., 2003, 44, 6609.

193 L. Zaman, O. Arakawa, A. Shimosu, Y. Onoue, S. Nishio, Y. Shida and T. Noguchi, Toxicon, 1997, 35, 205.

194 Y. Ni, K. K. D. Amarasinghe, B. Ksebati and J. Montgomery, Org. Lett., 2003, 5, 3771.

$\lfloor 445195$ V. Costantino, E. Fattorusso, C. Imperatore and A. Mangoni, Eur. J. Org. Chem., 2003, 1433.

196 V. Ledroit, C. Debitus, C. Lavaud and G. Massiot, Tetrahedron Lett., 2003, 44, 225.

197 W. Wang, Y. M. Lee, J. Hong, C.-O. Lee, J. H. Park and J. H. Jung, Nat. Prod. Sci., 2003, 9, 241. 
$\lfloor 450198$ S.-Y. Lee, Q. Zhao, K. Choi, J. Hong, D. S. Lee, C.-O. Lee and J. H. Jung, Nat. Prod. Sci., 2003, 9, 232.

199 Q. Zhao, Y. Liu, J. Hong, C.-O. Lee, J. H. Park, D. S. Lee and J. H. Jung, Nat. Prod. Sci., 2003, 9, 18.

200 M. Tsuda, T. Endo, M. Perpelescu, S. Yoshida, K. Watanabe, J. Fromont, Y. Mikami and J. Kobayashi, Tetrahedron, 2003, 59, 1137.

201 T. Rezanka and V. M. Dembitsky, Eur. J. Org. Chem., 2003, 2144.

202 M. Fujita, Y. Nakao, S. Matsunaga, R. W. M. van Soest, Y. Itoh, M. Seiki and N. Fusetani, J. Nat. Prod., 2003, 66, 569.

203 Q. Zhao, S.-Y. Lee, J. Hong, C.-O. Lee, K. S. Im, C. J. Sim, D. S. Lee and J. H. Jung, J. Nat. Prod., 2003, 66, 408.

204 Q. Zhao, T. A. Mansoor, J. Hong, C.-O. Lee, K. S. Im, D. S. Lee and J. H. Jung, J. Nat. Prod., 2003, 66, 725.

205 H.-S. Lee, J.-R. Rho, C. J. Sim and J. Shin, J. Nat. Prod., 2003, 66, 566.

206 J. C. Braekman, D. Daloze, C. Devijver, D. Dubut and R. W. M. van Soest, J. Nat. Prod., $2003,66,871$.

207 M. L. Lerch, M. K. Harper and D. J. Faulkner, J. Nat. Prod., 2003, 66, 667.

208 R. P. de Jesus and D. J. Faulkner, J. Nat. Prod., 2003, 66, 671.

209 R. P. Walker and D. J. Faulkner, J. Org. Chem., 1981, 46, 1475.

210 D. T. A. Youssef, R. W. M. van Soest and N. Fusetani, J. Nat. Prod., 2003, 66, 861.

211 S. Ohta, H. Okada, H. Kobayashi, J. M. Oclarit and S. Ikegami, Tetrahedron Lett., 1993, 34, 5935.

212 M. Ojika, Y. Itou and Y. Sakagami, Biosci. Biotechnol. Biochem., 2003, 67, 1568.

213 C. Jiménez and P. Crews, J. Nat. Prod., 1990, 53, 978.

214 M. Ichihashi and K. Mori, Biosci. Biotechnol. Biochem., 2003, 67, 329. 
216 N. M. Carballeira, H. Cruz, E. A. Orellano and F. A. González, Chem. Phys. Lipids, 2003, 126, 149.

217 K. Watanabe, Y. Tsuda, Y. Yamane, H. Takahashi, K. Higuchi, H. Naoki, T. Fujita and R. M. W. van Soest, Tetrahedron Lett., 2000, 41, 9271.

218 S. Reber, T. F. Knöpfel and E. M. Carreira, Tetrahedron, 2003, 59, 6813.

219 S. Tsukamoto, H. Kato, H. Hirota and N. Fusetani, J. Nat. Prod., 1997, 60, 126.

220 A. Umeyama, C. Nagano and S. Arihara, J. Nat. Prod., 1997, 60, 131.

221 S. López, F. Fernández-Trillo, L. Castedo and C. Saá, Org. Lett., 2003, 5, 3725.

222 I. van Altena, R. van Soest, M. Roberge and R. J. Andersen, J. Nat. Prod., 2003, 66, 561.

223 A. Rudi, R. Afanii, L. G. Gravalos, M. Aknin, E. Gaydou, J. Vacelet and Y. Kashman, J. Nat. Prod., 2003, 66, 682.

224 C.-Y. Wang, B.-G. Wang, S. Wiryowidagdo, V. Wray, R. van Soest, K. G. Steube, H.-S. Guan, P. Proksch and R. Ebel, J. Nat. Prod., 2003, 66, 51.

225 M. del-S. Jiménez, S. P. Garzón and A. D. Rodríguez, J. Nat. Prod., 2003, 66, 655.

226 M. Yanai, S. Ohta, E. Ohta, T. Hirata and S. Ikegami, Bioorg. Med. Chem., 2003, 11, 1715.

227 K. L. Erikson, J. A. Beutler, J. H. Cardellina and M. R. Boyd, Tetrahedron, 1995, 51, 11953.

228 C. M. Cerda-García-Rojas and D. J. Faulkner, Tetrahedron, 1995, 51, 1087.

229 I. R. Czuba, S. Zammit and M. A. Rizzacasa, Org. Biomol. Chem., 2003, 1, 2044.

230 W. M. Bandaranayake, G. Pattenden and W. A. Wickramasinghe, Trends Comp. Biochem. Physiol., 2002, 9, 205.

231 J. W. Blunt, B. R. Copp, M. H. G. Munro, P. T. Northcote and M. R. Prinsep, Nat. Prod. Rep., 2004, 21, 1.

232 K. Tachibana, P. J. Scheuer, Y. Tsukitani, H. Kikuchi, D. van Engen, J. Clardy, Y. Gopichand and F. J. Schmitz, J. Am. Chem. Soc., 1981, 103, 2469.

Ł500 233 T. Yasumoto, M. Murata, Y. Oshima, M. Sano, G. K. Matsumoto and J. Clardy, Tetrahedron, 1985, 41, 1019. 
234 Y. Murakami, Y. Oshima and T. Yasumoto, Bull. Jap. Soc. Sci. Fish., 1982, 48, 69.

235 M. Wiens, B. Luckas, F. Brümmer, M. Shokry, A. Ammar, R. Steffen, R. Batel, B. DiehlSeifert, H. C. Schröder and W. E. G. Müller, Mar. Biol., 2003, 142, 213.

236 R. Britton, M. Roberge, C. Brown, R. van Soest and R. J. Andersen, J. Nat. Prod., 2003, 66, 838.

237 R. Talpir, Y. Benayahu, Y. Kashman, L. Pannell and M. Schleyer, Tetrahedron Lett., 1994, $35,4453$.

238 P. Crews, J. J. Farias, R. Emrich and P. A. Keifer, J. Org. Chem., 1994, 59, 2932.

239 C. Chevallier, A. D. Richardson, M. C. Edler, E. Hamel, M. K. Harper and C. M. Ireland, Org. Lett., 2003, 5, 3737.

240 Y. Nakao, J. Kuo, W. Y. Yoshida, M. Kelly and P. J. Scheuer, Org. Lett., 2003, 5, 1387.

241 Y. Sera, K. Adachi, K. Fujii and Y. Shizuri, J. Nat. Prod., 2003, 66, 719.

242 K. L. Erickson, K. R. Gustafson, D. J. Milanowski, L. K. Pannell, J. R. Klose and M. R. Boyd, Tetrahedron, 2003, 59, 10231.

243 K. L. Erickson, K. R. Gustafson, L. K. Pannell, J. A. Beutler and M. R. Boyd, J. Nat. Prod., 2002, 65, 1303.

244 S. Kehraus, G. M. König, A. D. Wright and G. Woerheide, J. Org. Chem., 2002, 67, 4989.

245 W. Wang and F. Nan, J. Org. Chem., 2003, 68, 1636.

246 L. T. Tan, R.T. Williamson, W. H. Gerwick, K. S. Watts, K. McGough and R. Jacobs, J. Org. Chem., 2000, 65, 419.

247 S. Deng and J. Taunton, J. Am. Chem. Soc., 2002, 124, 916.

248 F. Yokokawa, T. Shiori, Y. In, K. Minoura and T. Ishida, Pept. Sci., 2002, 39, 41.

249 G. R. Pettit, Z. Cichacz, J. Barkoczy, A. C. Dorsaz, D. L. Herald, M. D. Williams, D. L. 
250 G. R. Pettit, R. Tan, Y. Ichihara, M. D. Williams, D. L. Doubek, L. P. Tackett, J. M.

Schmidt, R. L. Cerny, M. R. Boyd and J. N. A. Hooper, J. Nat. Prod., 1995, 58, 961.

251 A. Napolitano, M. Rodriquez, I. Bruno, S. Marzocco, G. Autore, R. Riccio and L. GomezPaloma, Tetrahedron, 2003, 59, 10203.

252 G. R. Pettit and R. Tan, Bioorg. Med. Chem. Lett., 2003, 13, 685.

253 W.-L. Li, Y.-H. Yi, H.-M. Wu, Q.-Z. Xu, H.-F. Tang, D.-Z. Zhou, H.-W. Lin and Z.-H. Wang, J. Nat. Prod., 2003, 66, 146.

254 D. E. Williams, M. Roberge, R. van Soest and R. J. Andersen, J. Am. Chem. Soc., 2003, 125, 5296.

255 L. M. West, P. T. Northcote and C. N. Battershill, J. Org. Chem., 2000, 65, 445.

256 X. Liao, Y. Wu and J. K. de Brabander, Angew. Chem. Int. Ed. Eng., 2003, 42, 1648.

257 M. V. D’Auria, L. Gomez-Paloma, L. Minale, A. Zampella, J. F. Verbist, C. Roussakis, C. Debitus and J. Patissou, Tetrahedron, 1994, 50, 4829.

258 A. Zampella, V. Sepe, R. D'Orsi, G. Bifulco, C. Bassarello and M. V. D'Auria, Tetrahedron: Asymmetry, 2003, 14, 1787.

259 N. Fusetani, T. Sugawara, S. Matsunaga and H. Hirota, J. Org. Chem., 1991, 56, 4971.

260 A. B. Smith III, C. M. Adams, S. A. Barbosa and A. P. Degnan, J. Am. Chem. Soc., 2003, $125,350$.

1545261 P. A. Horton, F. E. Koehn, R. E. Longley and O. J. McConnell, J. Am. Chem. Soc., 1994, 116, 6015.

262 H. Y. Song, J. M. Joo, J. W. Kang, D.-S. Kim, C.-K. Jung, H. S. Kwak, J. H. Park, E. Lee, C. Y. Hong, S. Jeong, K. Jeon and J. H. Park, J. Org. Chem., 2003, 68, 8080.

263 R. S. Norton, K. D. Croft and R. J. Wells, Tetrahedron, 1981, 37, 2341.

L550 264 J. Á. de la Fuente, S. Manzanaro, M. J. Martín, T. G. de Quesada, I. Reymundo, S. M. Luengo and F. Gago, J. Med. Chem., 2003, 46, 5208. 
265 R. Sakai, H. Matsubara, K. Shimamoto, M. Jimbo, H. Kamiya and M. Namikoshi, J. Nat. Prod., 2003, 66, 784.

266 N. Lysek, R. Kinscherf, R. Claus and T. Lindel, Z. Naturforsch. C BioSci., 2003, 58, 568.

C. Campagnuolo, C. Fattorusso, E. Fattorusso, A. Ianaro, B. Pisano and O. TaglialatelaScafati, Org. Lett., 2003, 5, 673.

268 C. A. Volk and M. Köck, Org. Lett., 2003, 5, 3567.

269 Y. Kashman, G. Koren-Goldshlager, M. D. Garcia Gravalos and M. Schleyer, Tetrahedron Lett., 1999, 40, 997.

Ł560 270 M. R. Heinrich, W. Steglich, M. G. Banwell and Y. Kashman, Tetrahedron, 2003, 59, 9239.

271 S. Sperry and P. Crews, Tetrahedron Lett., 1996, 37, 2389.

272 J. C. Daab and F. Bracher, Monatsh. Chem., 2003, 134, 573.

273 S. Tsukamoto, M. Takahashi, S. Matsunaga, N. Fusetani and R. W. M. van Soest, J. Nat. Prod., 2000, 63, 682.

274 W. R. F. Goundry, J. E. Baldwin and V. Lee, Tetrahedron, 2003, 59, 1719.

275 M. Tsuda, K. Hirano, T. Kubota and J. Kobayashi, Tetrahedron Lett., 1999, 40, 4819.

276 B. B. Snider and B. Shi, Tetrahedron Lett., 2001, 42, 1639.

277 S. P. Romeril, V. Lee, T. D. W. Claridge and J. E. Baldwin, Tetrahedron Lett., 2002, 43, 327.

L570 278 Y. Morimoto, S. Kitao, T. Okita and T. Shoji, Org. Lett., 2003, 5, 2611.

279 S. P. Romeril, V. Lee, J. E. Baldwin, T. D. W. Claridge and B. Odell, Tetrahedron Lett., 2003, 44, 7757.

280 J. C. Braekman, D. Daloze, P. Macedo de Abreu, C. Piccinni-Leopardi, G. Germain and M. van Meerssche, Tetrahedron Lett., 1982, 23, 4277.

Ł575 281 J. C. Braekman, D. Daloze, N. Defay and D. Zimmermann, Bull. Soc. Chim. Belg., 1984, 93, 941. 
282 T. V. Goud, N. S. Reddy, N. R. Swamy, T. S. Ram and Y. Venkateswarlu, Biol. Pharm. Bull., 2003, 26, 1498.

283 J. Kobayashi, D. Watanabe, N. Kawasaki and M. Tsuda, J. Org. Chem., 1997, 62, 9236.

284 T. Nagata, M. Nakagawa and A. Nishida, J. Am. Chem. Soc., 2003, 125, 7484.

285 K. V. Rao, B. D. Santarsiero, A. D. Mesecar, R. F. Schinazi, B. L. Tekwani and M. T. Hamann, J. Nat. Prod., 2003, 66, 823.

286 N. L. Segraves, S. Lopez, T. A. Johnson, S. A. Said, X. Fu, F. J. Schmitz, H. Pietraszkiewicz, F. A. Valeriote and P. Crews, Tetrahedron Lett., 2003, 44, 3471.

287 C. Campagnuolo, E. Fattorusso and O. Taglialatela-Scafati, Eur. J. Org. Chem., 2003, 284.

288 D. B. Stierle and D. J. Faulkner, J. Nat. Prod., 1991, 54, 1131.

289 N. K. Utkina, A. V. Gerasimenko and D. Y. Popov, Russ. Chem. Bull., 2003, 52, 258.

290 C. M. Zeng, M. Ishibashi, K. Matsumoto, S. Nakaike and J. Kobayashi, Tetrahedron, 1993, 49, 8337.

291 S. Aoki, H. Wei, K. Matsui, R. Rachmat and M. Kobayashi, Bioorg. Med. Chem., 2003, 11, 1969.

292 L. Calcul, A. Longeon, A. Al-Mourabit, M. Guyot and M. Bourguet-Kondracki, Tetrahedron, 2003, 59, 6539.

293 N. Oku, S. Matsunaga, R. W. M. van Soest and N. Fusetani, J. Nat. Prod., 2003, 66, 1136.

294 G. R. Pettit, J. C. Collins, J. C. Knight, D. L. Herald, R. A. Nieman, M. D. Williams and R. K. Pettit, J. Nat. Prod., 2003, 66, 544.

295 K. Warabi, S. Matsunaga, R. W. M van Soest and N. Fusetani, J. Org. Chem., 2003, 68, 2765.

296 E. Kourany-Lefoll, O. Laprévote, T. Sévenet, A. Montagnac, M. Païs and C. Debitus, Tetrahedron, 1994, 50, 3415.

297 B. J. Neubert and B. B. Snider, Org. Lett., 2003, 5, 765.

298 P. Crews, D. P. Clark and K. Tenney, J. Nat. Prod., 2003, 66, 177. 
299 R. A. Edrada, C. C. Stessman and P. Crews, J. Nat. Prod., 2003, 66, 939.

300 K. A. Alvi, B. M. Peters, L. M. Hunter and P. Crews, Tetrahedron, 1993, 49, 329.

1605301 S. Nakamura, I. Kawasaki, M. Yamashita and S. Ohta, Heterocycles, 2003, 60, 583.

302 M. Assmann, S. Zea and M. Köck, J. Nat. Prod., 2001, 64, 1593.

303 G. Breckle, K. Polborn and T. Lindel, Z. Naturforsch. B Chem. Sci., 2003, 58, 451.

304 M. Fujita, Y. Nakao, S. Matsunaga, M. Seiki, Y. Itoh, J. Yamashita, R. W. M. van Soest and N. Fusetani, J. Am. Chem. Soc., 2003, 125, 15700.

$\lfloor 610305$ R. G. Linington, D. E. Williams, A. Tahir, R. van Soest and R. J. Andersen, Org. Lett., 2003, $5,2735$.

306 S. Nishimura, S. Matsunaga, M. Shibazaki, K. Suzuki, K. Furihata, R. W. M. van Soest and N. Fusetani, Org. Lett., 2003, 5, 2255.

307 E. A. Jares-Erijman, R. Sakai and K. L. Rinehart, J. Org. Chem., 1991, 56, 5712.

$\lfloor 615308$ E. Palagiano, S. De Marino, L. Minale, R. Riccio, F. Zollo, M. Iorizzi, J. B. Carré, C. Debitus, L. Lucarain and J. Provost, Tetrahedron, 1995, 51, 3675.

309 L. Chang, N. F. Whittaker and C. A. Bewley, J. Nat. Prod., 2003, 66, 1490.

310 S.-W. Yang, T.-M. Chang, S. A. Pomponi, G. Chen, A. E. Wright, M. Patel, V. Gullo, B. Pramanik and M. Chu, J. Antibiot., 2003, 56, 970.

1620311 E. Manzo, R. van Soest, L. Matainaho, M. Roberge and R. J. Andersen, Org. Lett., 2003, 5, 4591.

312 T. V. Goud, M. Srinivasulu, V. L. N. Reddy, A. V. Reddy, T. P. Rao, D. S. Kumar, U. S. Murty, and Y. Venkateswarlu, Chem. Pharm. Bull., 2003, 51, 990.

313 K. Moody, R. H. Thomson, E. Fattorusso, L. Minale and G. Sodano, J. Chem. Soc. Perkins 1625 Trans. 1, 1972, 18.

314 R. Encarnación-Dimayuga, M. R. Ramírez and J. Luna-Herrera, Pharm. Biology, 2003, 41, 384. 
315 X.-H. Xu, G.-M. Yao, Y.-M. Li, J.-H. Lu, C. Lin, X. Wang and C.-H. Kong, J. Nat. Prod., 2003, 66, 285.

630316 H.-D. Yoo, D. Leung, J. Sanghara, D. Daley, R. van Soest and R. J. Andersen, Pharm. Biology, 2003, 41, 223.

317 R. Kazlauskas, P. T. Murphy, R. G. Warren, R. J. Wells and J. F. Blount, Aust. J. Chem., 1978, 31, 2685.

318 A. Bernet, J. Schröder and K. Seifert, Helv. Chim. Acta, 2003, 86, 2009.

1635319 V. J. R. V. Mukku, R. A. Edrada, F. J. Schmitz, M. K. Shanks, B. Chaudhuri and D. Fabbro, J. Nat. Prod., 2003, 66, 686.

320 B. Sullivan, P. Djura, D. E. McIntyre and D. J. Faulkner, Tetrahedron, 1981, 37, 979.

321 H. Mitome, T. Nagasawa, H. Miyaoka, Y. Yamada and R. W. M. van Soest, J. Nat. Prod., 2003, 66, 46.

1640322 N. K. Utkina, V. A. Denisenko, O. V. Scholokova, M. V. Virovaya and N. G. Prokof'eva, Tetrahedron Lett., 2003, 44, 101.

323 I. C. Piña, M. L. Sanders and P. Crews, J. Nat. Prod., 2003, 66, 2.

324 J. S. Simpson, P. Raniga and M. J. Garson, Tetrahedron Lett., 1997, 38, 7947.

325 A. Brust and M. J. Garson, Tetrahedron Lett., 2003, 44, 327.

1645326 Y. Nogata, E. Yoshimura, K. Shinshima, Y. Kitano and I. Sakaguchi, Biofouling, 2003, 19, 193.

327 Yasman, R. A. Edrada, V. Wray and P. Proksch, J. Nat. Prod., 2003, 66, 1512.

328 A. T. Pham, T. Ichiba, W. Y. Yoshida, P. J. Scheuer, T. Uchida, J.-I. Tanaka and T. Higa, Tetrahedron Lett., 1991, 32, 4843.

650329 H.-Y. He, J. Salva, R. F. Catalos and D. J. Faulkner, J. Org. Chem., 1992, 57, 3191.

330 A. Srikishna and S. Gharpure, J. Chem. Soc. Perkin Trans. 1, 2000, 3191.

331 A. Srikrishna, S. J. Gharpure and P. Venugopalan, Indian J. Chem. Sect. B, 2003, 42, 129.

332 K. Kodama, R. Higuchi, T. Miyamoto and R. W. M. van Soest, Org. Lett., 2003, 5, 169. 
333 N. Soji, A. Umeyama, M. Teranaka and S. Arihara, J. Nat. Prod., 1996, 59, 448.

L655 334 S. Díaz, J. Cuesta, A. González and J. Bonjoch, J. Org. Chem., 2003, 68, 7400.

335 W. C. Taylor and S. Toth, Aust. J. Chem., 1997, 50, 895.

336 M. Arnó, M. A. González and R. J. Zaragozá, J. Org. Chem., 2003, 68, 1242.

337 R. Lucas, A. Casapullo, L. Ciasullo, L. Gomez-Paloma and M. Payá, Life Sci., 2003, 72, 2543.

1660338 L. Ciasullo, A. Cutignano, A. Casapullo, R. Puliti, C. A. Mattia, C. Debitus, R. Riccio and L. Gomez-Paloma, J. Nat. Prod., 2002, 65, 1210.

339 P. Phuwapraisirisan, S. Matsunaga, N. Fusetani, N. Chaitanawisuti, S. Kritsanapuntu and P. Menasveta, J. Nat. Prod., 2003, 66, 289.

340 Y. Liu, T. A. Mansoor, J. Hong, C.-O. Lee, C. J. Sim, K. S. Im, N. D. Kim and J. H. Jung, J. $\lfloor 665$ Nat. Prod., 2003, 66, 1451.

341 Y. Liu, J. Hong, C.-O. Lee, K. S. Im, N. D. Kim, J. S. Choi and J. H. Jung, J. Nat. Prod., $2002, \mathbf{6 5}, 1307$.

342 H. H. Issa, J. Tanaka and T. Higa, J. Nat. Prod., 2003, 66, 251.

343 T. N. Makarieva, J.-R. Rho, H.-S. Lee, E. A. Santalova, V. Stonik and J. Shin, J. Nat. Prod., 2003, 66, 1010.

344 S.-W. Yang, T.-M. Chan, S. A. Pomponi, W. Gonsiorek, G. Chen, A. E. Wright, W. Hipkin, M. Patel, V. Gullo, B. Pramanik, P. Zavodny and M. Chu, J. Antibiot., 2003, 56, 783.

345 A. R. Díaz-Marrero, I. Brito, E. Dorta, M. Cueto, A. San-Martín and J. Darias, Tetrahedron Lett., 2003, 44, 5939.

1675346 S. De Rosa, A. Crispino, A. De Giulio, C. Iodice, P. Amodeo and T. Tancredi, J. Nat. Prod., 1999, 62, 1316.

347 D. Demeke and C. J. Forsyth, Org. Lett., 2003, 5, 991.

348 M. Tsoukatou, H. Siapi, C. Vagias and V. Roussis, J. Nat. Prod., 2003, 66, 444.

349 S. Tsukamoto, S. Miura, R. W. M. van Soest and T. Ohta, J. Nat. Prod., 2003, 66, 438. 
1680350 S. Tsukamoto, M. Tatsuno, R. W. M. van Soest, H. Yokosawa and T. Ohta, J. Nat. Prod., 2003, 66, 1181.

351 R. A. Keyzers, P. T. Northcote and M. V. Berridge, Aust. J. Chem., 2003, 56, 279.

352 N. Fusetani, S. Matsunaga and S. Konosu, Tetrahedron Lett., 1981, 22, 1985.

353 S.-W. Yang, A. Buivich, T.-M. Chan, M. Smith, J. Lachowicz, S. A. Pomponi, A. E. Wright,

R. Mierzwa, M. Patel, V. Gullo and M. Chu, Bioorg. Med. Chem. Lett., 2003, 13, 1791.

354 S.-W. Yang, T.-M. Chan, S. A. Pomponi, G. Chen, D. Loebenberg, A. Wright, M. Patel, V. Gullo, B. Pramanik and M. Chu, J. Antibiot., 2003, 56, 186.

355 A. S. Antonov, S. S. Afiyatullov, A. I. Kalinovsky, L. P. Ponomarenko, P. S. Dmitrenok, D.

L. Aminin, I. G. Agafonova and V. A. Stonik, J. Nat. Prod., 2003, 66, 1082.

356 C. P. Ridley and D. J. Faulkner, J. Nat. Prod., 2003, 66, 1536.

357 T. Teruya, S. Nakagawa, T. Koyama, K. Suenaga, M. Kita and D. Uemura, Tetrahedron Lett., 2003, 44, 5171.

358 S. Ohta, M. Uno, M. Tokumasu, Y. Hiraga and S. Ikegami, Tetrahedron Lett., 1996, 37, 7765.

359 Y. Mizushina, C. Murakami, H. Takikawa, N. Kasai, X. Xu, K. Mori, M. Oshige, T. Yamaguchi, M. Saneyoshi, N. Shimazaki, O. Koiwai, H. Yoshida, F. Sugawara and K. Sakaguchi, J. Biochem., 2003, 133, 541.

360 I. Carletti, C. Long, C. Funel and P. Amade, J. Nat. Prod., 2003, 66, 25.

361 C. B. Rao, V. C. Sekhar, D. V. Rao, B. Sarvani and D. K. M. Lakshmi, Asian J. Chem., 2003, 15, 1161.

362 A. S. Dmitrenok, P. Radhika, V. Anjaneyulu, S. Subrahmanyam, P. V. Subba Rao, P. S. Dmitrenok and V. M. Boguslavsky, Russ. Chem. Bull., 2003, 52, 1868.

363 A. Patra and A. Majumdar, ARKIVOC, 2003, 133.

364 M. Ojika, M. K. Islam, T. Shintani, Y. Zhang, T. Okamoto and Y. Sakagami, Biosci. 
365 M. Hirono, M. Ojika, H. Mimura, Y. Nakanishi and M. Maeshima, J. Biochem., 2003, 133, 811.

366 Y. T. Chang, C. L. Lin, A. T. Khalil and Y. C. Shen, Chin. Pharm. J., 2003, 55, 129.

367 T. Iwagawa, M. Miyazaki, H. Okamura, M. Nakatani, M. Doe and K. Takemura, Tetrahedron Lett., 2003, 44, 2533.

368 T. Rezanka and V. M. Dembitsky, Eur. J. Org. Chem., 2003, 309.

369 K. Watanabe, M. Sekine and K. Iguchi, J. Nat. Prod., 2003, 66, 1434.

370 K. Watanabe, M. Sekine and K. Iguchi, Chem. Pharm. Bull., 2003, 51, 909.

371 N. Hashimoto, S. Fujiwara, K. Watanabe, K. Iguchi and M. Tsuzuki, Lipids, 2003, 38, 991.

1715372 K. B. Iken and B. J. Baker, J. Nat. Prod., 2003, 66, 888.

373 M. Gavagnin, E. Mollo, F. Castelluccio, A. Crispino and G. Cimino, J. Nat. Prod., 2003, 66, 1517.

374 K. Iguchi, K. Mori, M. Suzuki, H. Takahashi and Y. Yamada, Chem. Lett., 1986, 1789.

375 E. P. Kündig, R. Cannas, M. Laxmisha, L. Ronggang and S. Tchertchian, J. Am. Chem. Soc., $2003, \mathbf{1 2 5}, 5642$.

376 J. Tanaka, H. Miki and T. Higa, J. Nat. Prod., 1992, 55, 1522.

377 H. K. Yim, Y. Liao and H. N. C. Wong, Tetrahedron, 2003, 59, 1877.

378 J. Y. Su, Y. Y. Kuang and L. M. Zeng, Huaxue Xuebao, 2003, 61, 1097.

379 A. Ata, J. Ackerman and P. Radhika, Tetrahedron Lett., 2003, 44, 6951.

380 K. Mori, K. Iguchi, N. Yamada, Y. Yamada and Y. Inouye, Chem. Pharm. Bull., 1988, 36, 2840.

381 J. Shin and W. Fenical, J. Org. Chem., 1991, 56, 3392.

382 S. A. Look and W. Fenical, J. Org. Chem., 1982, 47, 4129.

383 H. Miyaoka, Y. Isaji, H. Mitome and Y. Yamada, Tetrahedron, 2003, 59, 61.

$\lfloor 730384$ B. F. Bowden, J. C. Coll, J. M. Gulbis, M. F. Mackay and R. H. Willis, Aust. J. Chem., 1986, 39, 803. 
385 D. R. Williams and R. W. Heidebrecht, J. Am. Chem. Soc., 2003, 125, 1843.

386 J. Marrero, A. D. Rodríguez, P. Baran and R. G. Raptis, J. Org. Chem., 2003, 68, 4977.

387 A. D. Rodríguez, E. González and S. D. Huang, J. Org. Chem., 1998, 63, 7083.

388 T. J. Heckrodt and J. Mulzer, J. Am. Chem. Soc., 2003, 125, 4680.

389 A. D. Rodríguez, C. Ramirez, I. I. Rodríguez and C. L. Barnes, J. Org. Chem., 2000, 65, 1390.

390 A. D. Rodríguez and C. Ramirez, Org. Lett., 2000, 2, 507.

391 A. I. Kim and S. D. Rychnovsky, Angew. Chem. Int. Ed. Eng., 2003, 42, 1267.

392 Y. P. Shi, I. I. Rodríguez and A. D. Rodríguez, Tetrahedron Lett., 2003, 44, 3249.

393 A. Ata, R. G. Kerr, C. E. Moya and R. S. Jacobs, Tetrahedron, 2003, 59, 4215.

394 A. C. Kohl, A. Ata and R. G. Kerr, J. Ind. Microbiol. Biotechnol., 2003, 30, 495.

395 L. D. Mydlarz, R. S. Jacobs, J. Boehnlein and R. G. Kerr, Chem. Biol., 2003, 10, 1051.

396 A. D. Rodríguez, C. Ramirez, I. I. Rodríguez and E. González, Org. Lett., 1999, 1, 527.

1745397 J. P. Davidson and E. J. Corey, J. Am. Chem. Soc., 2003, 125, 13486.

398 I. I. Rodríguez and A. D. Rodríguez, J. Nat. Prod., 2003, 66, 855.

399 A. D. Rodríguez, C. Ramirez and I. I. Rodríguez, J. Nat. Prod., 1999, 62, 997.

400 A. D. Rodríguez and Y. P. Shi, Tetrahedron, 2000, 56, 9015.

401 P. Baran, R. G. Raptis, A. D. Rodríguez, I. I. Rodríguez and Y. P. Shi, J. Chem. Crystallogr., 2003, 33, 711.

402 H. Gross, S. Kehraus, M. Nett, G. M. König, W. Beil and A. D. Wright, Org. Biomol. Chem., 2003, 1, 944.

403 S. Carmely, A. Groweiss and Y. Kashman, J. Org. Chem., 1981, 46, 4279.

404 X. H. Xu, C. H. Kong, C. J. Lin, X. Wang and J. H. Lu, Gaodeng Xuexiao Huaxue Xuebao, 2003, 24, 1023.

405 X. H. Xu, C. H. Kong, C. J. Lin, X. Wang, Y. D. Zhu and H. S. Yang, Chin. J. Chem., 2003, 21, 1506. 
406 P. W. Hsieh, F. R. Chang, A. T. McPhail, K. H. Lee and Y. C. Wu, Nat. Prod. Res., 2003, 17, 409 .

1760407 Y. Kashman, M. Bodner, Y. Loya and Y. Benayahu, Isr. J. Chem., 1977, 16, 1.

408 A. F. Ahmed, R. T. Shiue, G. H. Wang, C. F. Dai, Y. H. Kuo and J. H. Sheu, Tetrahedron, 2003, 59, 7337.

409 K. I. Marville, S. McLean, W. F. Reynolds and W. F. Tinto, J. Nat. Prod., 2003, 66, 1284.

410 J. Marrero, A. D. Rodríguez, P. Baran and R. G. Raptis, Org. Lett., 2003, 5, 2551.

411 Y. C. Shen, Y. L. Pan, C. L. Ko, Y. H. Kuo and C. Y. Chen, J. Chin. Chem. Soc., 2003, 50, 471.

412 J. H. Sheu, G. H. Wang, C. Y. Duh and K. Soong, J. Nat. Prod., 2003, 66, 662.

413 Y. Nakao, S. Yoshida, S. Matsunaga and N. Fusetani, J. Nat. Prod., 2003, 66, 524.

414 T. Kusumi, H. Uchida, M. O. Ishitsuka, H. Yamamoto and H. Kakisawa, Chem. Lett., 1988, 1077.

415 O. Corminboeuf, L. E. Overman and L. D. Pennington, Org. Lett., 2003, 5, 1543.

416 A. D. Rodríguez and O. M. Cóbar, Chem. Pharm. Bull., 1995, 43, 1853.

417 O. Corminboeuf, L. E. Overman and L. D. Pennington, J. Am. Chem. Soc., 2003, 125, 6650.

418 C. A. Ospina, A. D. Rodríguez, E. Ortega-Barria and T. L. Capson, J. Nat. Prod., 2003, 66, 357.

419 A. D. Rodríguez and O. M. Cóbar, Tetrahedron, 1995, 51, 6869.

420 B. F. Bowden, J. C. Coll and I. M. Vasilescu, Aust. J. Chem., 1989, 42, 1705.

421 A. S. R. Anjaneyulu, V. L. Rao, V. G. Sastry, M. J. R. V. Venugopal and F. J. Schmitz, J. Nat. Prod., 2003, 66, 507.

1780422 P. J. Sung, T. Y. Fan, L. S. Fang, J. H. Sheu, S. L. Wu, G. H. Wang and M. R. Lin, Heterocycles, 2003, 61, 587.

423 Y. C. Shen, Y. C. Lin, C. L. Ko and L. T. Wang, J. Nat. Prod., 2003, 66, 302.

424 Y. C. Shen, Y. C. Lin and Y. L. Huang, J. Chin. Chem. Soc., 2003, 50, 1267. 
425 N. Krishna, P. Muralidhar, M. M. K. Kumar, D. V. Rao and C. B. Rao, Asian J. Chem., 1785 $2003,15,344$.

426

P. J. Sung and T. Y. Fan, Heterocycles, 2003, 60, 1199.

427 S. L. Wu, P. J. Sung, J. H. Su and J. H. Sheu, J. Nat. Prod., 2003, 66, 1252.

428 P. J. Sung, T. Y. Fan, L. S. Fang, S. L. Wu, J. J. Li, M. C. Chen, Y. M. Cheng and G. H. Wang, Chem. Pharm. Bull., 2003, 51, 1429.

429 T. Iwagawa, N. Nishitani, S. Kurosaki, H. Okamura, M. Nakatani, M. Doe and K. Takemura, J. Nat. Prod., 2003, 66, 1412.

430 O. Taglialatela-Scafati, K. S. Craig, D. Rebérioux, M. Roberge and R. J. Andersen, Eur. J. Org. Chem., 2003, 3515.

431 O. Taglialatela-Scafati, U. Deo-Jangra, M. Campbell, M. Roberge and R. J. Andersen, Org. 1795 Lett., 2002, 4, 4085.

432 D. Banjoo, B. S. Mootoo, R. S. Ramsewak, R. Sharma, A. J. Lough, S. McLean and W. F. Reynolds, J. Nat. Prod., 2002, 65, 314.

433 R. Dookran, D. Maharaj, B. S. Mootoo, R. Ramsewak, S. McLean, W. F. Reynolds and W. F. Tinto, J. Nat. Prod., 1993, 56, 1051.

1800434 Y. Kashman and A. Groweiss, Tetrahedron Lett., 1978, 4833.

435 H. Miyaoka, M. Nakano, K. Iguchi and Y. Yamada, Heterocycles, 2003, 61, 189.

436 H. Miyaoka, H. Mitome, H. M. Nakano and Y. Yamada, Tetrahedron, 2000, 56, 7737.

437 B. F. Bowden, B. J. Cusack and A. Dangel, Marine Drugs, 2003, 18.

438 J. C. Braekman, D. Daloze, B. Tursch, J. P. Declercq, G. Germain and M. van Meerssche, Bull. Soc. Chim. Belg., 1979, 88, 71.

439 A. Fontana, M. L. Ciavatta and G. Cimino, J. Org. Chem., 1998, 63, 2845.

440 H. Miyaoka, M. Yamanishi, Y. Kajiwara and Y. Yamada, J. Org. Chem., 2003, 68, 3476.

441 I. S. Marcos, A. B. Pedrero, M. J. Sexmero, D. Diez, P. Basabe, N. García, R. F. Moro, H. B. Broughton, F. Mollinedo and J. G. Urones, J. Org. Chem., 2003, 68, 7496. 
1810442 C. Subrahmanyam, S. R. Kumar and G. D. Reddy, Indian J. Chem. Sect. B, 2003, 42, 219.

443 J. H. Sheu, L. F. Huang, S. P. Chen, Y. L. Yang, P. J. Sung, G. H. Wang, J. H. Su, C. H. Chao, W. P. Hu and J. J. Wang, J. Nat. Prod., 2003, 66, 917.

444 A. D. Wright, E. Goclik and G. M. König, J. Nat. Prod., 2003, 66, 157.

445 A. S. R. Anjaneyulu, V. L. Rao and V. G. Sastry, Nat. Prod. Res., 2003, 17, 149.

1815446 A. F. Ahmed, C. F. Dai, Y. H. Kuo and J. H. Sheu, Steroids, 2003, 68, 377.

447 W. H. Zhang, W. K. Liu and C. T. Che, Chem. Pharm. Bull., 2003, 51, 1009.

448 W. J. Lan, C. W. Lin, J. Y. Su and L. M. Zeng, Gaodeng Xuexiao Huaxue Xuebao, 2003, 24, 2019.

449 S. Diochot, E. Loret, T. Bruhn, L. Béress and M. Lazdunski, Mol. Pharmacol., 2003, 64, 59.

$1820450 \quad$ P. Macek and D. Lebez, Toxicon, 1988, 26, 441.

451 B. B. Bonev, Y. H. Lam, G. Anderluh, A. Watts, R. S. Norton and F. Separovic, Biophys. J., 2003, 84, 2382.

452 G. Anderluh, M. D. Serra, G. Viero, G. Guella, P. Macek and G. Menestrina, J. Biol. Chem., 2003, 278, 45216.

453 P. Malovrh, G. Viero, M. D. Serra, Z. Podlesek, J. H. Lakey, P. Macek, G. Menestrina and G. Anderluh, J. Biol. Chem., 2003, 278, 22678.

454 G. Anderluh, P. Macek and J. H. Lakey, Toxicon, 2003, 42, 225.

455 B. Yao, M. R. Prinsep, B. K. Nicholson and D. P. Gordon, J. Nat. Prod., 2003, 66, 1074.

456 D. T. Harwood, S. Urban, J. W. Blunt and M. H. G. Munro, Nat. Prod. Res., 2003, 17, 15.

1830457 L. Peters, G. M. König, H. Terlau and A. D. Wright, J. Nat. Prod., 2002, 65, 1633.

458 L. Peters, G. M. König, A. D. Wright, R. Pukall, E. Stackebrandt, L. Eberl and K. Riedel, Appl. Environ. Microbiol., 2003, 69, 3469.

459 P. Wulff, J. S. Carle and C. Christophersen, J. Chem. Soc. Perkin Trans. 1, 1981, 2895.

460 J. S. Carle and C. Christophersen, J. Org. Chem., 1981, 46, 3440. 
1835461 M. V. Laycock, J. L. C. Wright, J. A. Findlay and A. D. Patil, Can. J. Chem., 1986, 64, 1312.

462 J. L. C. Wright, J. Nat. Prod., 1984, 47, 893.

463 Y. H. Choi, A. Park, F. J. Schmitz and I. van Altena, J. Nat. Prod., 1993, 56, 1431.

464 V. F. Ferreira, A. Park, F. J. Schmitz and F. A. Valeriote, Tetrahedron, 2003, 59, 1349.

1840465 A. Cutignano, A. Fontana, L. Renzulli and G. Cimino, J. Nat. Prod., 2003, 66, 1399.

466 R. R. Vardaro, V. Di Marzo and G. Cimino, Tetrahedron Lett., 1992, 33, 2875.

467 C. Ireland and P. J. Scheuer, Science, 1979, 205, 922.

468 M. Gavagnin, A. Spinella, F. Castelluccio, G. Cimino and A. Marin, J. Nat. Prod., 1994, 57, 298.

1845469 A. K. Miller and D. Trauner, Angew. Chem. Int. Ed. Eng., 2003, 42, 549.

470 K. J. James, M. D. Sierra, M. Lehane, A. B. Magdalena and A. Furey, Toxicon, 2003, 41, 277.

471 M. Satake, K. Ofuji, H. Naoki, K. J. James, A. Furey, T. McMahon, J. Silke and T. Yasumoto, J. Am. Chem. Soc., 1998, 120, 9967.

472 K. C. Nicolaou, Y. Li, N. Uesaka, T. V. Koftis, S. Vyskocil, T. Ling, M. Govindasamy, W. Qian, F. Bernal and D. Y. K. Chen, Angew. Chem. Int. Ed. Eng., 2003, 42, 3643.

473 K. C. Nicolaou, D. Y. K. Chen, Y. Li, W. Qian, T. Ling, S. Vyskocil, T. V. Koftis, M. Govindasamy and N. Uesaka, Angew. Chem. Int. Ed. Eng., 2003, 42, 3649.

474 A. Tarui, K. Shibata, S. Takahashi, Y. Kera, T. Munegumi and R. H. Yamada, Comp. Biochem. Physiol., 2003, 134B, 79.

475 W. P. Kelley, A. M. Wolters, J. T. Sack, R. A. Jockusch, J. C. Jurchen, E. R. Williams, J. V. Sweedler and W. F. Gilly, J. Biol. Chem., 2003, 278, 34934.

476 L. Meijer, A. L. Skaltsounis, P. Magiatis, P. Polychronopoulos, M. Knockaert, M. Leost, X. P. Ryan, C. A. Vonica, A. Brivanlou, R. Dajani, C. Crovace, C. Tarricone, A. Musacchio, S. M. Roe, L. Pearl and P. Greengard, Chem. Biol., 2003, 10, 1255. 
477 A. Cutignano, A. Tramice, S. De Caro, G. Villani, G. Cimino and A. Fontana, Angew. Chem. Int. Ed. Eng., 2003, 42, 2633.

478 A. Spinella, L. A. Alvarez, A. Passeggio and G. Cimino, Tetrahedron, 1993, 49, 1307.

479 O. Grovel, Y. F. Pouchus and J. F. Verbist, Toxicon, 2003, 42, 297.

480 R. J. Andersen, D. J. Faulkner, H. C. Heng, G. D. van Duyne and J. Clardy, J. Am. Chem. Soc., 1985, 107, 5492.

481 M. Facompré, C. Tardy, C. Bal-Mahieu, P. Colson, C. Perez, I. Manzanares, C. Cuevas and C. Bailly, Cancer Res., 2003, 63, 7392.

482 Y. Furukawa, K. Nakamaru, K. Sasaki, Y. Fujisawa, H. Minakata, S. Ohta, F. Morishita, O. Matsushima, L. Li, V. Alexeeva, T. A. Ellis, N. C. Dembrow, J. Jing, J. V. Sweedler, K. R. Weiss and F. S. Vilim, J. Neurophysiology, 2003, 89, 3114.

483 E. C. Jimenez, R. P. Shetty, M. Lirazan, J. Rivier, C. Walker, F. C. Abogadie, D. Yoshikami, L. J. Cruz and B. M. Olivera, J. Neurochem., 2003, 85, 610.

484 R. Jacobsen, D. Yoshikami, M. Ellison, J. Martinez, W. R. Gray, G. E. Cartier, K. J. Shon, D. R. Groebe, S. N. Abramson, B. M. Olivera and J. M. McIntosh, J. Biol. Chem., 1997, 272, 22531.

485 S. W. Chi, K. H. Park, J. E. Suk, B. M. Olivera, J. M. McIntosh and K. H. Han, J. Biol. Chem., 2003, 278, 42208.

486 C. X. Fan, X. K. Chen, C. Zhang, L. X. Wang, K. L. Duan, L. L. He, Y. Cao, S. Y. Liu, M. N. Zhong, C. Ulens, J. Tytgat, J. S. Chen, C. W. Chi and Z. Zhou, J. Biol. Chem., 2003, 278, 12624.

487 A. López-Macià, J. C. Jiménez, M. Royo, E. Giralt and F. Albericio, J. Am. Chem. Soc., 2001, 123, 11398.

488 Y. Suarez, L. Gonzalez, A. Cuadrado, M. Berciano, M. Lafarga and A. Munoz, Molecular Cancer Therapeutics, 2003, 2, 863. 
489 G. R. Pettit, Y. Kamano, H. Kizu, C. Dufresne, C. L. Herald, R. J. Bontems, J. M. Schmidt, F. E. Boettner and R. A. Nieman, Heterocycles, 1989, 28, 553.

490 T. Oda, Z. D. Crane, C. W. Dicus, B. A. Sufi and R. B. Bates, J. Mol. Biol., 2003, 328, 319.

491 R. Iijima, J. Kisugi and M. Yamazaki, Dev. Comp. Immunol., 2003, 27, 305.

492 R. Garimella, Y. Xu, C. H. Schein, K. Rajarathnam, G. T. Nagle, S. D. Painter and W. Braun, Biochemistry, 2003, 42, 9970.

493 M. Gavagnin, M. Carbone, E. Mollo and G. Cimino, Tetrahedron Lett., 2003, 44, 1495.

494 A. Spinella, L. A. Alvarez, C. Avila and G. Cimino, Tetrahedron Lett., 1994, 35, 8665.

495 A. Fontana, A. Tramice, A. Cutignano, G. d'Ippolito, M. Gavagnin and G. Cimino, J. Org. Chem., 2003, 68, 2405.

496 M. Gavagnin, M. Carbone, E. Mollo and G. Cimino, Tetrahedron, 2003, 59, 5579.

497 M. T. Davies-Coleman and D. J. Faulkner, Tetrahedron, 1991, 47, 9743.

498 M. Gavagnin, A. de Napoli, G. Cimino, K. Iken, C. Avila and F. J. Garcia, Tetrahedron: Asymmetry, 1999, 10, 2647.

1900499 G. Cimino, M. Gavagnin, G. Sodano, R. Puliti, C. A. Mattia and L. Mazzarella, Tetrahedron, 1988, 44, 2301.

500 M. Gavagnin, A. Spinella, G. Cimino and G. Sodano, Tetrahedron Lett., 1990, 31, 6093.

501 A. Fontana, A. Tramice, A. Cutignano, G. d'Ippolito, L. Renzulli and G. Cimino, Eur. J. Org. Chem., 2003, 3104.

505 A. R. Díaz-Marrero, E. Dorta, M. Cueto, J. Rovirosa, A. San-Martín, A. Loyola and J. Darias, Tetrahedron, 2003, 59, 4805.

503 Y. Okamoto, N. Nitanda, M. Ojika and Y. Sakagami, Biosci. Biotechnol. Biochem., 2001, 65, 474 .

504 Y. Okamoto, N. Nitanda, M. Ojika and Y. Sakagami, Biosci. Biotechnol. Biochem., 2003, $\lfloor 910$ 67, 460 .

505 M. Suzuki and E. Kurosawa, Phytochemistry, 1985, 24, 1999. 
506 M. B. Ksebati and F. J. Schmitz, J. Org. Chem., 1987, 52, 3766.

507 E. J. Dumdei, J. Kubanek, J. E. Coleman, J. Pika, R. J. Andersen, J. R. Steiner and J. Clardy, Can. J. Chem., 1997, 75, 773.

1915508 A. R. Díaz-Marrero, E. Dorta, M. Cueto, J. Rovirosa, A. San-Martín, A. Loyola and J. Darias, ARKIVOC, 2003, 107.

509 A. Aiello, E. Fattorusso, A. Mangoni and M. Menna, Eur. J. Org. Chem., 2003, 734.

510 T. C. McKee, D. L. Galinis, L. K. Pannell, J. H. Cardellina, J. Laakso, C. M. Ireland, L. Murray, R. J. Capon and M. R. Boyd, J. Org. Chem., 1998, 63, 7805.

Ł920 511 R. Shen, C. T. Lin, E. J. Bowman, B. J. Bowman and J. A. Porco, J. Am. Chem. Soc., 2003, $125,7889$.

512 J. Kobayashi, J. F. Cheng, T. Ohta, H. Nakamura, S. Nozoe, Y. Hirata, Y. Ohizumi and T. Sasaki, J. Org. Chem., 1988, 53, 6147.

513 M. Tsuda, K. Nozawa, K. Shimbo, H. Ishiyama, E. Fukushi, J. Kawabata and J. Kobayashi, 1925 Tetrahedron Lett., 2003, 44, 1395.

514 H. H. Issa, J. Tanaka, R. Rachmat and T. Higa, Tetrahedron Lett., 2003, 44, 1243.

515 L. Garrido, E. Zubía, M. J. Ortega and J. Salvá, J. Org. Chem., 2003, 68, 293.

516 A. Rudi, L. Chill, M. Aknin and Y. Kashman, J. Nat. Prod., 2003, 66, 575.

517 L. J. Perez and D. J. Faulkner, J. Nat. Prod., 2003, 66, 247.

1930518 A. R. Carroll, B. F. Bowden, J. C. Coll, D. C. R. Hockless, B. W. Skelton and A. H. White, Aust. J. Chem., 1994, 47, 61.

519 B. McKeever and G. Pattenden, Tetrahedron, 2003, 59, 2701.

520 A. R. Carroll, J. C. Coll, D. J. Bourne, J. K. MacLeod, M. T. Zabriskie, C. M. Ireland and B. F. Bowden, Aust. J. Chem., 1996, 49, 659.

935521 P. Wipf and Y. Uto, J. Org. Chem., 2000, 65, 1037.

522 X. Salvatella, J. M. Caba, F. Albericio and E. Giralt, J. Org. Chem., 2003, 68, 211. 
523 M. M. Joullié, M. S. Leonard, P. Portonovo, B. Liang, X. Ding and J. J. La Clair, Bioconjugate Chem., 2003, 14, 30.

524 J. A. Tincu, A. G. Craig and S. W. Taylor, Biochem. Biophys. Res. Commun., 2000, 270, 1940 421.

525 J. A. Tincu, L. P. Menzel, R. Azimov, J. Sands, T. Hong, A. J. Waring, S. W. Taylor and R. I. Lehrer, J. Biol. Chem., 2003, 278, 13546.

526 W. S. Jang, K. N. Kim, Y. S. Lee, M. H. Nam and I. H. Lee, FEBS Lett., 2002, 521, 81.

527 W. S. Jang, C. H. Kim, K. N. Kim, S. Y. Park, J. H. Lee, S. M. Son and I. H. Lee, Antimicrob. Agents Chemother., 2003, 47, 2481.

528 J. L. Urdiales, P. Morata, I. Nunez de Castro and F. Sanchez-Jimenez, Cancer Letters, 1996, 102,31 .

529 M. Broggini, S. V. Marchini, E. Galliera, P. Borsotti, G. Taraboletti, E. Erba, M. Sironi, J. Jimeno, G. T. Faircloth, R. Giavazzi and M. D'Incalci, Leukemia, 2003, 17, 52.

1950530 M. Pérez, M. Sadqi, V. Muñoz and J. Ávila, Biochim. Biophys. Acta, 2003, 1639, 133.

531 K. Fukui, T. Ueki, H. Ohya and H. Michibata, J. Am. Chem. Soc., 2003, 125, 6352.

532 S. Hirsch, A. Miroz, P. McCarthy and Y. Kashman, Tetrahedron Lett., 1989, 30, 4291.

533 E. Vaz, M. Fernandez-Suarez and L. Muñoz, Tetrahedron: Asymmetry, 2003, 14, 1935.

534 M. F. Raub, J. H. Cardellina, M. I. Choudhary, C. Z. Ni, J. Clardy and M. C. Alley, J. Am. 1955 Chem. Soc., 1991, 113, 3178.

535 C. Agami, F. Couty, G. Evano, F. Darro and R. Kiss, Eur. J. Org. Chem., 2003, 2062.

536 J. F. Biard, S. Guyot, C. Roussakis, J. F. Verbist, J. Vercauteren, J. F. Weber and K. Boukef, Tetrahedron Lett., 1994, 35, 2691.

537 M. Jugé, N. Grimaud, J. F. Biard, M. P. Sauviat, M. Nabil, J. F. Verbist and J. Y. Petit, 1960 Toxicon, 2001, 39, 1231.

538 S. M. Weinreb, Acc. Chem. Res., 2003, 36, 59.

539 C. Kibayashi, S. Aoyagi and H. Abe, Bull. Chem. Soc. Japan, 2003, 76, 2059. 
540 C. Li and A. J. Blackman, Aust. J. Chem., 1994, 47, 1355.

541 B. M. Trost and M. T. Rudd, Org. Lett., 2003, 5, 4599.

965542 A. Aiello, F. Borrelli, R. Capasso, E. Fattorusso, P. Luciano and M. Menna, Bioorg. Med. Chem. Lett., 2003, 13, 4481.

543 J. Bergman, Acta Chem. Scand., 1971, 25, 2865.

544 A. Abourriche, Y. Abboud, S. Maoufoud, H. Mohou, T. Seffaj, M. Charrouf, N. Chaib, A. Bennamara, N. Bontemps and C. Francisco, Il Farmaco, 2003, 58, 1351.

545 L. Chill, M. Aknin and Y. Kashman, Org. Lett., 2003, 5, 2433.

546 A. Aiello, E. Fattorusso, P. Luciano, M. Menna, G. Esposito, T. Iuvone and D. Pala, Eur. J. Org. Chem., 2003, 898.

547 D. R. Appleton and B. R. Copp, Tetrahedron Lett., 2003, 44, 8963.

548 B. S. Davidson, T. F. Molinski, L. R. Barrows and C. M. Ireland, J. Am. Chem. Soc., 1991, $\lfloor 975$ $113,4709$.

549 M. Litaudon and M. Guyot, Tetrahedron Lett., 1991, 32, 911.

550 M. Litaudon, F. Trigalo, M. T. Martin, F. Frappier and M. Guyot, Tetrahedron, 1994, 50, 5323.

551 T. Kimura, M. Hanzawa, S. Ogawa, R. Sato, T. Fujii and Y. Kawai, Heteroatom Chemistry, $\lfloor 980$ 2003, 14, 88 .

552 R. A. Davis, I. T. Sandoval, G. P. Concepcion, R. M. da Rocha and C. M. Ireland, Tetrahedron, 2003, 59, 2855.

553 M. Tsuda, K. Nozawa, K. Shimbo and J. Kobayashi, J. Nat. Prod., 2003, 66, 292.

554 R. A. Davis, L. V. Christensen, A. D. Richardson, R. M. da Rocha and C. M. Ireland, Marine $\lfloor 985$ Drugs, 2003, 27.

555 J. Kobayashi, J. F. Cheng, Y. Kikuchi, M. Ishibashi, S. Yamamura, Y. Ohizumi, T. Ohta and S. Nozoe, Tetrahedron Lett., 1990, 31, 4617. 
556 P. Schupp, T. Poehner, R. A. Edrada, R. Ebel, A. Berg, V. Wray and P. Proksch, J. Nat. Prod., 2003, 66, 272.

1990557 N. Oku, S. Matsunaga and N. Fusetani, J. Am. Chem. Soc., 2003, 125, 2044.

558 A. N. Pearce, D. R. Appleton, R. C. Babcock and B. R. Copp, Tetrahedron Lett., 2003, 44, 3897.

559 B. R. Copp, J. Jompa, A. Tahir and C. M. Ireland, J. Org. Chem., 1998, 63, 8024.

560 S. Nakahara and A. Kubo, Heterocycles, 2003, 60, 2017.

1995561 Y. R. Torres, T. S. Bugni, R. G. S. Berlinck, C. M. Ireland, A. Magalhães, A. G. Ferreira and R. M. da Rocha, J. Org. Chem., 2002, 67, 5429.

562 L. Legentil, J. Bastide and E. Delfourne, Tetrahedron Lett., 2003, 44, 2473.

563 J. Kobayashi, J. F. Cheng, H. Nakamura, Y. Ohizumi, Y. Hirata, T. Sasaki, T. Ohta and S. Nozoe, Tetrahedron Lett., 1988, 29, 1177.

2000564 B. R. Copp, O. Kayser, R. Brun and A. F. Kiderlen, Planta Med., 2003, 69, 527.

565 B. Debnath, S. Gayen, S. Bhattacharya, S. Samanta and T. Jha, Bioorg. Med. Chem., 2003, 11, 5493.

566 E. Delfourne, F. Darro, P. Portefaix, C. Galaup, S. Bayssade, A. Bouteillé, L. Le Corre, J. Bastide, F. Collignon, B. Lesur, A. Frydman and R. Kiss, J. Med. Chem., 2002, 45, 3765.

2005567 S. S. Matsumoto, J. Biggs, B. R. Copp, J. A. Holden and L. R. Barrows, Chem. Res. Toxicol., 2003, 16, 113.

568 T. A. Foderaro, L. R. Barrows, P. Lassota and C. M. Ireland, J. Org. Chem., 1997, $62,6064$.

569 A. Pouilhès, Y. Langlois and A. Chiaroni, Synlett, 2003, 10, 1488.

570 A. R. Carroll, B. F. Bowden and J. C. Coll, Aust. J. Chem., 1993, 46, 489.

2010571 M. V. R. Reddy and D. J. Faulkner, Tetrahedron, 1997, 53, 3457.

572 P. Cironi, I. Manzanares, F. Albericio and M. Álvarez, Org. Lett., 2003, 5, 2959.

573 K. C. Nicolaou, P. B. Rao, J. Hao, M. V. Reddy, G. Rassias, X. Huang, D. Y. K. Chen and S. A. Snyder, Angew. Chem. Int. Ed., 2003, 42, 1753. 
574 A. W. G. Burgett, Q. Li, Q. Wei and P. G. Harran, Angew. Chem. Int. Ed., 2003, 42, 4961.

2015575 Z. Cruz-Monserrate, H. C. Vervoort, R. Bai, D. J. Newman, S. B. Howell, G. Los, J. T.

Mullaney, M. D. Williams, G. R. Pettit, W. Fenical and E. Hamel, Mol. Pharmacol., 2003, 63, 1273.

576 K. L. Rinehart, T. G. Holt, N. L. Fregeau, J. G. Stroh, P. A. Keifer, F. Sun, L. H. Li and D.

G. Martin, J. Org. Chem., 1990, 55, 4512.

2020577 A. E. Wright, D. A. Forleo, G. P. Gunawardana, S. P. Gunasekera, F. E. Koehn and O. J. McConnell, J. Org. Chem., 1990, 55, 4508.

578 K. L. Rinehart, T. G. Holt, N. L. Fregeau, J. G. Stroh, P. A. Keifer, F. Sun, L. H. Li and D. G. Martin, J. Org. Chem., 1991, 56, 1676.

579 R. Sakai, K. L. Rinehart, Y. Guan and A. H. J. Wang, Proc. Natl. Acad. Sci. U. S. A., 1992, 2025 89, 11456.

580 R. Sakai, E. A. Jares-Erijman, I. Manzanares, M. V. S. Elipe and K. L. Rinehart, J. Am. Chem. Soc., 1996, 118, 9017.

581 R. Menchaca, V. Martínez, A. Rodríguez, N. Rodríguez, M. Flores, P. Gallego, I.

Manzanares and C. Cuevas, J. Org. Chem., 2003, 68, 8859.

2030582 M. D'Incalci and J. Jimeno, Expert opinion on investigational drugs, 2003, 12, 1843.

583 C. Laverdiere, E. A. Kolb, J. G. Supko, R. Gorlick, P. A. Meyers, R. G. Maki, L. Wexler, G.

D. Demetri, J. H. Healey, A. G. Huvos, A. M. Goorin, R. Bagatell, A. Ruiz-Casado, C.

Guzman, J. Jimeno and D. Harmon, Cancer, 2003, 98, 832.

584 Ch. Van Kesteren, M. M. M. de Vooght, L. López-Lázaro, R. A. A. Mathôt, J. H. M.

Schellens, J. M. Jimeno and J. H. Beijnen, Anti-Cancer Drugs, 2003, 14, 487.

585 S. Fukuzawa, S. Matsunaga and N. Fusetani, J. Org. Chem., 1995, 60, 608.

586 T. Komiya, N. Fusetani, S. Matsunaga, A. Kubo, F. J. Kaye, M. J. Kelley, K. Tamura, M. Yoshida, M. Fukuoka and K. Nakagawa, Cancer Chemother. Pharmacol., 2003, 51, 202. 
587 A. Aiello, G. Esposito, E. Fattorusso, T. Iuvone, P. Luciano and M. Menna, Steroids, 2003, 2040 68, 719.

588 M. Yoshida, M. Murata, K. Inaba and M. Morisawa, Proc. Natl. Acad. Sci. U. S. A., 2002, 99, 14831.

589 T. Oishi, H. Tsuchikawa, M. Murata, M. Yoshida and M. Morisawa, Tetrahedron Lett., 2003, 44, 6387.

2045590 H. D. Chludil, A. M. Seldes and M. S. Maier, Z. Naturforsch. C Biosci., 2003, 58, 433.

591 M. E. Díaz de Vivar, A. M. Seldes and M. S. Maier, Lipids, 2002, 37, 597.

592 M. S. Maier, A. Kuriss and A. M. Seldes, Lipids, 1998, 33, 825.

593 M. Inagaki, K. Nakamura, S. Kawatake and R. Higuchi, Eur. J. Org. Chem., 2003, 325.

594 K. Yamada, A. Hamada, F. Kisa, T. Miyamoto and R. Higuchi, Chem. Pharm. Bull., 2003, 2050 $51,46$.

595 M. Kaneko, F. Kisa, K. Yamada, T. Miyamoto and R. Higuchi, Eur. J. Org. Chem., 2003, 1004.

596 W. Wang, F. Li, Y. Park, J. Hong, C. O. Lee, J. Y. Kong, S. Shin, K. S. Im and J. H. Jung, J. Nat. Prod., 2003, 66, 384.

2055597 R. Riccio, M. V. D’Auria, M. Iorizzi, L. Minale, D. Laurent and D. Duhet, Gazz. Chim. Ital., $1985, \mathbf{1 1 5}, 405$.

598 N. V. Ivanchina, A. A. Kicha, A. I. Kalinovsky, P. S. Dmitrenok and V. A. Stonik, J. Nat. Prod., 2003, 66, 298.

599 A. A. Kicha, N. V. Ivanchina, A. I. Kalinovsky, P. S. Dmitrenok and V. A. Stonik, Tetrahedron Lett., 2003, 44, 1935.

600 H. D. Chludil, A. P. Murray, A. M. Seldes and M. S. Maier, Stud. Nat. Prod. Chem., 2003, 28, 587.

601 N. G. Prokof'eva, E. L. Chaikina, A. A. Kicha and N. V. Ivanchina, Comp. Biochem. Physiol. B Comp. Biochem., 2003, 134, 695. 
2065602 W. H. Wang, F. M. Li, J. K. Hong, C. O. Lee, H. Y. Cho, K. S. Im and J. H. Jung, Chem. Pharm. Bull., 2003, 51, 435.

603 E. V. Levina, A. I. Kalinovskii, V. A. Stonik and P. S. Dmitrenok, Russ. Chem. Bull., 2003, $52,1623$.

604 Z. R. Zou, Y. H. Yi, H. M. Wu, J. H. Wu, C. C. Liaw and K. H. Lee, J. Nat. Prod., 2003, 66, 2070 1055.

605 S. A. Avilov, A. S. Antonov, A. S. Silchenko, V. I. Kalinin, A. I. Kalinovsky, P. S. Dmitrenok, V. A. Stonik, R. Riguera and C. Jimenez, J. Nat. Prod., 2003, 66, 910.

606 M. Sandvoss, A. Preiss, K. Levsen, R. Weisemann and M. Spraul, Magn. Reson. Chem., 2003, 41, 949.

2075607 S. de Marino, N. Borbone, M. Iorizzi, G. Esposito, J. B. McClintock and F. Zollo, J. Nat. Prod., 2003, 66, 515.

608 H. Nakagawa, T. Tanigawa, K. Tomita, Y. Tomihara, Y. Araki and E. Tachikawa, J. Toxicol. Toxin Rev., 2003, 22, 633.

609 T. Barsby, C. E. Kicklighter, M. E. Hay, M. C. Sullards and J. Kubanek, J. Nat. Prod., 2003, 2080 66, 1110.

610 T. Goto, Y. Kishi, S. Takahashi and Y. Hirata, Tetrahedron, 1965, 21, 2059.

611 K. Tsuda, S. Ikuma, M. Kawamura, R. Tachikawa, K. Sakai, C. Tamura and O. Amakasu, Chem. Pharm. Bull., 1964, 12, 1357.

612 R. B. Woodward, Pure Appl. Chem., 1964, 9, 49.

2085613 N. Ohyabu, T. Nishikawa and M. Isobe, J. Am. Chem. Soc., 2003, 125, 8798.

614 A. Hinman and J. Du Bois, J. Am. Chem. Soc., 2003, 125, 11510.

615 D. J. Faulkner, Tetrahedron, 1977, 33, 1421.

616 D. J. Newman and G. M. Cragg, J. Nat. Prod., 2004, 67, 11216.

617 W. Bergmann and R. J. Feeney, J. Am. Chem. Soc., 1950, 72, 2809.

2090618 W. Bergmann and R. J. Feeney, J. Org. Chem., 1951, 16, 981. 
619 W. Bergmann and R. J. Feeney, J. Org. Chem., 1955, 20, 1501. 


\section{Captions for Figures 1-3}

Fig. 1 Distribution of biologically-active and non-active marine natural products by phylum, 2003.

(Non-active - compounds for which no biological activity has been reported; Active - compounds that are active in at least one bioassay)

Fig. 2 Distribution of biological activity by phylum.

(AC - cancer related assays including cytotoxicity, antimitotic, histone deacetylase, proteasome, TNF, a range of kinases, DNA binding and matrix metalloproteinase; $\mathbf{A M}$ - antimicrobial, antiinfective, antiTb, antimalarial assays; AO - antioxidant assays; IV - in vivo assays such as brine shrimp and sea urchin eggs; Other includes antiviral assays, assays based on central nervous system responses, feeding deterrent assays, ion channel assays, antifouling assays and assays for Fe siderophores, neuronal differentiation, oocyte lysis, sperm attractant and UV-A activity)

Fig. 3 Numbers and distribution of marine and marine-derived compounds in clinical and preclinical trials. 